\title{
Parametric Study of Coal Liberation Behavior Using Silica Grinding Media
}

Adewale Wasiu Adeniji

West Virginia University, awa0001@mix.wvu.edu

Follow this and additional works at: https://researchrepository.wvu.edu/etd

Part of the Mining Engineering Commons

\section{Recommended Citation}

Adeniji, Adewale Wasiu, "Parametric Study of Coal Liberation Behavior Using Silica Grinding Media" (2018). Graduate Theses, Dissertations, and Problem Reports. 3714.

https://researchrepository.wvu.edu/etd/3714

This Thesis is protected by copyright and/or related rights. It has been brought to you by the The Research Repository @ WVU with permission from the rights-holder(s). You are free to use this Thesis in any way that is permitted by the copyright and related rights legislation that applies to your use. For other uses you must obtain permission from the rights-holder(s) directly, unless additional rights are indicated by a Creative Commons license in the record and/ or on the work itself. This Thesis has been accepted for inclusion in WVU Graduate Theses, Dissertations, and Problem Reports collection by an authorized administrator of The Research Repository @ WVU. For more information, please contact researchrepository@mail.wvu.edu. 


\title{
Parametric Study of Coal Liberation Behavior Using Silica Grinding Media
}

\section{Adewale Wasiu Adeniji}

\author{
Thesis submitted \\ to the Benjamin M. Statler College of Engineering and Mineral Resources \\ at West Virginia University \\ in partial fulfillment of the requirements for the degree of \\ Master of Science in \\ Mining Engineering
}

\author{
Qingqing Huang, Ph.D., Chair \\ Yi Luo, Ph.D. \\ Berk Tulu, Ph.D. \\ Department of Mining Engineering
}

Morgantown, West Virginia

2018

Keywords: Coal, Grinding, Silica, Product P80, Specific Energy, Ash analysis, Fractional Factorial Design, Particle Swarm Optimization

Copyright 2018 Adewale Wasiu Adeniji 


\section{Abstract \\ Parametric Study of Coal Liberation Behavior Using Silica Grinding Media}

\section{Adewale Wasiu Adeniji}

This study evaluates the coal liberation behavior using silica as the grinding media by assessing the effects of four operating factors including nominal feed size, media size, shaft speed and grinding time, each of three levels on two response variables, the product $\mathrm{P}_{80}$ and the specific energy. The coal material used in this study was mixed-phase particles commonly referred to as middlings, sampled from dense medium circuit at the Leatherwood preparation plant in Kentucky. One-third fractional factorial design of resolution $I I I$ was implemented. Since silica was obtained in three standard size ranges as per manufacturer's design, media size was qualitative while other factors were quantitative.

The experiment was custom designed, and the results were analyzed with JMP statistical software. Both ash analysis of the grind products and the shape analysis of the media before and after the grinding tests indicate no media degradation occurred during the grinding process. Statistical analyses were initially performed to determine the operating parameters that significantly influence the product $\mathrm{P}_{80}$ and the specific energy. For the product $\mathrm{P}_{80}$, feed size has a p-Value of 0.001 at a five-percent significance level. In addition, the normal probability plot of effect estimates also shows feed size deviates from the straight line. Hence, only feed size amongst the four operating factors has a significant effect on the product $\mathrm{P}_{80}$. However, for specific energy, grinding time and shaft speed have p-Values of 0.03 and 0.05 , respectively at a five-percent significance level. This is also corroborated on the normal probability plot of effect estimates where only grinding time and shaft speed deviate from the straight line. Therefore, only grinding time and shaft speed significantly influence specific energy.

Based on the mathematical models that were further developed, it can be deduced that the product $\mathrm{P}_{80}$ decreases with decreasing feed size and vice versa. On the other hand, the specific energy decreases with decreasing grinding time and shaft speed and vice versa. Irrespective of other factors investigated in this study, the lowest and highest product $\mathrm{P}_{80}$ (4.5 microns and 137.5 microns, respectively) were measured when the nominal feed size was at its low level (25 microns) and high level (250 microns), respectively. In the same vein, the lowest and highest specific energy (16 kWh/ton and $416 \mathrm{kWh} /$ ton, respectively) were obtained when grinding time and shaft speed were at their low levels (16 minutes and $200 \mathrm{rpm})$ and high levels (64 minutes and $400 \mathrm{rpm}$ ), separately.

Finally, the batch grinding process was numerically simulated with the population balance model using the experimental data. Particle swarm optimization, a stochastic algorithm in MATLAB was used to iteratively fit the model to the experimental data with a mean squared error of 0.01 . The selection and breakage function parameters of Leatherwood coal were determined as $0.05,4.98,-2.03$ and $1.34,0.06,10.15$, respectively. 


\section{Dedication}

This research work is dedicated to Almighty Allah and the human race. 


\section{Acknowledgements}

My undiluted gratitude goes to Almighty Allah for the gift of life and the successful completion of my second master's program. I thank my family most especially my wife, Olabimpe Cynthia Fasuyi and my daughter, Bushrah Ebunoluwa Adeniji. I appreciate my parents and my in-laws for their support through the challenging times. I cannot thank my thesis advisor, Dr. Qingqing Huang enough for her patience and positive critique. I extend my gratitude to my thesis committee members, Dr. Yi Luo and Dr. Berk Tulu for their technical inputs. A big shout out to all friends and family members especially, Tope Akinmoladun for their love, prayers and support throughout the journey. 


\section{Table of Contents}

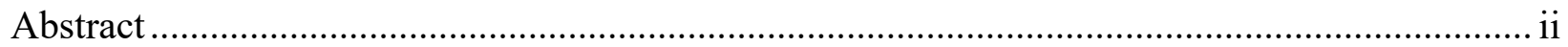

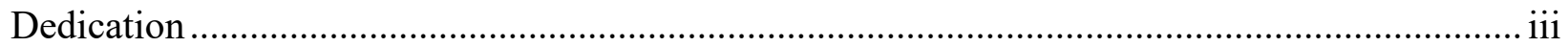

Acknowledgements ....................................................................................................... iv

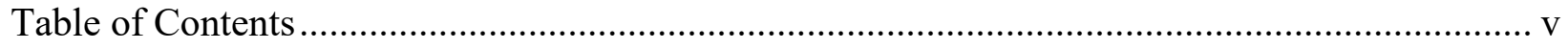

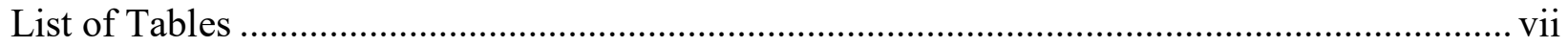

List of Figures ......................................................................................................

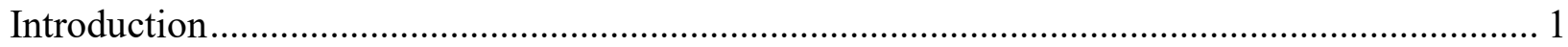

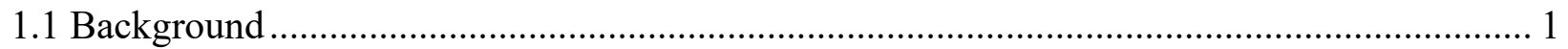

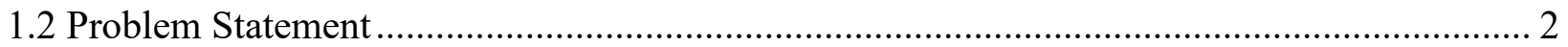

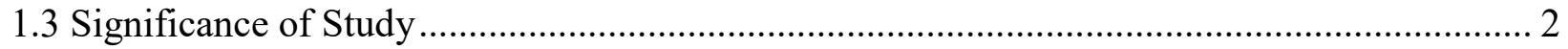

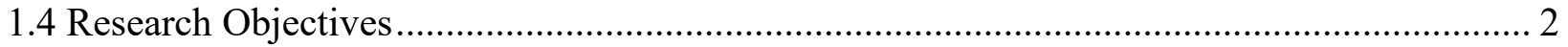

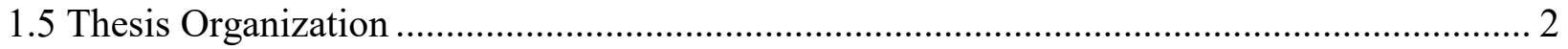

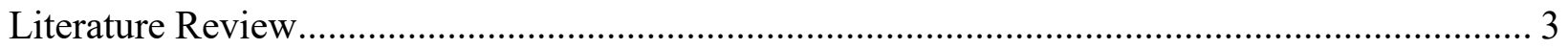

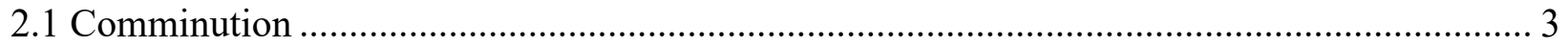

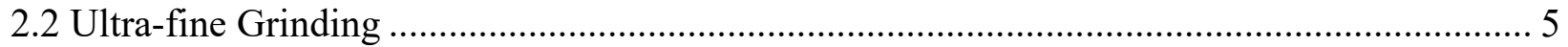

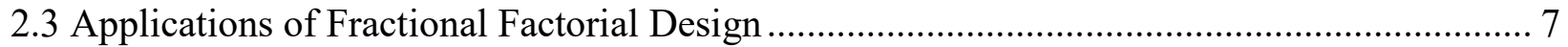

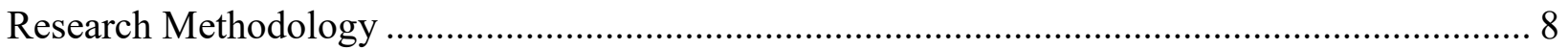

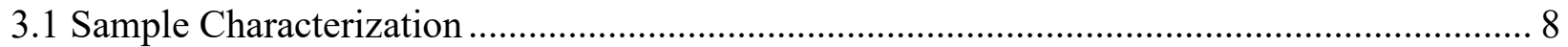

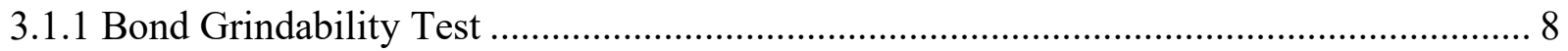

3.1.2 Hardgrove Grindability Test ................................................................................ 12

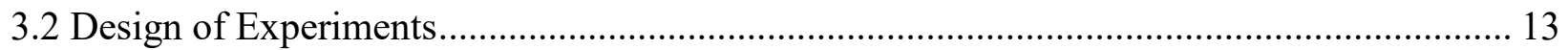

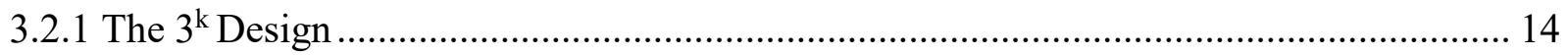

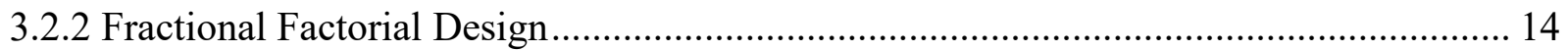

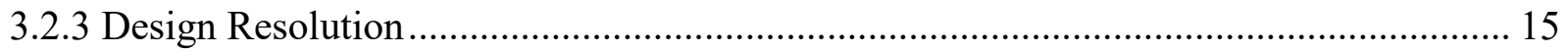

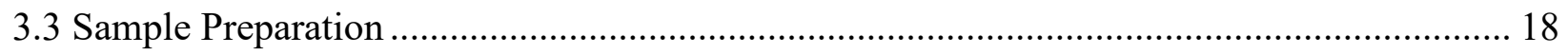

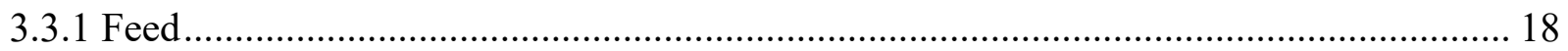

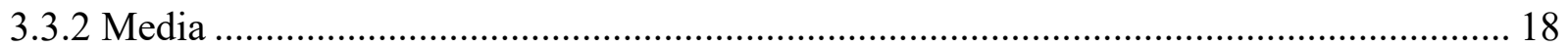

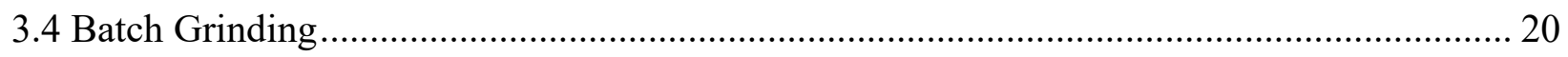

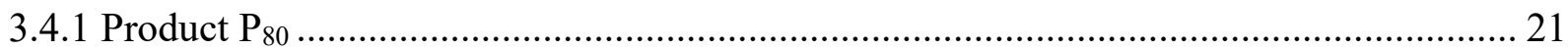

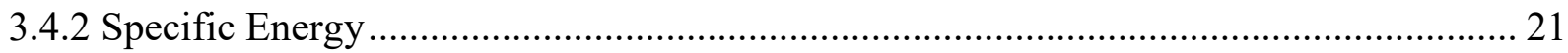

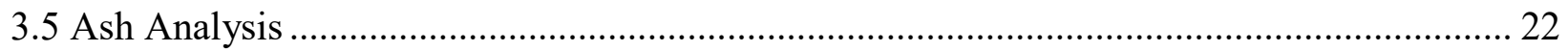

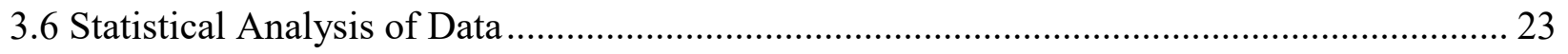

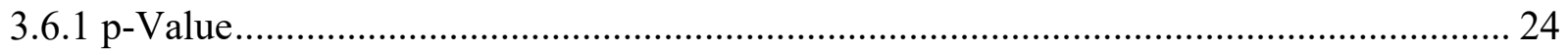




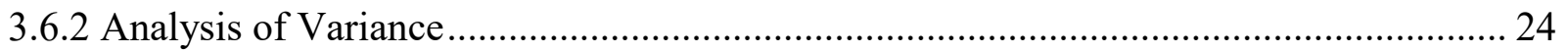

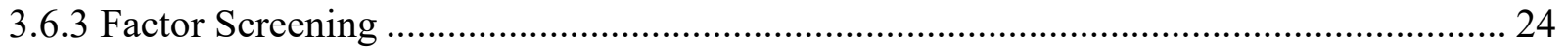

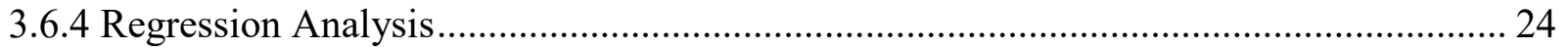

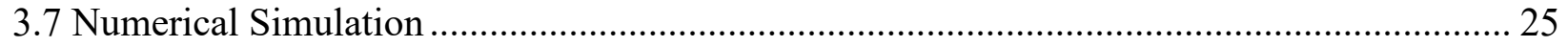

3.7.1 Population Balance Model ..................................................................................... 25

3.7.2 Particle Swarm Optimization................................................................................ 26

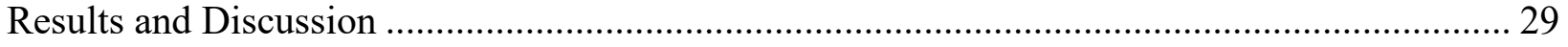

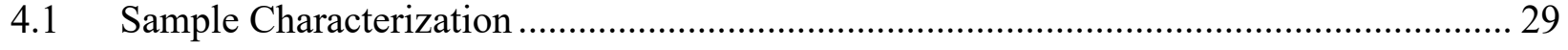

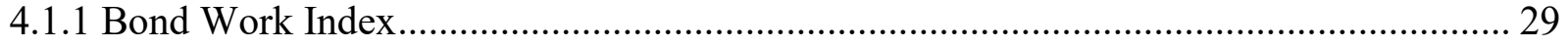

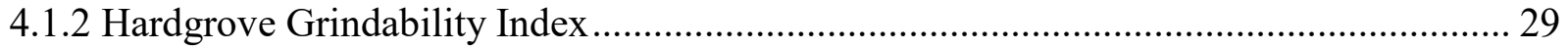

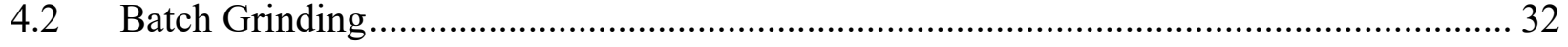

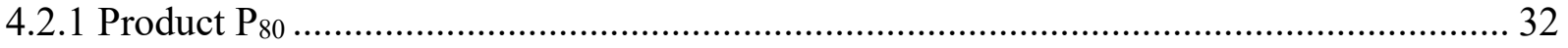

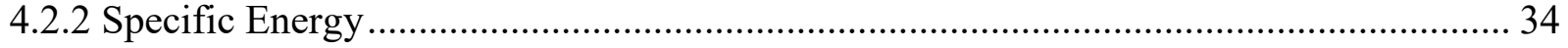

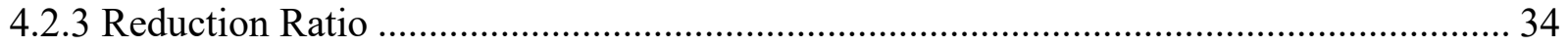

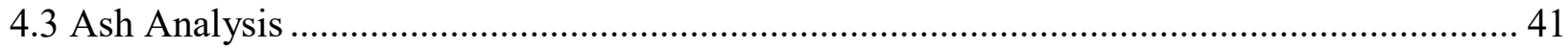

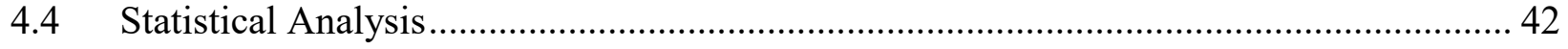

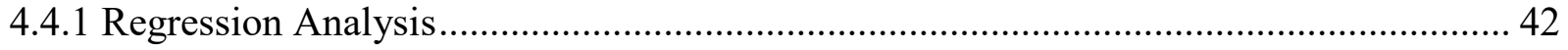

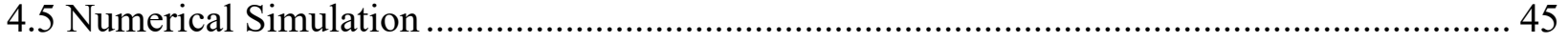

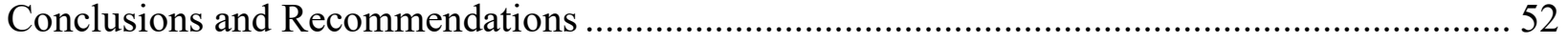

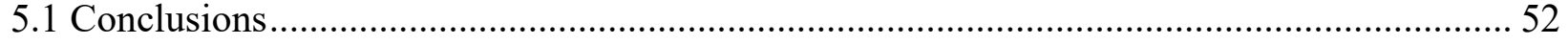

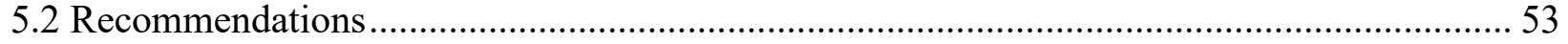

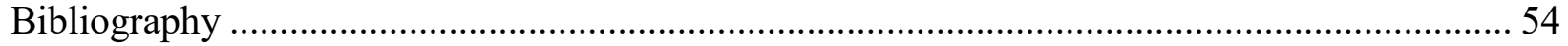

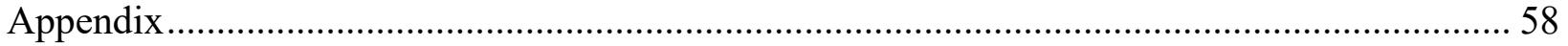




\section{List of Tables}

Table 3.2: Operating factors and their corresponding levels. ................................................ 14

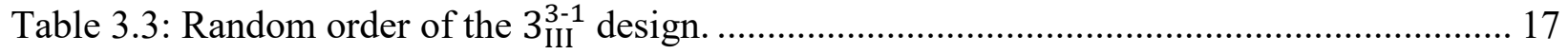

Table 3.4: Experimental conditions for batch grinding tests. .......................................... 21

Table 4.1: Raw data from Bond work index tests.............................................................. 29

Table 4.2: Calibration of Preiser Scientific Hardgrove grindability machine. ............................ 30

Table 4.3: Hardgrove grindability index of Leatherwood coal................................................. 31

Table 4.4: Variation of power with time during batch grinding tests. .................................... 34

Table 4.5: Unloaded motor power for the calculation of specific energy. ................................ 35

Table 4.6: Raw data from batch grinding tests. ............................................................ 40

Table 4.7: Results from the ash analysis of all feeds and products. ...................................... 41

Table 4.9: Sorted parameter estimates for specific energy................................................... 44

Table 4.10: Bounds and optimum values of selection and breakage function parameters......... 46 


\section{List of Figures}

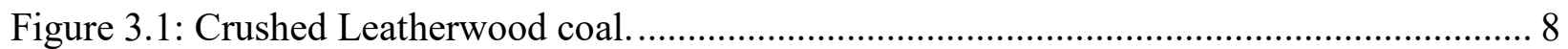

Figure 3.2: Sturtevant laboratory jaw crusher for staged crushing. ....................................... 9

Figure 3.3: Sturtevant laboratory roll crusher for staged crushing. ..................................... 10

Figure 3.4: Tyler Ro-tap test sieve shaker for sieve analysis. ............................................... 10

Figure 3.5: Sepor FC Bond mill for Bond grindability test. ................................................ 11

Figure 3.6: Cilas 1190L laser particle size analyzer for size analysis. ................................... 11

Figure 3.7: Preiser Scientific Hardgrove grindability machine. ............................................. 13

Figure 3.8: Assignment of the treatment combinations to blocks with $A B^{2} C$ as the defining

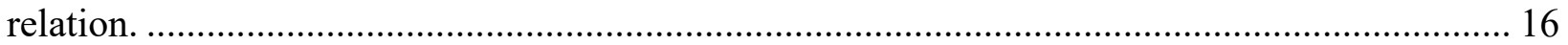

Figure 3.9: Holmes pulverizer for sample preparation. .................................................. 18

Figure 3.10: Union Process attritor for batch grinding. .................................................... 19

Figure 3.11: Overhead agitator for homogeneous mixing. ............................................... 19

Figure 3.12: Silica (potters glass beads) as grinding media.................................................. 20

Figure 3.13: Sweco separator for screening the grinding media (silica). ................................ 20

Figure 3.14: Sepor filter press for filtering the wet feeds and products. ................................... 22

Figure 3.15: Lindberg electric oven for ash analysis. ......................................................... 23

Figure 3.16: Desiccator for cooling the crucibles plus ash............................................... 23

Figure 4.1: Bond work index of Leatherwood coal. ......................................................... 30

Figure 4.2: Calibration of Preiser Scientific Hardgrove grindability machine........................... 30

Figure 4.3: Hardgrove grindability index of Leatherwood coal. .............................................. 31

Figure 4.4: Particle size distribution of the 25-micron feed and the corresponding products...... 32

Figure 4.5: Particle size distribution of the 150-micron feed and the corresponding products.... 33

Figure 4.6: Particle size distribution of the 250-micron feed and the corresponding products.... 33

Figure 4.7: Power versus time graph for batch grinding pattern 000_D_1 . ............................ 35

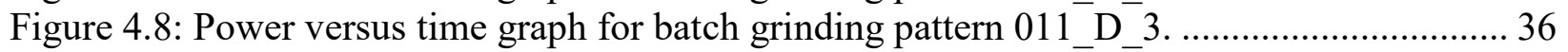

Figure 4.9: Power versus time graph for batch grinding pattern $022 \_-D_{-} 2$.............................. 36

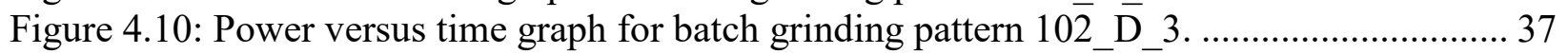

Figure 4.11: Power versus time graph for batch grinding pattern 110_D_2 ............................ 37

Figure 4.12: Power versus time graph for batch grinding pattern 121_D_1............................ 38

Figure 4.13: Power versus time graph for batch grinding pattern 201_D_2 ........................... 38

Figure 4.14: Power versus time graph for batch grinding pattern 212_D_1 ............................ 39

Figure 4.15: Power versus time graph for batch grinding pattern 220_D_3........................... 39

Figure 4.16: Specific energy, product $\mathrm{P}_{80}$ and reduction ratio for all grinding tests. ................. 40

Figure 4.17: Shape analysis of silica beads $(250 \times 420 \mu \mathrm{m})$ before grinding (left) and after grinding (right) (Huang et al., 2018)................................................................................................ 41

Figure 4.18: Normal probability plot of effect estimates for P80 ......................................... 42

Figure 4.19: Normal probability plot of effect estimates for specific energy ........................... 42

Figure 4.20: Decay of objective function using Particle swarm optimization............................ 46

Figure 4.21: Particle size distribution of the feed and the grinding product from both the experiment and numerical simulation for pattern 000_D_1 ............................................... 47

Figure 4.22: Particle size distribution of the feed and the grinding product from both the experiment and numerical simulation for pattern 011_D_3 ............................................. 47

Figure 4.23: Particle size distribution of the feed and the grinding product from both the experiment and numerical simulation for pattern 022_D_2. 
Figure 4.24: Particle size distribution of the feed and the grinding product from both the experiment and numerical simulation for pattern 102 D 3 48

Figure 4.25: Particle size distribution of the feed and the grinding product from both the experiment and numerical simulation for pattern 110_D_2.

Figure 4.26: Particle size distribution of the feed and the grinding product from both the experiment and numerical simulation for pattern 121_D_1

Figure 4.27: Particle size distribution of the feed and the grinding product from both the experiment and numerical simulation for pattern 201_D_1.

Figure 4.28: Particle size distribution of the feed and the grinding product from both the experiment and numerical simulation for pattern 212_D_1. 50 Figure 4.29: Particle size distribution of the feed and the grinding product from both the experiment and numerical simulation for pattern 220_D_1 


\section{Chapter 1}

\section{Introduction}

\subsection{Background}

Run-of-mine, ore coming directly from the mine comprises valuable minerals and unwanted materials (gangue). To meet quality specifications, the desirable minerals must be separated from the gangue. The wanted minerals are liberated by comminution, the first unit operation in mineral processing where particle sizes are reduced to liberate the minerals of interest before being recovered by other processes (Ozcan and Benzer, 2013). Comminution includes crushing and grinding (Gupty, 2003; Sahoo, De \& Meikap, 2011). Particles are broken down in comminution by three types of forces: compression; impact; and attrition. Crushing is achieved mostly by compression and impact forces while attrition force is the major force in grinding. Freshly mined ores are relatively massive and may not be directly ground.

Therefore, materials whose sizes are too large to be fed directly into the grinding mill are first crushed. For example, coal particles sizes are first reduced by roll crushers and maybe followed by rotary coal breaker before grinding. Crushing is carried out dry in the following order: primary; secondary; tertiary and quaternary, depending on the ore size and hardness. Primary and secondary crushers are used for soft to medium hard coarse ores while tertiary and quaternary crushers are typically applied for medium to very hard fine ores. Jaw crushers and gyratory crushers are regarded as primary crushers, secondary crushers are cone crushers, roll crushers and impact crushers while tertiary and quaternary crushers include hammer mills and rotary coal breakers (Kumar, 2012).

Grinding is usually performed wet in ball mills, pebble mills, rod mills, and stirred mills or attritors. As such, grinding consumes more energy than crushing (Wills, 2006). The effectiveness of the grinding process is marked by the final grade of recovered mineral as only the free desirable minerals are separated from the ore. High final grade translates to high revenue.

To optimize grinding efficiency, this study investigated the effects of four operating factors including nominal feed size, media size, shaft speed and grinding time, each of three levels on two response variables, product $\mathrm{P}_{80}$ and specific energy measured during the batch grinding of Leatherwood coal using silica as the grinding media in a stirred mill. The experiment was designed and implemented as a one-third fractional factorial design of resolution III. Degradation of silica during grinding was investigated by conducting ash analysis for the Leatherwood coal before and after grinding. Statistical analyses of the experimental data were performed with JMP statistical software to determine the design factors that significantly influence the product $\mathrm{P}_{80}$ and the specific energy. From these analyses, mathematical models were developed to predict the product $\mathrm{P}_{80}$ and the specific energy based on the factors that significantly influence them. Finally, the batch grinding experiment was numerically simulated by solving the population balance method with the particle swarm optimization algorithm in MATLAB to determine the selection and breakage function parameters of the Leatherwood coal material. 


\subsection{Problem Statement}

Grinding is energy intensive and energy costs a fortune. Minimizing grinding energy is crucial to reducing costs during mineral processing. Grinding processes involve interactions between the feed material, grinding media, and the grinding equipment. Since feed size reduces with time during grinding, the desired product size determines how long the grinding process would be. Because grinding is a factorial process, different factors may determine the amount of energy consumed during the process. Determining the factors that actually influence grinding energy would be extremely beneficial in optimizing grinding efficiency.

\subsection{Significance of Study}

This study optimized grinding efficiency of Leatherwood coal using silica grinding media in a stirred mill by assessing the effects of nominal feed size, media size, shaft speed and grinding time on the product $\mathrm{P}_{80}$ and the specific energy. The findings of this study were expected to improve the grinding efficiency in mineral processing circuit in terms of minimizing comminution cost and maximizing plant profit.

\subsection{Research Objectives}

The objectives of this study were to:

1. Optimize grinding efficiency of Leatherwood coal using silica grinding media in a stirred mill by assessing the effects of nominal feed size, media size, shaft speed and grinding time on the product $\mathrm{P}_{80}$ and the specific energy by implementing a one-third fractional factorial design of experiments of resolution III.

2. Investigate the degradation of silica during grinding by conducting ash analysis for the Leatherwood coal and comparing the shape analysis of the media before and after grinding.

3. Statistically analyze experimental data to determine what design factors significantly influence the product $\mathrm{P}_{80}$ and the specific energy.

4. Develop mathematical models to predict the product $\mathrm{P}_{80}$ and the specific energy using factors that significantly influence them.

5. Determine selection and breakage function parameters of Leatherwood coal by numerically simulating batch grinding using the experimental data.

\subsection{Thesis Organization}

This thesis is comprised of five chapters. Chapter 1 gives the general overview of comminution, problem statement, significance of study and research objectives. Chapter 2 presents the review of existing literatures on comminution, ultra-fine grinding, population balance model and factorial design of experiments. Chapter 3 presents the methodology employed during this study including sample characterization, design of experiments, sample preparation, batch grinding, ash analysis and statistical analysis of experimental data. Chapter 4 presents the results obtained from sample characterization, design of experiments, sample and media preparation, batch grinding experiment, ash analysis, statistical analysis of experimental results and finally, numerical simulation of batch grinding. Chapter 5 summarizes the conclusions of this study and possible recommendations for future studies are given. 


\section{Chapter 2 \\ Literature Review}

In this chapter, existing literatures on comminution, ultra-fine grinding, population balance model and factorial design of experiments are reviewed.

\subsection{Comminution}

Mineral processing operations are considered as an important aspect of mining. Mineral processing refers to the process of successfully separating commercially valuable minerals from their ores. Mineral processing operations can involve four different types of unit operations referred as: size reduction or comminution, size separation, concentration, and dewatering (Kelly \& Spottiswood, 1982).

Size reduction or comminution refers to crushing and grinding. The main purpose of crushing and grinding is to (1) liberate valuable minerals from the ore matrix, (2) to increase surface are for high reactivity, and (3) to facilitate the transport of ore particles between unit operations. Size separation refers to the classification of grinding products by particle size; sizing is accomplished by using classifiers and screens. Concentration refers to the increase of the percentage of the valuable mineral in the concentrate; froth flotation and gravity concentration are used extensively in mineral processing. Dewatering refers to the processing of separating solids from water with the use of thickeners and filters (Fuerstenau, 2003).

As grinding is an important operation used to release and retrieve valuable materials, it is numerically characterized by a few parameters including the following:

One of the variables used to typify grinding is the Bond work index. As particles fracture and their sizes diminished, they become stronger and more difficult to further fragment. Hence, lots of energy is expended during grinding. Bond's test is an ideal grindability test developed for any ore type in tube and ball mills (Bond, 1952; Williams, Eastwick, Kingman, Giddings, Lormor \& Lester, 2015). Asides determining the grindability of ore, the index can also be used to design a new comminution (grinding) circuit if the test has been conducted on a new sample to be fed into the circuit. Kaya, Fletcher and Thompson (2002) reported that "over the years, Bond grindability testing has become a standard part of ore characterization for sizing and analyzing the comminution circuits" (p. 1).

The work index is a measure of energy in kilowatt needed to breakdown a large sized particle (feed) to $80 \%$ passing 100 microns. It can be obtained in a classic closed-circuit ball mill grindability test. The higher the Bond work index of an ore, the more the grinding resistance and consequently, the more the energy required to pulverize to the given product size in a ball mill (Bond, 1952; Bond, 1961). The amount of work input required to grind the ore to a given product size is estimated using Equation 2.1:

$$
W=W_{i}\left(\frac{10}{\sqrt{\mathrm{P}_{80}}}-\frac{10}{\sqrt{\mathrm{F}_{80}}}\right)
$$

Where,

W: Amount of work input in kilowatts hour per ton

$\mathrm{W}_{\mathrm{i}}$ : Bond work index in kilowatts hour per ton 
$\mathrm{P}_{80}: 80$ percent passing size of product in microns

$\mathrm{F}_{80}: 80$ percent passing size of feed in microns

Furthermore, grinding is parameterized by another indicator, the Hardgrove grindability index. During granulation, particles' surface area increases as size decreases. Rittinger's theory which states that the amount of work done during grinding is commensurate to the newly formed surface, is the basis of HGI (Jankovic, Dapkunas \& Lum, 2010; Williams et al., 2015). The finer the choice of particle size, the more energy to be input into the mill.

Bond (1961) described the relationship between the Hardgrove grindability index and the wet grinding Bond work index with the empirical models in Equations 2.3 and 2.3:

$$
\begin{aligned}
& \mathrm{W}_{\mathrm{i}}=\frac{435}{H G I^{0.91}} \\
& \mathrm{~W}_{\mathrm{i}}=\frac{1622}{H G I^{1.08}}
\end{aligned}
$$

Where HGI is the Hardgrove grindability index. Equations 2.2 and 2.3 are used for ores whose Bond work index is below and above $8.5 \mathrm{kWh} /$ ton, respectively. As a basis for comparison with the feed, the ground materials are screened to determine their particle size distribution, another distinctive feature of grinding.

Particle size distribution is the relative quantity of a material according to size (Jillavenkatesa et al., 2001). The ground samples are subjected to sieve analysis and are separated into different size classes. The mass distribution, the amount of valuable minerals in each size group is determined by weighing. A narrow particle size distribution is increasingly desirable because it reduces energy consumption during grinding, classification and separation (Kotake et al, 2010).

Lastly, by analyzing the parent and daughter ores for mineral-maceral compositions, the amount of impurity liberated from the mineral of interest or vice versa can be estimated. Another parameter for qualifying grinding operation is the degree of liberation. The amount of valuable mineral that is recovered from an ore is a function of its degree of liberation (O'Brien, Flirth \& Adair, 2011). Parent minerals with high degree of liberation will give high yield and grade of daughter minerals. Conversely, low yield and grade of minerals are obtained from ores with low degree of liberation. One way to improve liberation degree is by comminution to a given size (liberation size) small enough to detach the invaluable material from the valuable one. Flirth and O'Brien (2002) stated that liberation of coal can be augmented by miniaturization. They also propose that the amount of liberation as well as the liberation size can be obtained from coal grain analysis, a compositional investigation of coal particles. O'Brien et al. (2011) concluded from their research conducted on coal that higher liberation and recovery were discovered by grinding coal to finer sizes as compared to coarse sizes. In addition, their study suggests that the degree of liberation as well as recovery depends on individual coal. That is, coals with different origins and locations differ. Bokányi and Csöke (2003) demonstrated through experiment the feasibility of segregating distinct petrographic components of Bituminous coal from Southern Hungary and determined the degree of liberation based on petrographic composition, flotation kinetic study of isolated components (groups of components), scanning electron microscopy and microprobe analyses. Oki, Yotsumoto and Owada (2004) studied a way to estimate the degree of mineral liberation by the sink float separation data of coal with Equation 2.4. Column flotation cells are usually used to improve 
recovery of ultrafine particles at low capital and operating costs and ease of automation (Wills, 1997).

$$
\mathrm{DL}(\%)=\frac{\text { Liberated } M}{M} * 100
$$

Where,

DL: degree of mineral liberation

$M$ : amount of mineral (ash content) in the coal.

\subsection{Ultra-fine Grinding}

To achieve improved liberation and separation of useful minerals, ultrafine grinding of ores is increasingly desired in the mineral industry and ball mills are being replaced by stirred mills or attritors because stirred mills are designed to produce finer particles with higher efficiency. (Parry, 2006). Both ball mills and stirred mills are being used for regrinding in flotation circuits. In ball mills, grinding is achieved by impact between the grinding media (steel balls) and the particles. As the mill chamber rotates, the steel balls are set into motion thereby colliding with the walls of the chamber and then cascading on the particles causing them to break. The optimum rotational speed of the chamber is affected by the critical speed of the mill. The critical speed is the speed at which the balls would centrifuge and causes no grinding. The typical sizes of balls in ball mills are between 20 microns and 50 microns (Andreatidis, 1995). The drawbacks of ball mills include lower energy efficiency, higher rate of sliming, larger space requirement and higher ball wear rate relative to stirred mills (Lichter et al., 2002). Below 75-micron product particle size, the rate of specific energy consumption in ball mills is exponential and may be uneconomical for ultrafine grinding (Parry, 2006).

Because ball mills are less energy efficient, a considerable amount of energy and time are consumed which often results in overgrinding and the minerals of interest maybe lost in form of slimes (Lofthouse et al., 1999). Stirred mills are commonly used in industries such as industrial minerals, pharmaceuticals, and cosmetics for ultrafine grinding due to higher energy efficiency and grinding rate and ease of operation compared to ball mills (Jimbo et al., 1992; Gao et al., 1995; Zheng et al., 1996; Kano et al., 2001).

In stirred mills, grinding of particles is achieved by attrition between the media and the particles. In either vertical or horizontal stirred mills, the media is set in motion by the rotating impeller in the stationary grinding chamber. Stirred mills generates product particles with clean surfaces by polishing particle surfaces through attrition grinding. While the common breakage mechanism in stirred mills is attrition breakage, some studies have proved that impact breakage also occurs in stirred mills (Kwade et al., 1999; Yue, 2003). Stirred mills can be grouped into either slow speed or high-speed stirred mill. The slow speed mill is most efficient at grinding coarse hard ores while the high-speed stirred mill is more efficient for ultrafine grinding of fine soft ore. High-speed stirred mills grind majorly by attrition while low-speed stirred mills grind with a combination of attrition and impact (Andreatidis, 1995). Examples of slow speed mill are tower mill or Vertimill and pin mills. High speed mills include stirred media detritor and Netzsch/IsaMill. (Parry, 2006). Stirred mills are also used to achieve better kinetics of leaching and pressure oxidation processes due to increased surface area to volume ratio of product particles. The KCGM Gidji roaster uses 
IsaMill for ultrafine grinding of gold-bearing sulphide ore before cyanidation (Parry, 2006). Tati Hydrometallurgical demonstration plant uses both horizontal and vertical stirred mills for ultrafine grinding of Nickel sulphide concentrates before pressure oxidation (Nel et al., 2006).

There are various factors affecting the performance of a stirred mill. Studies have been conducted to investigate the effect of stirred mill type and operating conditions on grinding energy requirements, product particle size distributions, particle breakage rates and mineral liberation (Parry, 2006; Kwade et al., 2002; Yue et al., 2003; Ma et al., 1998). Nesset et al. (2006) compared stirred media detritor, IsaMill and tower mill in regrinding zinc concentrate at the Tati hydrometallurgical demonstration plant and found that the tower mill has 57 percent lower specific energy consumption compared to the other stirred mills. The better energy efficiency of the tower mill is due to less energy being used for fluid flow and ball-particle interactions.

Aside the mill type, the amount of energy required in a stirred mill depends on mass hold-up, impeller speed, slurry density, media size and media type (Parry, 2006). According to Lichter et al. (2002), media size has the most influence on grinding efficiency and mostly affect the fineness of the product particle in a mill. It was proposed that the main attributes of the media to be considered are size, type, hardness and competency. Sand, ceramic and slag are the prominently used media type in high-speed stirred mills while steel or chrome steel balls are mostly used in low-speed stirred mills. Sand is relatively cheaper than ceramic, however, producing sand with the desired size distribution and competency is challenging. Due to energy loss during media wear and tear, ceramic offers better grinding efficiency and specific breakage rates than sand (Nel et al., 2006).

There is an optimum media size depending on the particle specific breakage rate and desired product size distribution, for a given feed size (Yue, 2003). A coarse media has less chance of media-particle collisions and hence reduces energy efficiency. Kotake et al. (2010) reported that dry grinding with large balls, is useful for breaking the particles, and wet grinding with small balls, is effective in producing fine or ultra-fine products. It was observed that the product size obtained from wet grinding was one-quarter the product size obtained from dry grinding. Hence, wet grinding produced a narrower product size distribution compared to dry grinding. Weller et al. (1999) showed that lower specific energy can be achieved by using higher flow rates in a horizontal stirred mill due to higher pressure facilitating particle breakage. However, extremely high flow rate may cause increased media and impeller wear and clogging of the media at the discharge.

Grinding aids have been known to improve grinding efficiency. Choi et al. (2009) studied the effect of grinding aids (poly-acrylic acid) on power and comminution coefficient or grinding rate during the ultrafine wet grinding of calcite in a stirred mill with ball media. Results showed that grinding rate was increased and a narrower particle size distribution was obtained with addition of grinding aids. Paramasivam et al. (1992) also reported that addition of grinding aids in stirred mill improved the ultrafine grinding of ground particles. This advantage is attributed to the fact grinding aids adsorbs to the surfaces of the particles thereby minimizing the agglomeration of fine particles due to Van der Walls forces (Hasegawa et al., 2001; Zheng et al., 1997; Choi et al., 2001; Kanda et al., 1998; Saito et al., 1998). 


\subsection{Applications of Fractional Factorial Design}

Experimental investigations that involves the assessment of the effects of more than one factor on a response variable are conducted using factorial designs. As the number of factors increases, the number of runs needed for a complete replicate of the factorial design may be more than the available resources. For fast and economic reasons, fractional factorial design was developed. Fractional factorial design is a technique that allows experimental conditions to be optimized more economically by running fewer tests compared to the full factorial design (Montgomery, 2013). Fractional factorial designs have been widely applied in screening operating factors for product and process design and process optimization in industries including biofuel, nanotechnology, food and so on.

Due to increased energy demand in the globe, biofuels are increasingly produced as alternative to fossil fuels. Kalia et al. (2016) applied fractional factorial design to investigate the effect of 24 medium components on the production of 1,3-propanediol, which is a useful compound in the production of biodiesel. Each of the 24 factors has two levels and would have required $2^{24}$ runs for a full factorial design. With fractional factorial design, 32 runs were conducted in triplicates and partitioned in four blocks with each block having 24 tests. Due to the large number of factors, fractional factorial design provided a quick and efficient way to optimize the production of 1,3propanediol from glycerol by running a $2^{24-19}$ of resolution III design. Statistical analysis of the experimental data showed that only 8 out of the 24 factors were found to significantly increase the production of 1,3-propanediol. Rezende et al. (2018) optimized the effect of 5 pretreatment variables: milling time, temperature, double treatment, chemical concentration, and pretreatment time on two pretreatment methodologies: acid-alkali and acid-organosolv, applied to elephant grass leaves for the production of biofuels, using $2^{5-1}$ fractional factorial design of resolution $V$ with triplicate in the central point. With respect to the acid-alkali pretreatment methodology, chemical concentration and milling time were the only significant factors. For acid-organosolv pretreatment condition, the significant factors were chemical concentration and double treatment.

As the world's population increases, the demand for food also increases. Investigations on how to optimize food preservation and digestion are being conducted. Momen et al. (2006) implemented Plackett-Burman fractional factorial design to study the effect of seven factors: acids $\left(\mathrm{HNO}_{3}\right.$, $\mathrm{H}_{2} \mathrm{SO}_{4}$ and $\mathrm{H}_{2} \mathrm{O}_{2}$ ) volume, digestion time, pre-digestion time, temperature of the hot plate and sample weight on the optimization of nuts digestion. Instead of running a $2^{7}$ tests, only 8 tests were conducted. Results showed that three of the investigated factors: acids $\left(\mathrm{HNO}_{3}\right.$ and $\left.\mathrm{H}_{2} \mathrm{O}_{2}\right)$ volume and digestion time were most significant. Sokamte et al. (2017) studied the effect of two-level seven factors: brine concentration, brining time, preliminary smoking-drying time, smoking time, hot smoking time, smoking temperature and hot smoking temperature on moisture, salt and total phenol content of hot smoked Nile Perch fish using a $2^{7-3}$ fractional factorial design with resolution $V$. A combination of 16 tests and additional 4 replicates at the center point were run. For the total phenol content, only the smoking temperature was statistically significant. For salt content, all factors except brining time and smoking temperature have a significant influence. Lastly, all factors except brining time have significant impact on moisture. 


\section{Chapter 3}

\section{Research Methodology}

This chapter presents the methodology employed during this study including sample characterization, design of experiments, sample preparation, batch grinding, ash analysis and statistical analysis of experimental data. The following describes the procedures employed in conducting this research.

\subsection{Sample Characterization}

The coal material used in this study was the mixed-phase particles commonly referred to as middlings, sampled from the dense medium circuit at the Leatherwood preparation plant in Kentucky (Figure 3.1). The sample was crushed to minus 1 millimeter and delivered from the University of Kentucky to West Virginia University. The sample was initially characterized by conducting Bond and Hardgrove grindability tests to study its grindability. The as-received dry Leatherwood coal was thoroughly mixed in a galvanized iron pan and then divided in a universal sample splitter to obtain representative portions used for the Bond and Hardgrove grindability tests.

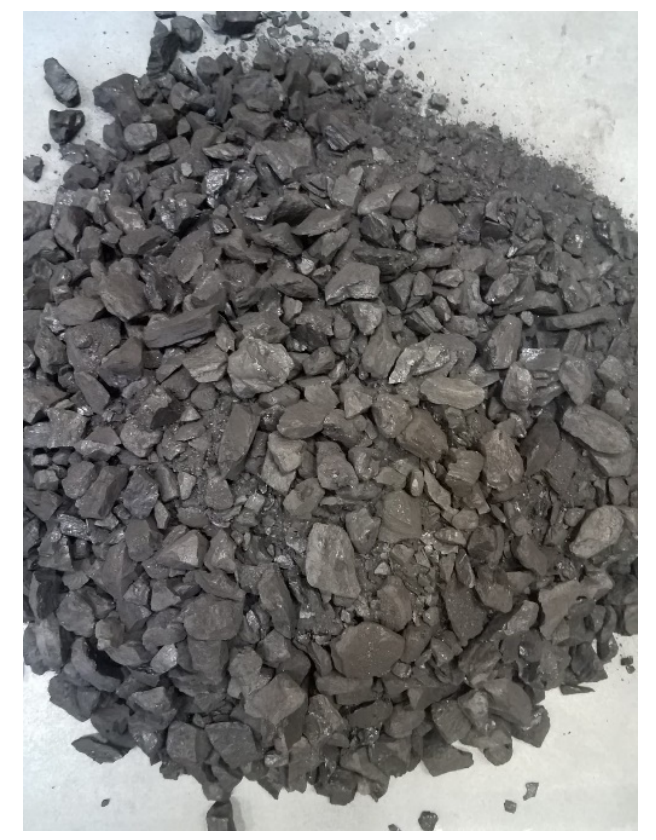

Figure 3.1: Crushed Leatherwood coal.

The well-mixed sample was evenly poured into the dividing head of the universal sample splitter. The sample passed through the alternately arranged openings in the opposite direction into the two collecting trays under the dividing head outlets. With every split, the sample was halved. The process was repeated a few times until the desired quantity was obtained.

\subsubsection{Bond Grindability Test}

The Bond grindability test was conducted to determine the Bond work index of the Leatherwood coal material. The Bond work index is a measure of the resistance of an ore to grinding and it is dependent on the ore's hardness, structure and discontinuities (Todorovic et al., 2016). 
A representative sample of approximately six kilograms was obtained from the splitter and stage crushed in the Sturtevant laboratory jaw crusher shown in Figure 3.2 followed by the Sturtevant laboratory roll crusher in Figure 3.3. The product was screened with a 6-mesh sieve in the Tyler Ro-tap test sieve shaker in Figure 3.4. Particles coarser than 6 mesh were fed to the aforementioned stage crushing process again to make sure that the final ground particles had a top size less than 6 mesh. It was also ensured that most of the material (at least $80 \%$ ) passed through the 6-mesh screen but retained on the 14-mesh screen, as desired for the subsequent Bond grindability test. The amount of undersize in the test feed (minus 149 microns (100 mesh)) was determined and recorded. The feed size mostly had no undersize.

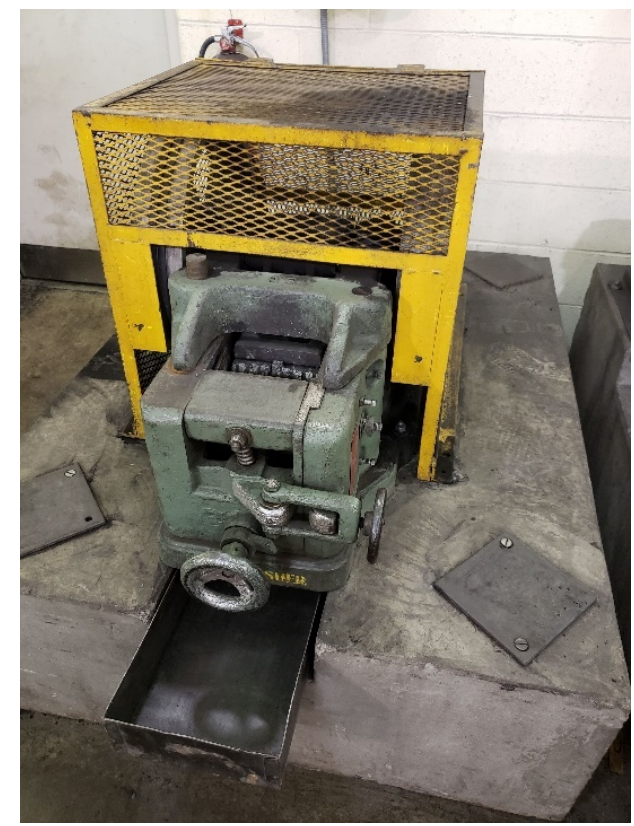

Figure 3.2: Sturtevant laboratory jaw crusher for staged crushing.

The material was poured in a 1000-millimeter clear graduated cylinder and compacted until the 700-millimeter mark was reached. The weight of 700-millimeter sample was recorded and then divided by 3.5 to get the Ideal Period Product (IPP). The 700-millimeter feed sample was screened in the Tyler Ro-tap test sieve shaker to determine its particle size distribution. Each size fraction was weighed and recorded. The feed was placed in the rotating drum of the Sepor FC Bond mill shown in Figure 3.5. The drum was charged with 285 steel balls, ranging in size from $5 / 8$ inch to $1 \frac{1}{2}$ inch in diameter, with all steel balls totaling weighing 44.5 pounds. The distribution of the ball charge is given in Table 3.1. The material was dry ground by setting the revolution counter to100 revolutions (for fine grinding). When the number of revolutions, in this case, 100 was reached, the mill shut off. The mill was emptied through a screen to retain the grinding balls to be used for the next cycle. The product was screened to determine the weight of the undersize (minus 149 microns (100 mesh screen)). The number of net grams produced per revolution was estimated by dividing the undersize weight (in grams) by the number of revolutions the mill rotated. Afterwards, the weight to be ground in the next cycle to maintain the 250 percent circulating load was estimated from the difference between the IPP and the amount of undersize in the test feed. 


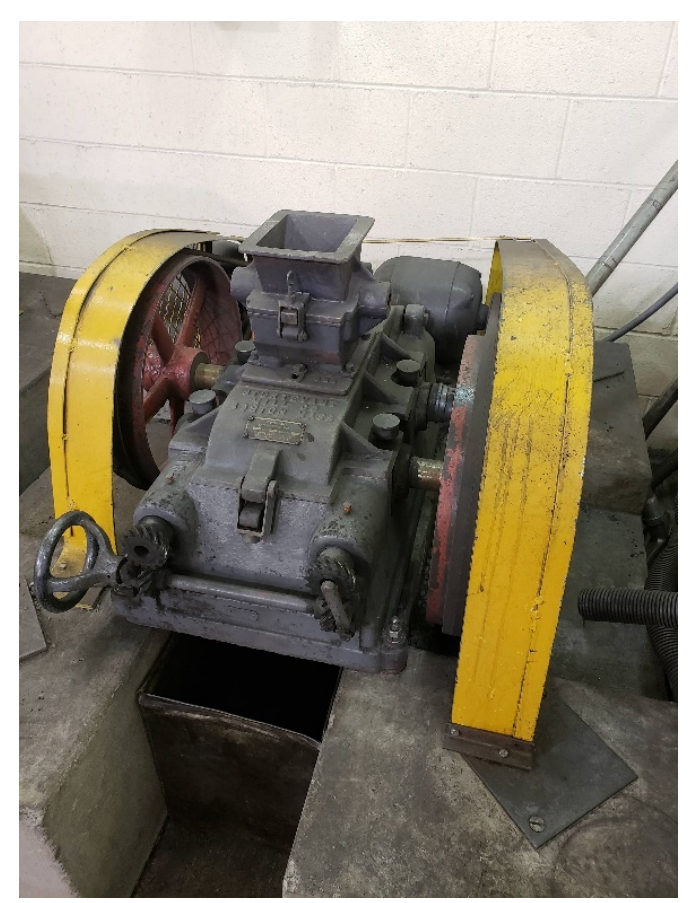

Figure 3.3: Sturtevant laboratory roll crusher for staged crushing.

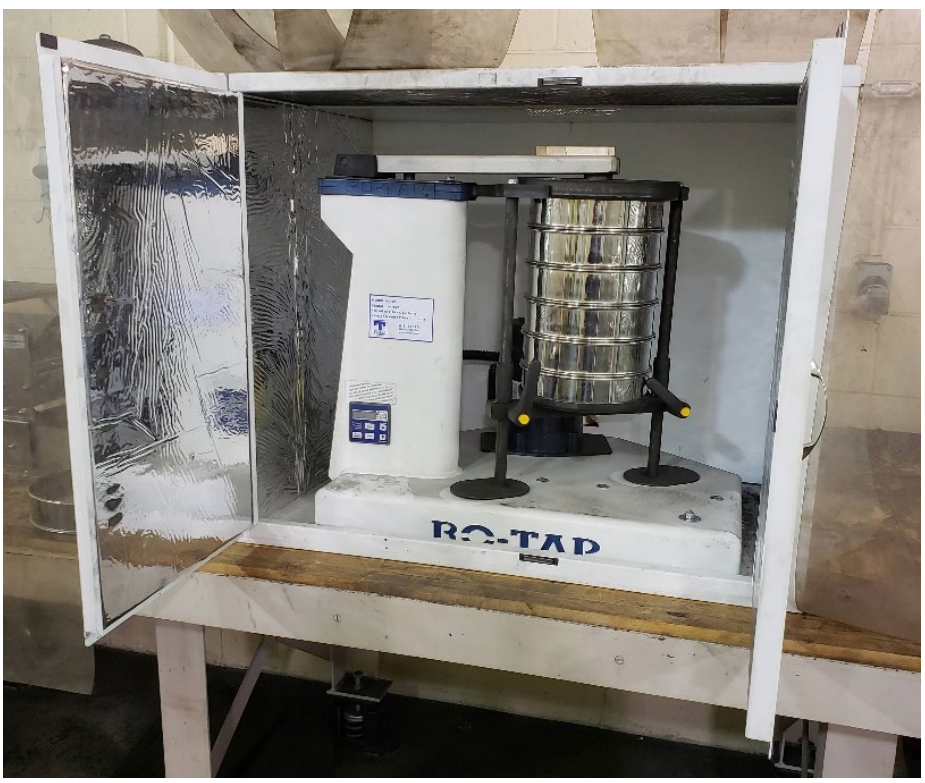

Figure 3.4: Tyler Ro-tap test sieve shaker for sieve analysis.

The amount of unsegregated fresh feed equivalent to weight of the undersize in the previous test was added to the mill with the oversize to retain a mill load equivalent to the starting amount of 700 millimeter. The number of revolutions for the subsequent test was adjusted to reach a desired circulating load of 250 percent by dividing the weight to be ground by the number of net grams produced per revolution. The grinding cycles were then continued for five to seven times until the net weight of the sieve undersize produced per mill revolution reached equilibrium. All grinding was conducted dry, and all sieving was performed in the Tyler Ro-tap test sieve shaker with a 
screening time of five minutes. The final size distributions of the product were determined using the Cilas 1190L laser particle size analyzer in Figure 3.6.

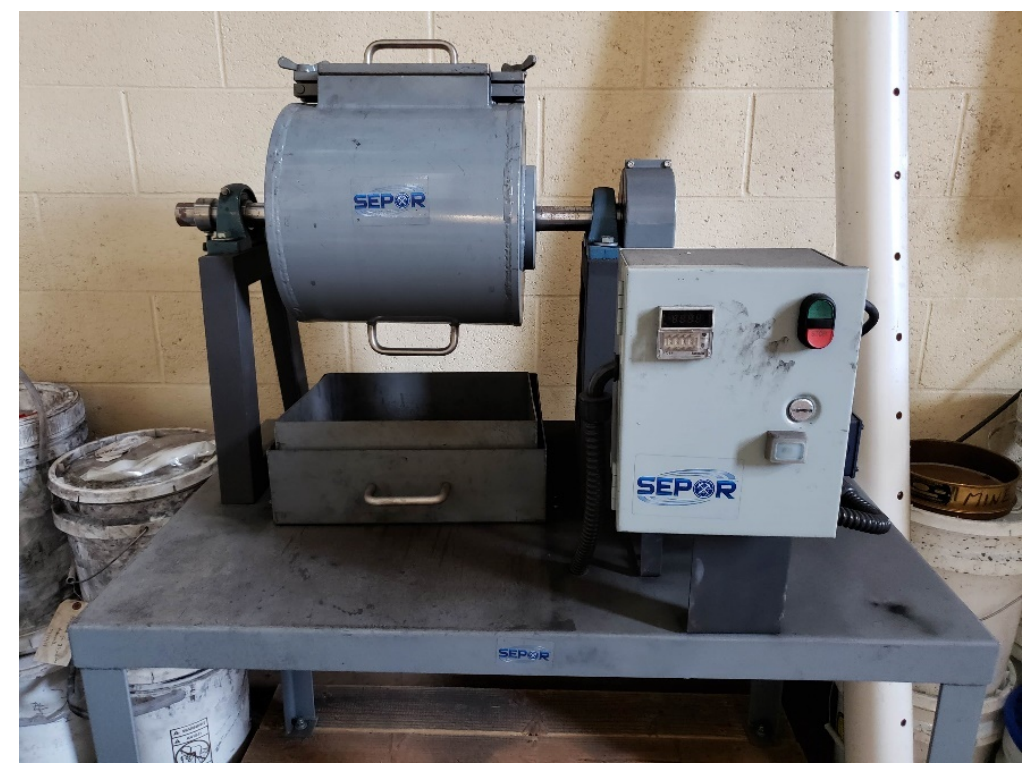

Figure 3.5: Sepor FC Bond mill for Bond grindability test.

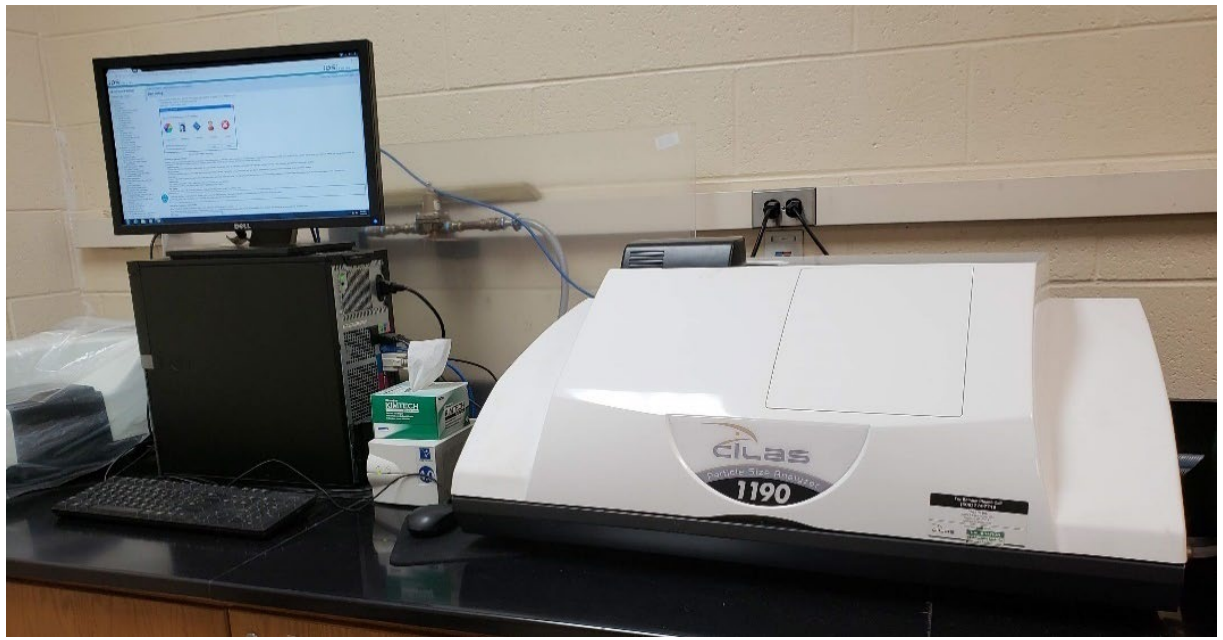

Figure 3.6: Cilas 1190L laser particle size analyzer for size analysis.

Three standard Bond mill grindability tests were conducted on the sample to ensure reproducibility of results. The work index for each of the three tests was then calculated using the Fred Bond's formula (Bond, 1961) in Equation 3.1.

$$
W_{i}=\frac{44.5}{\left(P_{1}^{0.23} \times G_{b p}^{0.82} \times\left(\frac{10}{\sqrt{P_{80}}}-\frac{10}{\sqrt{F_{80}}}\right)\right)}
$$


Where,

$\mathrm{W}_{\mathrm{i}}$ : Bond work index

$\mathrm{F}_{80}: 80 \%$ passing size of feed (microns)

$\mathrm{P}_{80}: 80 \%$ passing size of product (microns)

$P_{1}$ : opening size of the sieve being tested (microns)

$G_{b p}$ : grindability in net gram of mesh undersize produced per revolution of the mill.

Table 3.1: Distribution of ball charge for Bond's grindability test.

\begin{tabular}{llll}
\hline Ball Diameter (inch) & Number of balls & Each Ball Weight (Lb) & Total Weight (Lb) \\
\hline $1 \frac{1}{2}$ & 41 & 0.5009 & 20.5384 \\
\hline $1 \frac{1}{4}$ & 50 & 0.2899 & 14.4947 \\
\hline 1 & 6 & 0.1484 & 0.8906 \\
\hline $3 / 4$ & 68 & 0.0626 & 4.2580 \\
\hline $5 / 8$ & 120 & 0.0362 & 4.3484 \\
\hline TOTAL & 285 & & 44.5301 \\
\hline
\end{tabular}

\subsubsection{Hardgrove Grindability Test}

Hardgrove grindability test is an established test exclusively designed to determine the grindability of coal in vertical spindle mills. Hardgrove grindability index (HGI) ranges from 20 to 110 with materials with higher index values being more grindable and requiring less energy to grind to fine sizes (Williams et al., 2015). HGI tests were conducted on the Leatherwood coal sample using the Preiser Scientific Hardgrove grindability machine shown in Figure 3.7. To calibrate the machine, the Hargrove grindability test was conducted for the four reference materials of known HGI values provided by Preiser Scientific and the corresponding masses of materials passing the 75-micron screen were determined and recorded according to the ASTM D409/D409M- Standard Test Method for Grindability of Coal by the Hardgrove-Machine Method. Afterwards, the as-received coal sample was divided in the universal sample splitter to get a representative portion which was stage-crushed with a Sturtevant laboratory jaw crusher followed by a Sturtevant laboratory roll crusher and then screened with the Tyler ro-tap test sieve shaker to minus 4.75 millimeter (No. 4). Afterwards, a representative lot of 250 grams was subjected to sieve analysis using a 1.18millimeter (No. 16) and a 0.60-millimeter (No. 30) sieve. The $1.18 \times 0.6$-millimeter material was retained for the subsequent HGI test whereas the oversize $(>1.18$ millimeter) returned to the crusher and continued to be crushed and re-sieved until it passed through the No. 16 screen. Eventually 50 grams of the $1.18 \times 0.6 \mathrm{~mm}$ material was added to the Preiser Scientific Hardgrove grindability machine and was ground under the specified 60 revolutions. To minimize the experimental error caused by sample loss associated with fine particles, the grinding product was 
reweighed and if the weight before and after the test differed by more than 0.5 gram, the tested was rejected and repeated. Sieve analysis was then performed on the ground material and the amount of material that passed through 75 microns (No. 200) sieve was weighed and recorded.

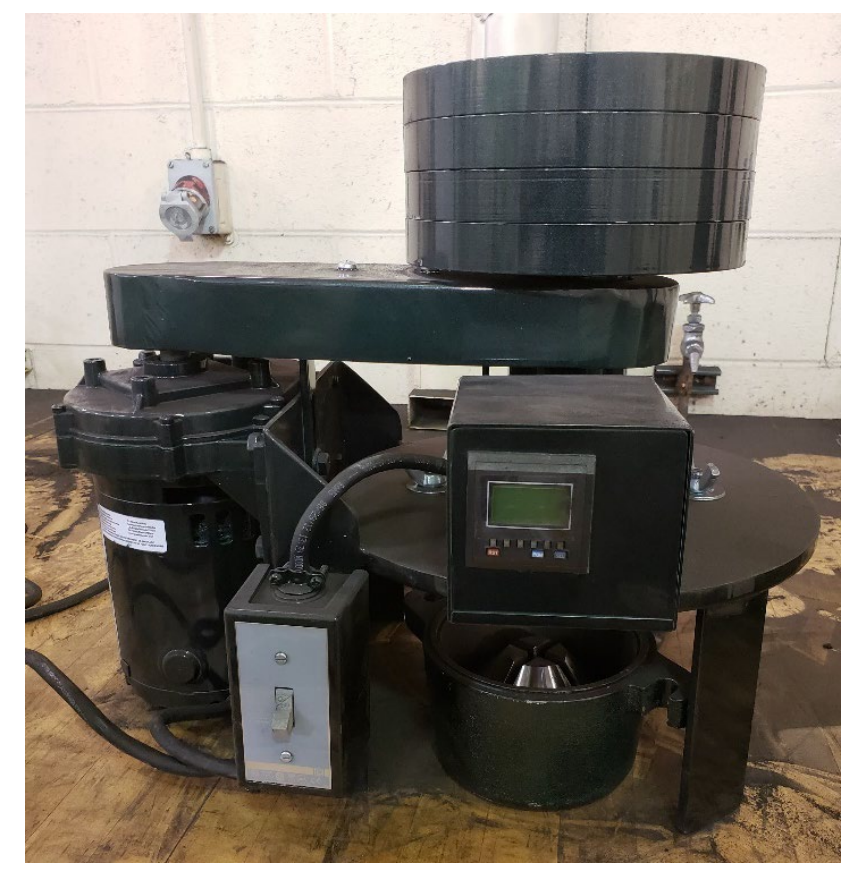

Figure 3.7: Preiser Scientific Hardgrove grindability machine.

$$
H G I=A+B * m
$$

The relationship between the known HGI values and the measured masses of reference materials passing the 75-micron sieve $(m)$ was linearly fit with Equation 3.2 and the fitting constants $(A$ and $B$ ) were determined. Finally, the recorded mass of the Leatherwood coal passing 75 microns and the values of fitting constants were substituted into Equation 3.2 to estimate the HGI of the Leatherwood coal. The test was repeated three times to ensure reproducibility of results.

\subsection{Design of Experiments}

As aforementioned, experiments that involve the investigation of the effects of more than one factor on a response variable are conducted using factorial designs. In this design, all possible combinations of the levels of the factors are studied in each trial or replicate of the experiment. The main effect of a factor is indicated by the difference in the response when the level of that factor is changed. The interaction between two or more factors is shown by the change in the response due to the combined effect of these factors on the response variable. Factorial designs are designated as $\mathrm{n}^{\mathrm{k}}$. Where $\mathrm{k}$ and $\mathrm{n}$ denote the number of factors and the number of factor levels, respectively.

This study assessed the effects of four operating factors: nominal feed size, media size, shaft speed and grinding time (represented as $A, B, C$, and $D$ ) on two response variables, product $\mathrm{P}_{80}$ and specific energy. Each operating factor has three levels: low level, intermediate level and high level coded as 0,1 , and 2 , respectively in Table 3.2. The grinding media (silica) was obtained in standard size ranges as per manufacturer's design, therefore, media size was a qualitative factor while other operating factors were quantitative. 
Table 3.2: Operating factors and their corresponding levels.

\begin{tabular}{llll}
\hline \multirow{2}{*}{ Operating Factor } & \multicolumn{3}{c}{ Level } \\
\cline { 2 - 4 } & $\mathbf{0}$ & $\mathbf{1}$ & $\mathbf{2}$ \\
\hline A. Grinding Time (minutes) & 16 & 32 & 64 \\
\hline B. Nominal Feed Size $(\mu \mathrm{m})$ & 25 & 150 & 250 \\
\hline C. Shaft Speed $(\mathrm{rpm})$ & 200 & 340 & 400 \\
\hline D. Media Size $(\mu \mathrm{m})$ & $297-420$ & $420-595$ & $595-841$ \\
\hline
\end{tabular}

Because media size (a qualitative factor) cannot be included in the interaction and the quadratic terms of a response surface model, this experiment was designed as a $3^{3}$ factorial experiment across the low, intermediate and high levels of media size represented with categorical variables D_1, D_2, and D_3, respectively.

\subsubsection{The $3^{\mathrm{k}}$ Design}

Generally, in $3^{\mathrm{k}}$ designs, main effects do not have orthogonal components but have 2 degrees of freedom each, $\mathrm{p}$-factor interactions have $2^{\mathrm{p}-1}$ orthogonal components and $2^{\mathrm{p}}$ degrees of freedom each. $p$ is the number of operating factors in the interaction. The orthogonal components have no physical meaning but are useful in constructing more complex designs.

While writing an orthogonal component in the form of $A^{x} B^{y}$, the established convention is that the only exponent allowed on the first letter is 1 . If the first letter exponent is not 1 , the entire expression is squared and the exponents ( $x$ and $y$ ) are reduced modulus 3 (Montgomery, 2013).

\subsubsection{Fractional Factorial Design}

The sparsity of effects principle states that "most systems are dominated by some of the main effects and low-order interactions, and most high-order interactions are negligible (Montgomery, 2013). The objective of any designed experiment is to obtain more information for less cost. Hence, information on the main effects and low-order interactions may be obtained by just running a fraction of the complete factorial experiment. According to Montgomery (2013), fractional factorial designs are widely employed in optimizing and designing products and processes that involves factor screening experiments to identify factors that have significant effects amongst many factors considered. The significant factors are then further investigated in subsequent experiments.

Fractional factorial design is achieved by confounding, which is an experimental design technique where a complete $3^{\mathrm{k}}$ factorial experiment is split in $3^{\mathrm{q}}$ blocks such that the block size $\left(3^{\mathrm{k}-\mathrm{q}}\right)$ is less than the number of runs $\left(3^{k}\right)$ in one full replicate and $q$ is user-defined. The resulting design is a $3^{\mathrm{k}-\mathrm{q}}$ fractional factorial experiment. All treatment combinations in any of the blocks are run and conclusions about the complete replicate will be made based on the fraction run. Confounding makes information about some treatment effects usually the high-order interactions (mostly negligible) to be inseparable from the blocks or some other low-order treatment effects. Two or more confounded effects are known as aliases. Each main effect or component of interaction from a $3^{\mathrm{k}-\mathrm{q}}$ design has $2^{\mathrm{q}}$ aliases, which can be obtained by multiplying the effect by both $I$ and $I^{2}$ modulus 3. If higher-order interactions (including their components) are small or negligible 
relative to the main effects and low-order interactions, then the main effects and low-order interaction can be easily estimated.

The general procedure for the $3^{\mathrm{k}}$ design in $3^{\mathrm{q}}$ blocks is that $\mathrm{q}$ orthogonal components of higherorder interactions with the same total degrees of freedom as the blocks are selected as the defining relation $(I)$ of the fractional factorial design from which the defining contrast in Equation 3.3 is constructed (Montgomery, 2013).

$$
L=\alpha_{1} x+\alpha_{2} x_{2}+\cdots+\alpha_{k} x_{k}
$$

where $\alpha_{i}$ represents the exponent on the $\mathrm{i}^{\text {th }}$ factor in the effect to be confounded and $x_{i}$ is the level of the $\mathrm{i}^{\text {th }}$ factor in a treatment combination. Each treatment combination in the $3^{\mathrm{k}}$ design is denoted by k-digits, where the first digit indicates the level of the first factor $\mathrm{A}$, the second digit indicates the level of the second factor $\mathrm{B}$, and so on. For the $3^{\mathrm{k}}$ design, $\alpha_{i}$ can either be 0,1 , or 2 with $\alpha_{1}$ always equal to 1 , and $x_{i}=0$ (low level), 1 (intermediate level), or 2 (high level). The treatment combinations in the $3^{\mathrm{k}}$ design are assigned to blocks based on the value of $\mathrm{L}(\bmod 3)$. Because $\mathrm{L}$ (mod 3$)$ can take on only the values 0,1 , or 2 , three blocks are uniquely defined. The treatment combinations satisfying $\mathrm{L}=0(\bmod 3)$ constitute the principal block because it will always contain the treatment combination where all the factors are at their low levels.

\subsubsection{Design Resolution}

The resolution of a fractional factorial design is the length of the shortest word in the defining relation. A $3^{\mathrm{k}-\mathrm{q}}$ design of resolution $\mathrm{R}$ is written as $3_{R}^{k-q}$ where $\mathrm{R}$ is written in Roman numeral. In resolution III designs, main effects are not aliased with one another, but at least one main effect is aliased with a two-factor interaction and some two-factor interactions may be aliased with each other. Therefore, all main effects can be estimated unbiasedly if all interactions are assumed to be negligible. Designs in which no main effect is aliased with any other main effect or with any twofactor interaction, but two-factor interactions are aliased with each other are of resolution $I V$. In these designs, all main effects are estimable if three and higher factor interactions are negligible. Resolution $V$ designs are designs in which no main effect or two-factor interaction is aliased with any other main effect or two-factor interaction, but two-factor interactions are aliased with threefactor interactions. Therefore, all main effects and two-factor interactions are estimable if three and higher factor interactions are negligible (Montgomery, 2013).

In a $3^{3}$ design, each main effect $(A, B, C)$ has 2 degrees of freedom, each two-factor interactions $A B, A C$ and $B C(\mathrm{p}=2)$ has $2^{2-1}=2$ orthogonal components and $2^{2}=4$ degrees of freedom: $A B$, and $A B^{2}, A C$ and $A C^{2}$, and $B C$ and $B C^{2}$, respectively. This indicates that each orthogonal component has 2 degrees of freedom. The three-factor interaction, $A B C$ has $2^{3-1}=4$ orthogonal components: $A B^{2} C^{2}, A B^{2} C, A B C^{2}$, and $A B C$, and $2^{3}=8$ degrees of freedom, indicating that each orthogonal component has 2 degrees of freedom.

By leveraging on the sparsity of effects principle, there are only 6 to 18 degrees of freedom associated with effects that may be of significant interest, a one-third fraction of three-factor threelevel factorial design was implemented in this study by partitioning the full $3^{3}$ factorial experiment into three blocks of nine runs each. Only the treatment combinations in the principal block (block 1) were run. So, only nine tests were run instead of 27 , from which valid conclusions about the complete factorial design were made. To partition the 27 runs into blocks, the three blocks have two degrees of freedom amongst them and was confounded with an orthogonal component with two degrees of freedom. 
The $A B^{2} C$ orthogonal component of the three-factor interaction $(A B C)$ was selected as the defining relation in Equation 3.4:

$$
I=A B^{2} C
$$

Thus, the defining contrast is given in Equation 3.5:

$$
L=x_{1}+2 x_{2}+x_{3}
$$

The following treatment combinations that satisfy $L=0(\bmod 3)$ are assigned to block 1 :

$$
\begin{aligned}
& \text { 000: } L=0+2(0)+0=0=0(\bmod 3) \\
& \text { 212: } L=2+2(1)+2=6=0(\bmod 3) \\
& 220: L=2+2(2)+0=6=0(\bmod 3)
\end{aligned}
$$

Some of the treatment combinations in block 2 were obtained thus:

$$
\begin{aligned}
& \text { 001: } L=0+2(0)+1=1=1(\bmod 3) \\
& \text { 210: } L=2+2(1)+0=4=1(\bmod 3) \\
& 221: L=2+2(2)+1=7=1(\bmod 3)
\end{aligned}
$$

Some of the treatment combinations in block 3 were obtained thus:

$$
\begin{aligned}
& 002: L=0+2(0)+2=2=2(\bmod 3) \\
& 211: L=2+2(1)+1=5=2(\bmod 3) \\
& 222: L=2+2(2)+2=8=2(\bmod 3)
\end{aligned}
$$

The first algorithm shown in the Appendix was written in MATLAB to facilitate the confoundment of the $3^{3}$ design into three blocks using the $A B^{2} C$ orthogonal component. Nonetheless, the algorithm can be modified to be used with any orthogonal component. The treatment combinations in each block are shown in Figure 3.8. However, only the principal block was used in this study.

\section{Block 1}

\begin{tabular}{|l|}
\hline 000 \\
011 \\
022 \\
102 \\
110 \\
121 \\
201 \\
212 \\
220 \\
\hline
\end{tabular}

Block 2

\begin{tabular}{|l|}
\hline 001 \\
012 \\
020 \\
100 \\
111 \\
122 \\
202 \\
210 \\
221 \\
\hline
\end{tabular}

Block 3

\begin{tabular}{|l|}
\hline 002 \\
010 \\
021 \\
101 \\
112 \\
120 \\
200 \\
211 \\
222 \\
\hline
\end{tabular}

Figure 3.8: Assignment of the treatment combinations to blocks with $A B^{2} C$ as the defining relation.

Any of the designs in Figure 3.11 has the following alias structure in mod 3:

$$
A=A I=A\left(A B^{2} C\right)=A^{2} B^{2} C=A B C^{2}
$$




$$
\begin{gathered}
A=A I^{2}=A\left(A B^{2} C\right)^{2}=A^{3} B^{4} C^{2}=B C^{2} \\
B=B I=B\left(A B^{2} C\right)=A B^{3} C=A C \\
B=B I^{2}=B\left(A B^{2} C\right)^{2}=A^{2} B^{5} C^{2}=A B C \\
C=C I=C\left(A B^{2} C\right)=A B^{2} C^{2} \\
C=C I^{2}=C\left(A B^{2} C\right)^{2}=A^{2} B^{4} C^{3}=A B^{2} \\
A B=A B I=A B\left(A B^{2} C\right)=A^{2} B^{3} C=A C^{2} \\
A B=A B I^{2}=A B\left(A B^{2} C\right)^{2}=A^{3} B^{5} C^{2}=B C
\end{gathered}
$$

Consequently, the eight degrees of freedom in the design were used to estimate the following four effects:

$$
\begin{gathered}
{[A] \rightarrow A+B C^{2}+A B C^{2}} \\
{[B] \rightarrow B+A C+A B C} \\
{[C] \rightarrow C+A B^{2}+A B^{2} C^{2}} \\
{[A B] \rightarrow A B+B C+A C^{2}}
\end{gathered}
$$

Because the main effects were aliased with two-factor interactions, this was a $3_{I I}^{3-1} \mathrm{design}$. If all interactions can be shown to be negligible, the main effects can be estimated unbiasedly.

Using JMP statistical software, the $3_{I I I}^{3-1}$ design was custom designed such that the treatment combinations in the principal block shown in Figure 3.11 were randomly assigned to the three levels of the media size factor. The tests were run in the order shown in Table 3.3.

Table 3.3: Random order of the $3_{I I I}^{3-1}$ design.

\begin{tabular}{lllll}
\hline $\begin{array}{l}\text { Coded } \\
\text { Variable }\end{array}$ & $\begin{array}{l}\text { Time } \\
\text { (minutes) }\end{array}$ & $\begin{array}{l}\text { Nominal Feed Size } \\
\text { (micron) }\end{array}$ & $\begin{array}{l}\text { Speed } \\
\text { (rpm) }\end{array}$ & $\begin{array}{l}\text { Media Size } \\
\text { (micron) }\end{array}$ \\
\hline 212 & 64 & 150 & 400 & D_1 \\
\hline 121 & 32 & 250 & 340 & D_1 \\
\hline 000 & 16 & 25 & 200 & D_1 \\
\hline 022 & 16 & 250 & 400 & D_2 \\
\hline 110 & 32 & 150 & 200 & D_2 \\
\hline 201 & 64 & 25 & 340 & D_2 \\
\hline 102 & 32 & 25 & 400 & D_3 \\
\hline 220 & 64 & 250 & 200 & D_3 \\
\hline 011 & 16 & 150 & 340 & D_3 \\
\hline
\end{tabular}




\subsection{Sample Preparation}

\subsubsection{Feed}

The feeds for the batch grinding tests were prepared from the minus $1 \mathrm{~mm}$ Leatherwood coal to the nominal feed sizes in Table 3.3. The remaining coal material after the characterization with Bond's and Hardgrove grindability tests was thoroughly mixed in the galvanized iron pan and partitioned with the universal sample splitter into three representative portions. Each portion was separately stage-crushed in the Sturtevant laboratory jaw crusher and then in the Sturtevant laboratory roll crusher followed by screen analysis with Tyler ro-tap test sieve shaker until all the materials passed through the 250-micron screen. One of the portions was used as the feed with a nominal size of 250 microns. The other two portions were further crushed and pulverized in the Holmes pulverizer shown in Figure 3.9 and then screened to minus 150 micron. One of the two portions was used as the feed with a nominal size of 150 microns. The last portion was wet ground in the Union Process attritor (shown in Figure 3.10) charged with steel balls for sixteen minutes (determined from previous tests using the same sample and operating conditions). After the wet product was well-mixed with the overhead agitator shown in Figure 3.11, six representative portions were sampled with syringes at various radical depths for sieve analysis using the CILAS particle size analyzer. The product $\mathrm{P}_{80}$ was found to be less than 25 microns. As such, the portion was used as the feed with a nominal size of 25 microns.

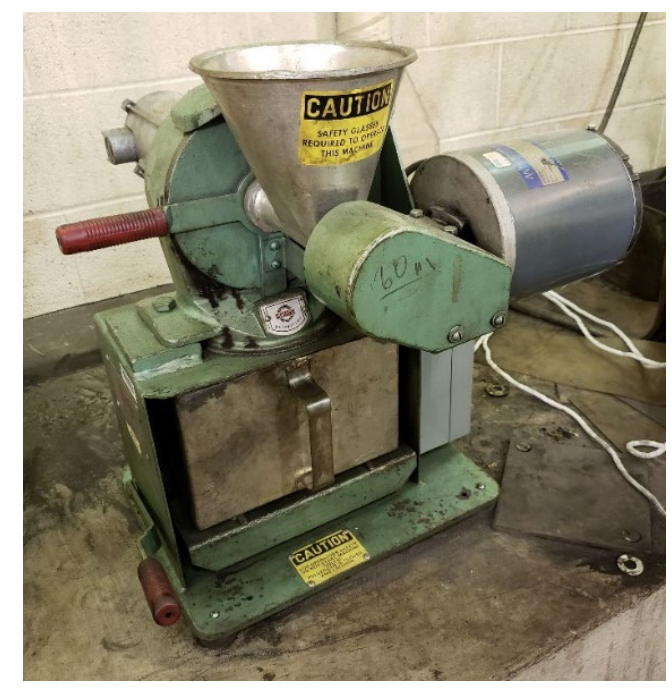

Figure 3.9: Holmes pulverizer for sample preparation.

\subsubsection{Media}

The select grinding media for this study is silica (otherwise known as potters glass beads) shown in Figure 3.12 based on its proven high grinding efficiency in previous study by Huang et al. (2018). Silica of three different standard size ranges (see Table 3.3) were purchased from Kleen Blast. The standard sizes were confirmed by screening the silica with screens in the Sweco separator shown in Figure 3.13. 


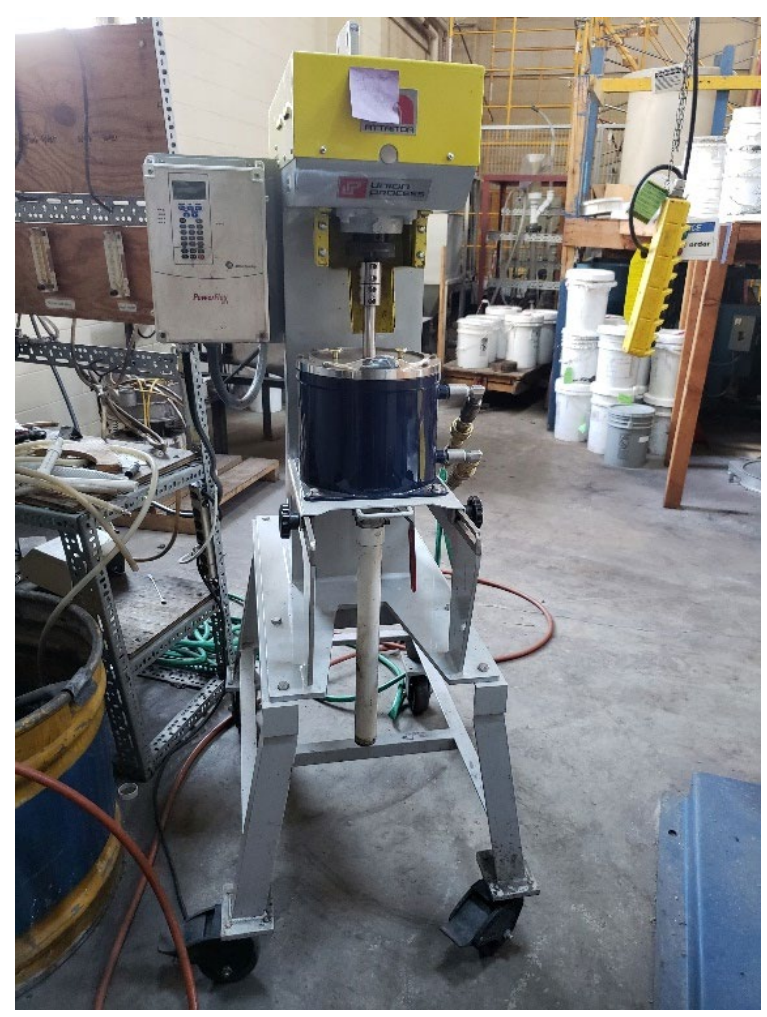

Figure 3.10: Union Process attritor for batch grinding.

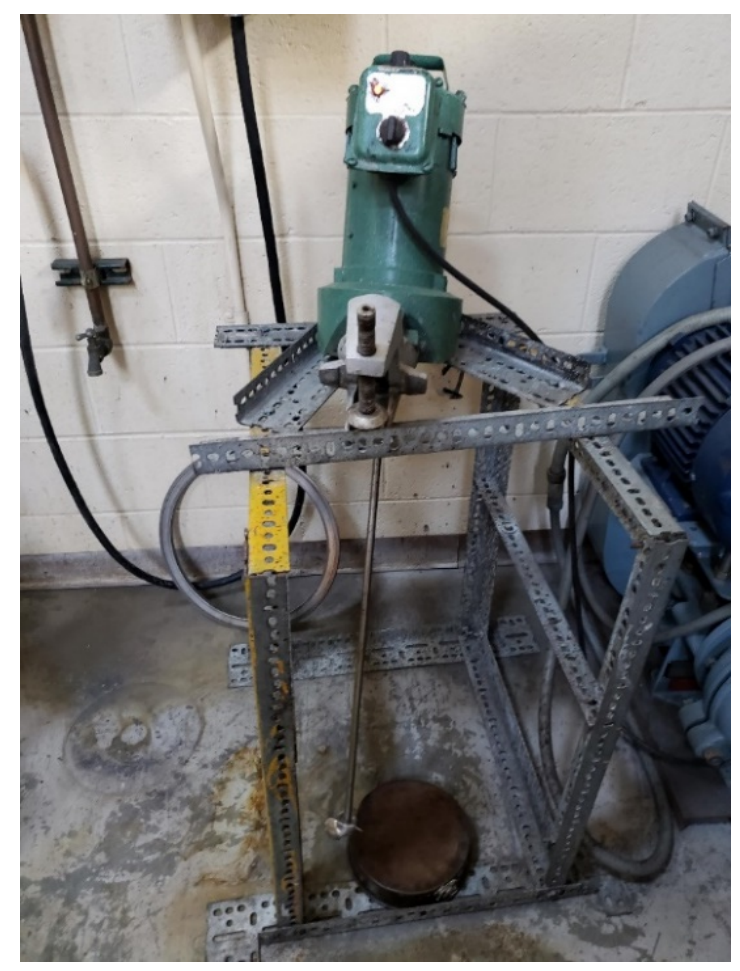

Figure 3.11: Overhead agitator for homogeneous mixing. 


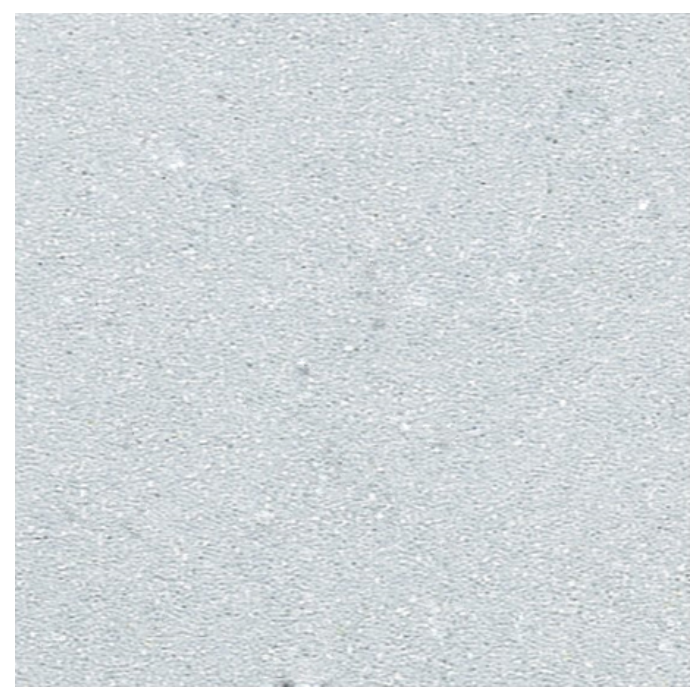

Figure 3.12: Silica (potters glass beads) as grinding media.

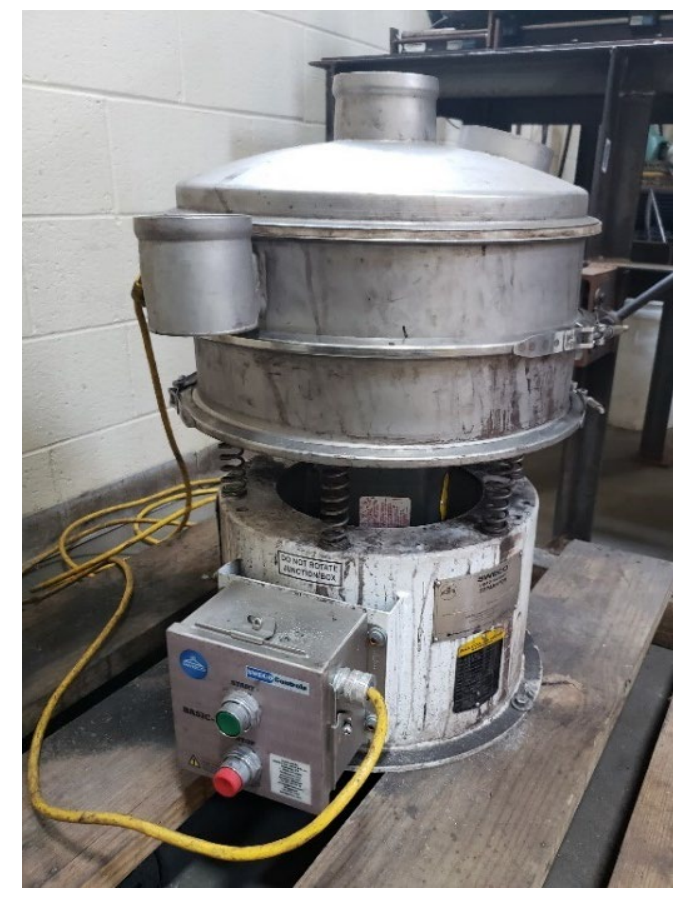

Figure 3.13: Sweco separator for screening the grinding media (silica).

\subsection{Batch Grinding}

The designs from the principal block were used to conduct wet batch grinding tests in the Union Process attritor with a cylindrical grinding chamber of 3.8 litres nominal capacity. The attritor also has a dynamometer and a tachometer for power measurements. The grinding media was silica. For each test, the response variables of interest were product $\mathrm{P}_{80}$ and specific energy.

Silica was weighed and poured into the grinding chamber of the attritor until the impeller was completely covered. The amount of silica was recorded. Table 3.4 shows the experimental conditions with which all batch grinding tests were conducted (Huang et al., 2018). 
Table 3.4: Experimental conditions for batch grinding tests.

\begin{tabular}{ll}
\hline Parameters & Value \\
\hline Solid mass (g) & 410 \\
\hline Solid (wt \%) & 30 \\
\hline Slurry mass (g) & 1366.67 \\
\hline Water mass (g) & 956.67 \\
\hline Media mass (g) & 5193.9
\end{tabular}

The feedstock coal particles with various nominal sizes were homogeneously mixed with water to target the desired solid concentration by weight. Each mixture was then poured in the attritor. To ensure that silica and slurry were properly mixed, the impeller was slightly joggled while transporting the feed to the grinding chamber. The shaft speed was pre-set by adjusting the frequency value of the motor according to the governing equation that shaft speed $=$ frequency/5.7. A timer was then started, and the power was observed and recorded as soon as the attritor was started. Subsequently, time and power were recorded periodically until the grinding time of interest was reached. Afterwards, the attritor was shut off and grinding stopped. The ground product and silica were ejected from the attritor through the bottom opening and collected in a bucket. The ejection was facilitated by flushing the grinding chamber with water. The ground coal was later separated from the silica by being screened in the Sweco separator until there was no visual presence of coal in silica and water coming from the screening process became totally clear.

\subsubsection{Product $\mathbf{P}_{80}$}

Product $\mathrm{P}_{80}$ is the size in microns which 80 percent of the particles in the product are finer than and normally used to determine the size distribution of a material. Therefore, the product $\mathrm{P}_{80}$ of all products from the batch grinding tests were analyzed to assess the grinding efficiency. Each ground product was well-mixed with the overhead agitator before six representative portions were sampled with syringes for the size analysis. The particle size distribution (PSD) of all portions were determined with the CILAS laser particle size analyzer and then averaged. If the product $\mathrm{P}_{80}$ of a portion significantly differed from others, it was not included in the average. Rather, a new representative portion was sampled, and PSD re-determined until the product $\mathrm{P}_{80}$ was no more an outlier.

\subsubsection{Specific Energy}

Specific energy is the amount of energy expended in grinding a unit ton of an ore from a feed size to a product size. As aforementioned, the grinding power was recorded periodically as a function of grinding time in order to precisely determine the specific energy consumption. The recorded power (in kilowatts) and time (in hours) were first plotted on the vertical and horizontal axes, respectively. The data points were fitted with a trendline that best describes the power-time curve. The specific energy $(\bar{E})$ in $(k W h / m t)$ was estimated using Equation 3.6 (Ouattara and Frances, 2014). 


$$
\bar{E}=\frac{\int_{0}^{t}\left(N(\tau)-N_{0}\right)}{m_{P}}
$$

Where,

$m_{P}$ : mass of the ground product

$N(\tau)$ : power at the time $\tau$

$N_{0}$ : unload power

\subsection{Ash Analysis}

Ash analysis was conducted to investigate whether or not the grinding media (silica) degraded during grinding by determining the amount of ash (incombustible material) in the coal before and after grinding. A significant difference in the ash content of a feed and the corresponding product is an indication of silica degradation. For wet feeds and products, representative samples were taken and filtered with the Sepor filter press shown in Figure 3.14. The wet filtrate cakes were dried in an oven at a temperature of $100^{\circ} \mathrm{C}$ for 24 hours.

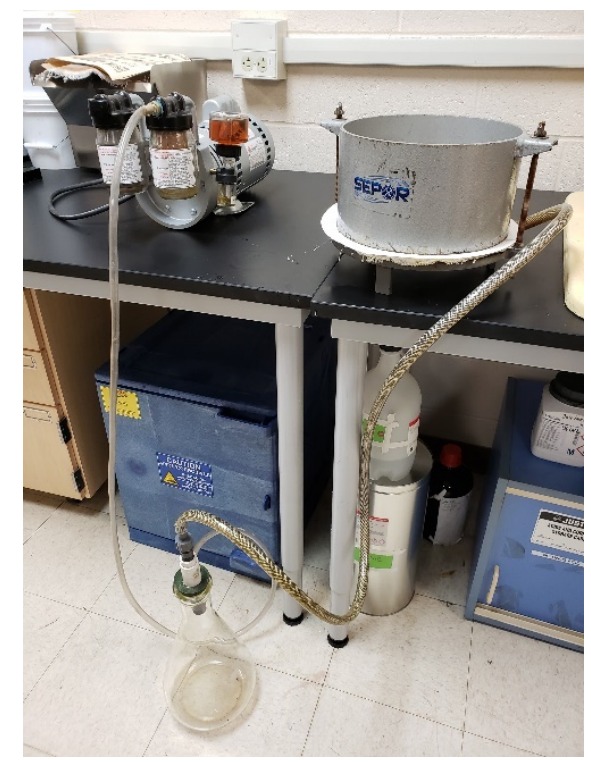

Figure 3.14: Sepor filter press for filtering the wet feeds and products.

Ash analysis was conducted in accordance to ASTM D3174- Standard Test Method for Ash in the Analysis Sample of Coal and Coke from Coal. A representative portion of dry sample with measured weight was obtained and placed in a dry crucible such that the net weight of the coal sample was close to 1 gram. The crucible was kept in the Lindberg electric oven shown in Figure 3.15 at $700^{\circ} \mathrm{C}$ for four hours after which it was removed and cooled in the desiccator shown in Figure 3.16. After cooling, the weight of the crucible plus the incombustible material was determined and recorded as the after weight. The percent ash was calculated using Equation 3.8. All weights were measured with the Sartorius weighing balance. The above procedure was repeated for all feeds and products.

$$
\text { Percent Ash }=\frac{\text { After weight }- \text { Weight of crucible }}{\text { Weight of coal and crucible }- \text { Weight of crucible }} * 100
$$




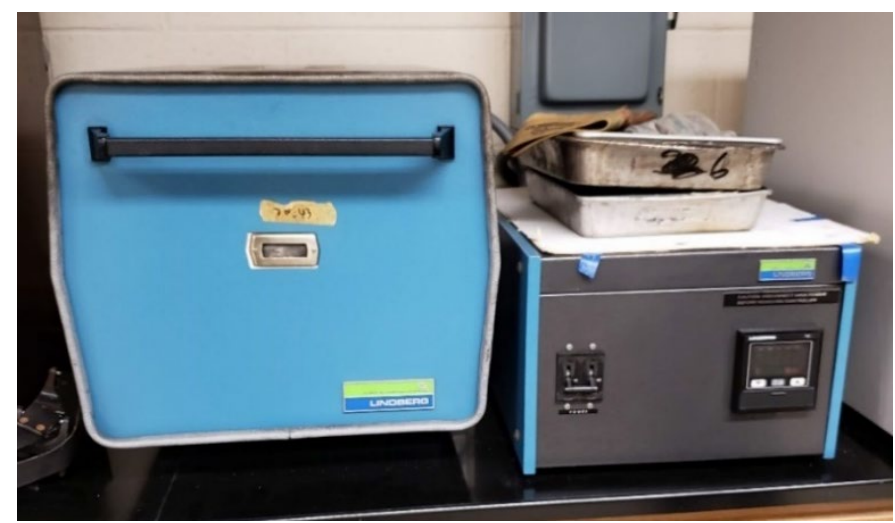

Figure 3.15: Lindberg electric oven for ash analysis.

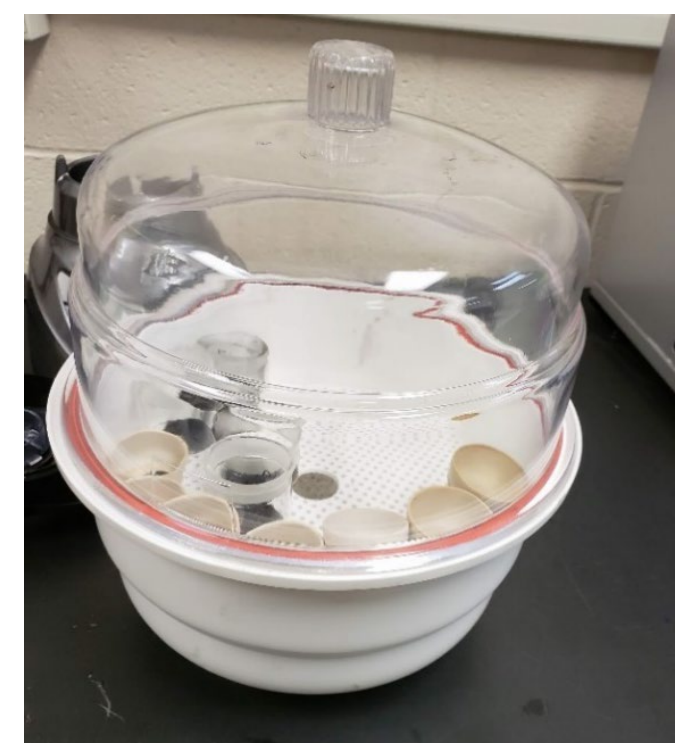

Figure 3.16: Desiccator for cooling the crucibles plus ash.

\subsection{Statistical Analysis of Data}

To ensure objective conclusions, statistical methods were used to analyze the data obtained from design experiments. There are many software packages including Design-Expert, Minitab and JMP developed to assist in data analysis. Since most questions researchers want to answer by conducting experiments are hypothetical, hypothesis testing is usually used in statistical analysis of experimental data. A statistical hypothesis is a statement (about the parameters of a model) which may be true or false. A null hypothesis defines the conjecture about the model and an alternative hypothesis is also provided to negate the null hypothesis. Two types of errors are associated with hypothesis testing. A type I error is made when the null hypothesis is rejected when it is true while a type II error is made when the null hypothesis is not rejected when it is false. As a general procedure in hypothesis testing, the probability of type I error also known as the significance level is specified such that the probability of type II error has a relatively small value. 


\subsection{1 p-Value}

Generally, the results of hypothesis tests are presented by stating whether or not the null hypothesis about a parameter is rejected by comparing the specified significance level to the p-Value of the parameter. The $\mathrm{p}$-Value is the probability that the test statistic will take on a value that is at least as extreme as the observed value of the statistic when the null hypothesis is true. A null hypothesis is rejected when the p-Value of the test statistic is less than the significance level, making the test statistic statistically significant to the model.

\subsubsection{Analysis of Variance}

Hypothesis testing is the basis of analysis of variance (ANOVA) which is a useful technique used for making statistical inferences. For hypothesis testing, the model errors are assumed to be normally and independently distributed random variables with mean zero and a variance assumed to be constant for all levels of the factor. The name analysis of variance is derived from the partitioning of total variability in the data into its component parts: variation between treatments and the variation within treatments (also known as error). The results obtained from the batch grinding tests were analyzed with JMP statistical software for the purposes of factor screening as well as regression analysis.

\subsubsection{Factor Screening}

It is imperative to know which operating factors have significant influence on the responses of interest. Typically, fractional factorial designs are used in screening or characterization experiments. After the system has been characterized, the knowledge of the important factors is used for optimization, that is, determine the values of the significant factors that would give the desirable values of the responses. In this study, the design factors that were significant to the product $\mathrm{P}_{80}$ and the specific energy were determined from ANOVA and the normal probability plot of effects estimates.

\subsubsection{Regression Analysis}

Regression analysis is a statistical concept of fitting empirical (mathematical) models to predict the response(s) at certain levels of the design factors. In an experiment, design factors can be either qualitative or quantitative. Usually, the experimenter is keen on knowing the differences, if any, between the levels of the factors. For qualitative factors, it is not meaningful to consider the response at an intermediate level between two consecutive levels of the factor. While ANOVA treats operating factors as if it were qualitative or categorical variables, regression analysis is particularly useful in determining the response at intermediate levels of quantitative design factors. The method of least squares is used to estimate the fitting constants in the empirical model. A regression model could be linear or polynomial (quadratic, cubic, and so on). The best practice is to fit a model with the lowest order polynomial that best describes the model to avoid overfitting problem. When adding high-order polynomial terms do not necessarily improve the fit but the complexity of the model, it is called overfitting.

In this study, for the purposes of forecasting, the experimental data were fit to mathematical models that characterize the relationship between the product $\mathrm{P}_{80}$ and the specific energy and their corresponding significant operating factors. The mathematical models can be used to predict P80 and specific energy at given values of the significant factors. 


\subsection{Numerical Simulation}

Comminution (size reduction) of ores is governed by their selection and breakage functions. Selection function describes the probability that a particle will be broken under certain load. Breakage function is the probability that fragments, or daughter particles will fall in a certain size class (Rozenblat et al., 2008). Both the selection and breakage functions parameters are presented in the population balance model.

Before a given grinding experiment, the selection and breakage functions of an ore are unknown, however, they can be estimated from experimental results using either a direct (graphical) method or indirect (numerical simulation) method from the population balance model. The correct estimation of these parameters is critical to improved equipment design criteria and forecasting of the particle size distribution of grinding product at certain operating conditions. The indirect method of estimating selection and breakage functions from the population balance model was employed in this study.

\subsubsection{Population Balance Model}

The general ordinary differential equation (ODE) for batch grinding in energy-based form is shown in Equation 3.9 (Klimpel \& Austin, 1977):

$$
\frac{\partial m_{i}}{\partial \bar{E}}=-S_{i}^{E} m_{i}+\sum_{j=1}^{i-1} b_{i j} S_{i}^{E} m_{j}
$$

In vector notation form, Equation 3.9 can be written as:

$$
\frac{d m(\bar{E})}{d \bar{E}}=-[I-B] \operatorname{Sm}(\bar{E})
$$

The solution of Equation 3.10 in vector notation is presented in Equation 3.11

$$
m(\bar{E})=\exp (-[I-B] S \bar{E}) m(0)
$$

Where,

$m_{i}$ : mass fraction of size class $i$

$m(\bar{E})$ : matrix of size $\mathrm{n} \times 1$ of mass fractions resulting from a specific energy input, $\bar{E}$.

$I$ : identity matrix of size $\mathrm{n} \times \mathrm{n}$

$B$ : breakage function matrix of size $\mathrm{n} \times \mathrm{n}$ with elements $b_{i j}$

$S$ : selection function matrix of size n x n with diagonal elements $S_{i}^{E}$

$\bar{E}$ : specific energy

$m(0)$ : matrix of size $\mathrm{n} \times 1$ of mass fractions of the feed

$n$ : number of size intervals

Equation 3.11 can also be written analytically as shown in Equation 3.12 (Herbst et al., 1971):

$$
m(\bar{E})=T J(\bar{E}) T^{-1} m(0)
$$


Where,

$T$ : matrix of eigenvectors (lower triangular, $\mathrm{n} \times \mathrm{n}$ ) for the matrix $[I-B] S$ with elements, $T_{i j}$

$$
T_{i j}= \begin{cases}0 & i<j \\ 1 & i=j \\ \sum_{k=j}^{i-1} \frac{b_{i k} s_{k}}{s_{i}-s_{j}} T_{k j} & i>j\end{cases}
$$

$J(\bar{E})$ : matrix (diagonal, $\mathrm{n} \times \mathrm{n}$ ) with diagonal elements, $J_{i j}(\bar{E})$

$$
J_{i j}(\bar{E})= \begin{cases}\exp \left(-S_{i}{ }^{E} \bar{E}\right) & i=j \\ 0 & i \neq j\end{cases}
$$

Equation 3.13 refers to the breakage $b$ function that is used in optimization methods.

$$
b_{i j}=\alpha_{1}\left(\frac{d_{i}}{d_{j+1}}\right)^{\alpha_{2}}+\left(1-\alpha_{1}\right)\left(\frac{d_{i}}{d_{j+1}}\right)^{\alpha_{3}}
$$

Equation 3.14 refers to the selection $s$ function that is used in optimization methods.

$$
s_{i}^{E}=s_{1}^{E} \exp \left\{\zeta_{1} \ln \left(\frac{d_{i}}{d_{1}}\right)+\zeta_{2}\left(\ln \left(\frac{d_{i}}{d_{1}}\right)\right)^{2}\right\}
$$

Where,

$S_{i}^{E}$ : energy-discretized selection function of ith size interval. It denotes the fractional rate at which particles are broken out of the ith size interval.

$d_{i}$ : top size of the ith size interval.

$b_{i j}$ : size discretized breakage function. It denotes the fraction of the product particle in the ith parent size interval that appears in jth daughter size interval.

Since PBM is a non-linear equation, it can be solved to determine the unknown selection and breakage functions using any iterative methods for solving non-linear equations. In this study, the iterative method of choice was the particle swarm optimization method.

\subsubsection{Particle Swarm Optimization}

Particle swarm optimization (PSO) algorithm was developed based on swarm intelligence in 1995 (Kennedy et al., 1995). A research on bird flock and fish school movement is the background of PSO algorithm (Bai, 2010). In the PSO algorithm, a swarm (population) of particles (candidate solutions) is iteratively improved by changing the particles' positions and velocities in the search space. Each particle shows behavioral traits which follow three rules (Dorigo, 2008):

1. Separation: each particle tries to separate from its too close neighbors.

2. Alignment: each particle steers towards the average heading of its neighbors.

3. Cohesion: each particle tries to move towards the average position of its neighbors.

In general, the movement of each particle is affected by its known local best position and that of the swarm. The objective is to move the swarm towards the best solution and making the cost or 
objective function converges. The PSO algorithm is known for its ease and simplicity and has been widely applied in the following fields: signal processing, vague system and automatic adaptation controls, neutral network training, function optimization, model classification, machine study, and so on (Zheng et al., 2004).

The benefits of the PSO algorithm are (Bai, 2010):

1. Very simple and easy computations.

2. Very fast speed of search because particles moves towards the best position of the swarm.

3. Applicable to scientific and engineering research because it is based on swarm intelligence.

The in-built PSO algorithm in MATLAB was used to optimize the selection and breakage function parameters in the PBM in the following procedures:

1. Population Initialization

The lower and upper bounds for the positions of the selection and breakage parameters were specified from which the algorithm initialized the positions of the parameters in the population based on Equation 3.15 and their velocities were initialized to zero.

$$
\vec{x}_{0}=\vec{l}_{b}+\operatorname{rand}(D, 1) \in \operatorname{rand}_{i, j}[0,1]\left(\vec{u}_{b}-\vec{l}_{b}\right)
$$

Where $\operatorname{rand}_{i, j}[0,1]$ is a uniformly distributed random number ranging from 0 and 1 (that is, $0 \leq$ $\operatorname{rand}_{i, j}[0,1] \leq 1$ ) independently instantiated for each component of the ith vector. $\mathrm{D}$ is the dimension of the optimization problem (that is, the number of unknown parameters or particles). $\vec{l}_{b}$ and $\vec{u}_{b}$ are vectors of the lower and upper bounds for the particles' positions.

\section{Best Parameter Determination}

Each parameter of the population was used to estimate $m(\bar{E})_{\text {model }}$ and then the objective function whose formulation is given in Equation 3.16.

$$
\theta(\vec{x})=\frac{1}{M}\left(m(\bar{E})_{\text {model }}-m(\bar{E})_{\text {experiment }}\right)^{T}\left(m(\bar{E})_{\text {model }}-m(\bar{E})_{\text {experiment }}\right)
$$

Where,

$\theta$ : objective function

$\vec{x}$ : parameter vector

$m(\bar{E})_{\text {model }}$ : vector of the product particle size distribution from the model

$m(\bar{E})_{\text {experiment }}$ : vector of the product particle size distribution from the experiment

$M$ : number of predictions which is equivalent to the number of elements in either $m(\bar{E})_{\text {model }}$ or $m(\bar{E})_{\text {experiment }}$.

The parameter that gave the minimum objective function (current local best objective function) was tagged the best particle in the population while other parameters remained at their positions. The position of the best particle and the corresponding objective function were assigned the swarm's best position and objective function, respectively. 


\section{Velocity Update}

The velocities of the particles are updated using Equation 3.17.

$$
\vec{v}_{i t e r+1}=w \vec{v}_{i t e r}+c_{1} \vec{r}_{1}(\vec{p}-\vec{x})+c_{2} \vec{r}_{2}(\vec{q}-\vec{x})
$$

Where $\vec{v}_{i t e r}$ and $\vec{v}_{\text {iter }+1}$ are the current and new particles' velocities, respectively, $w$ is the weight, $c_{1}$ and $c_{2}$ are cognitive and social parameters, respectively. $\vec{p}$ is the particles' best positions, $\vec{q}$ is the swarm's best position and $\vec{x}$ is the particles' current position. $\vec{r}_{1}$ and $\vec{r}_{2}$ are vectors of randomly generated numbers between 0 and 1 .

\section{Position Update}

A particle's position was updated based on its local best position and the swarm's best position. Equation 3.18 was used to update the position of all particles in the swarm.

$$
\vec{x}_{i t e r+1}=\vec{x}_{i t e r}+\vec{v}_{i t e r+1}
$$

During position update, the PSO algorithm ensured that particle's new position did not fall outside of the lower and upper bounds. The new swarm was evaluated by estimating the product particle size distribution and the corresponding objective function for all particles. If the new objective function of a particle is less than its old one, the new objective function was updated as its local best objective function. The swarm's best position and best objective function were updated accordingly. The velocity and position updates were repeated for until the specified number of iterations was reached.

In this study, the batch grinding of Leatherwood coal was numerically simulated using the population balance method (PBM). The following variables obtained from the batch grinding experiment: $m(0), m(\bar{E})$, and $\bar{E}$ were used as input in the simulation. Using the in-built particle swarm optimization algorithm in MATLAB, the unknown parameters: selection function parameters $\left(S_{1}^{E}, \zeta_{1}, \zeta_{2}\right)$ and breakage function parameters $\left(\alpha_{1}, \alpha_{2}, \alpha_{3}\right)$ were determined. The algorithm worked by iteratively perturbing the initial values specified for the unknown parameters until the modeled $m(\bar{E})_{\text {model }}$ and is close the experimental $m(\bar{E})_{\text {experiment. }}$ This is evident by an objective function or mean squared error (MSE) very close to zero. The values of the unknown parameters that give the minimum MSE are the optimum parameters for the selection and breakage functions. 


\section{Chapter 4 \\ Results and Discussion}

This chapter presents the results obtained from sample characterization, design of experiments, sample and media preparation, batch grinding experiment, ash analysis, statistical analysis of experimental results and finally, numerical simulation of batch grinding.

\subsection{Sample Characterization}

In this section, the results of the Leatherwood coal characterization using Bond and Hardgrove grindability tests are presented.

\subsubsection{Bond Work Index}

The data obtained from the Bond grindability tests are shown in Table 4.1. The work indices from the three tests show excellent repeatability (standard deviation $<10 \%$ ), with a noticeable outlier. The results from the three tests are displayed in Figure 4.1.

Table 4.1: Raw data from Bond work index tests.

\begin{tabular}{lllll}
\hline & & \multicolumn{3}{c}{ Replicate } \\
\cline { 3 - 5 } Parameter & micron & 149 & 149 & 149 \\
\hline Sieve Opening, $\mathrm{P}_{1}$ & $\mathrm{~g} / \mathrm{rev}$ & 0.504 & 0.437 & 0.444 \\
\hline Grindability, $\mathrm{G}_{\mathrm{bp}}$ & micron & 88.78 & 96.37 & 101.7 \\
\hline Product Size, $\mathrm{P}_{80}$ & micron & 2945 & 3010 & 2945 \\
\hline Feed Size, $\mathrm{F}_{80}$ & $\mathrm{kWhr} / \mathrm{ton}$ & 28.1 & 33.2 & 33.9 \\
\hline Work Index, $\mathrm{W}_{\mathrm{i}}$ & & & & 3 \\
\hline
\end{tabular}

The average BWI of $31.75 \mathrm{kWh} /$ ton was determined by calculating the average of the three BWI. The typical BWI for coal is between $13 \mathrm{kwh} /$ ton and $18 \mathrm{kwh} /$ ton (Bond, 1961). In fair comparison with the typical BWI for coal, the Leatherwood coal is hard to grind.

\subsubsection{Hardgrove Grindability Index}

Table 4.2 shows the calibration results for the Preiser Scientific Hardgrove grindability machine. Figure 4.2 shows the plot of the known HGI values of the reference coal materials versus the corresponding calculated mass of minus 75 microns material. The linear trendline governing the data points was used to determine the fitting constants $A$ and $B$ which are 8.7807 and 7.3358 , respectively. 


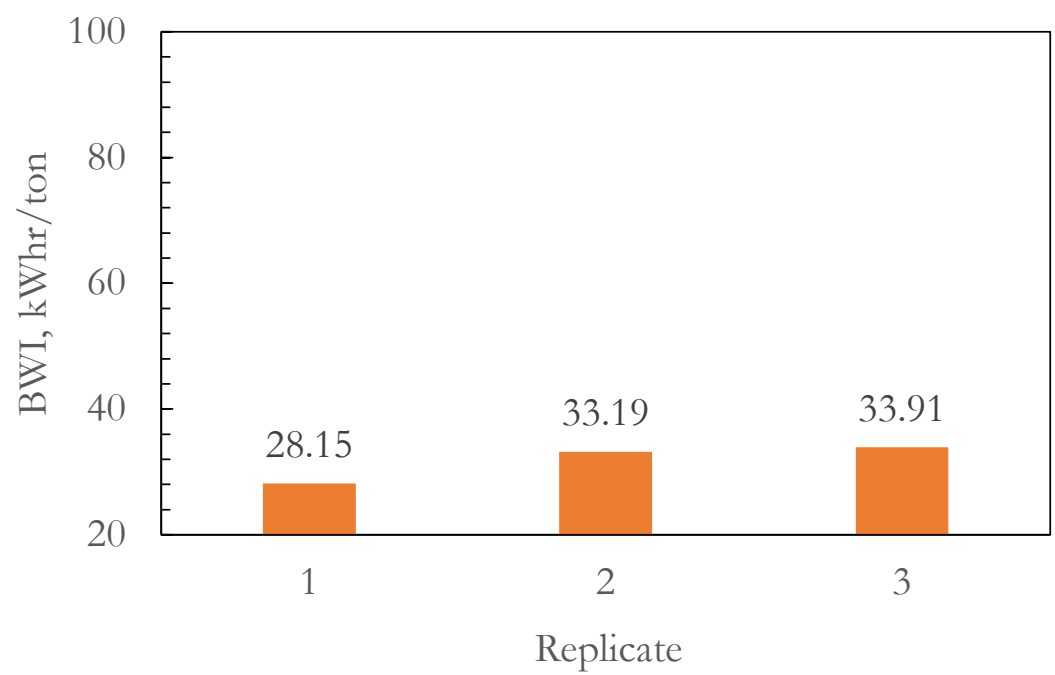

Figure 4.1: Bond work index of Leatherwood coal.

Table 4.2: Calibration of Preiser Scientific Hardgrove grindability machine.

\begin{tabular}{ccc}
\hline Reference Coal & $\begin{array}{c}\text { Calculated Mass of Minus 75 microns } \\
\text { Material (gram) }\end{array}$ & Known HGI \\
\hline 1 & 11.8 & 95 \\
\hline 2 & 6.8 & 58 \\
\hline 3 & 3.7 & 36 \\
\hline 4 & 8.9 & 75 \\
\hline
\end{tabular}

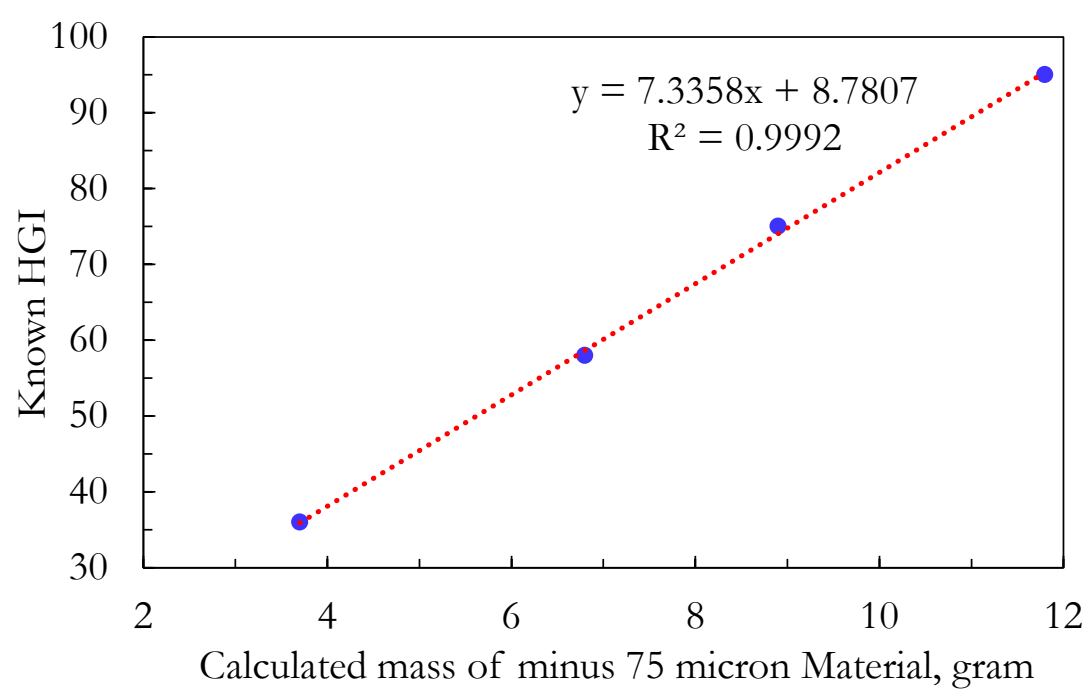

Figure 4.2: Calibration of Preiser Scientific Hardgrove grindability machine. 
By substituting the values of $A$ and $B$, Equation 3.2 becomes Equation 4.1:

$$
H G I=8.7807+7.3358 * m
$$

Table 4.3: Hardgrove grindability index of Leatherwood coal.

\begin{tabular}{ccc}
\hline Replicate & $\begin{array}{c}\text { Calculated Mass of Minus 75 microns } \\
\text { Material (gram) }\end{array}$ & Calculated HGI \\
\hline 1 & 4.5 & 41.79 \\
\hline 2 & 4.4 & 41.06 \\
\hline 3 & 4.3 & 40.32 \\
\hline
\end{tabular}

Using Equation 4.1 and substituting for $m$ with the calculated mass of minus 75 microns material in Table 4.3, the calculated HGI of Leatherwood coal shown in Figure 4.3 were estimated. The average HGI of 41.1 was determined by finding the average of the three calculated HGI.

According to Williams et al. (2015), the typical HGI for coal ranges from 20 to 110 with materials with higher index values being more grindable and requiring less energy to grind to fine sizes. It can be concluded that Leatherwood coal with HGI value of 41 is resistant to grinding, which is consistent with previous Bond grindability test results.

In addition, according to the relationship between the wet grinding Bond work index and the Hardgrove grindability index, as proposed by Bond (1961) and shown in Equation 2.3. The calculated BWI of Leatherwood coal is $\frac{1622}{H G I^{1.08}}=\frac{1622}{41.1^{1.08}}=29.32 \mathrm{kWhr} /$ ton, which agrees well with the calculated BWI value of 31.75 . The validity of both the Bond and Hardgrove grindability test results were thus confirmed suggesting that Leatherwood coal is hard to grind and consumes substantial amount of energy in order to be ground to a fine size.

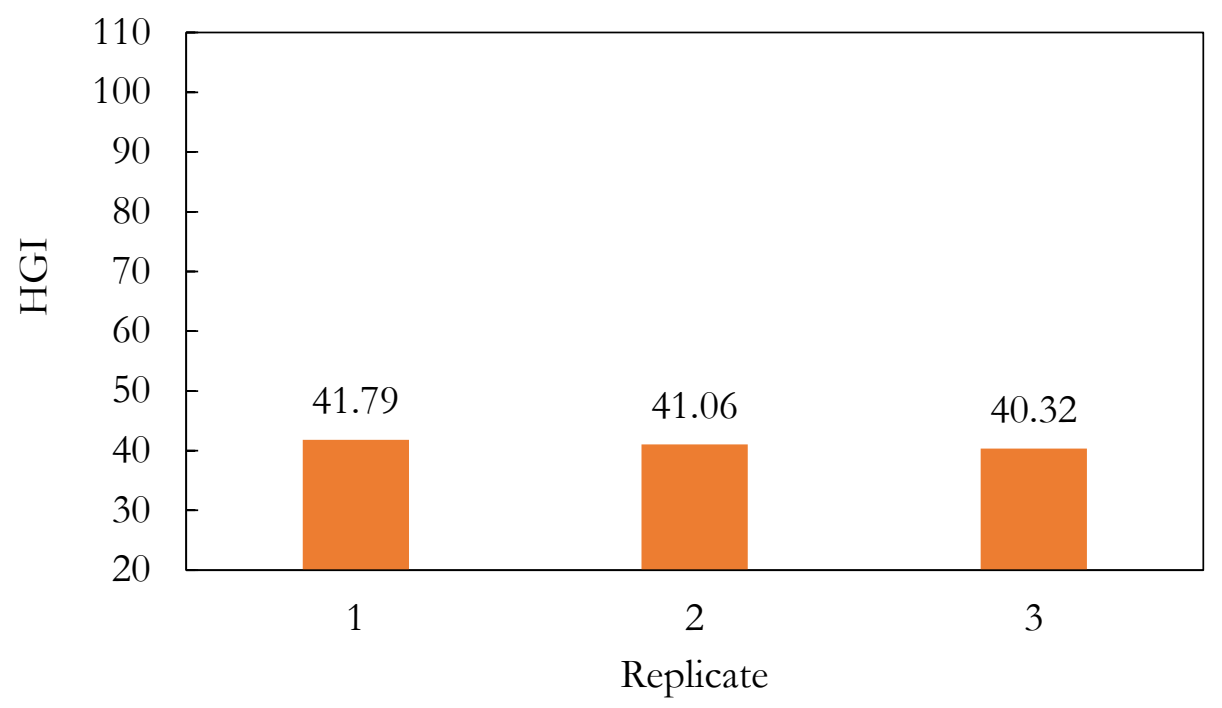

Figure 4.3: Hardgrove grindability index of Leatherwood coal. 


\subsection{Batch Grinding}

In this section, the response variables (product $\mathrm{P}_{80}$ and specific energy) for all the batch grinding tests are presented. A new calculated variable, reduction ratio is also presented.

\subsubsection{Product $\mathbf{P}_{80}$}

The particle size distribution of the feeds and their corresponding products (from which the feed $\mathrm{F}_{80}$ and product $\mathrm{P}_{80}$ were obtained) were measured using the Cilas 1190L laser particle size analyzer and are presented in Figures 4.4- 4.6.

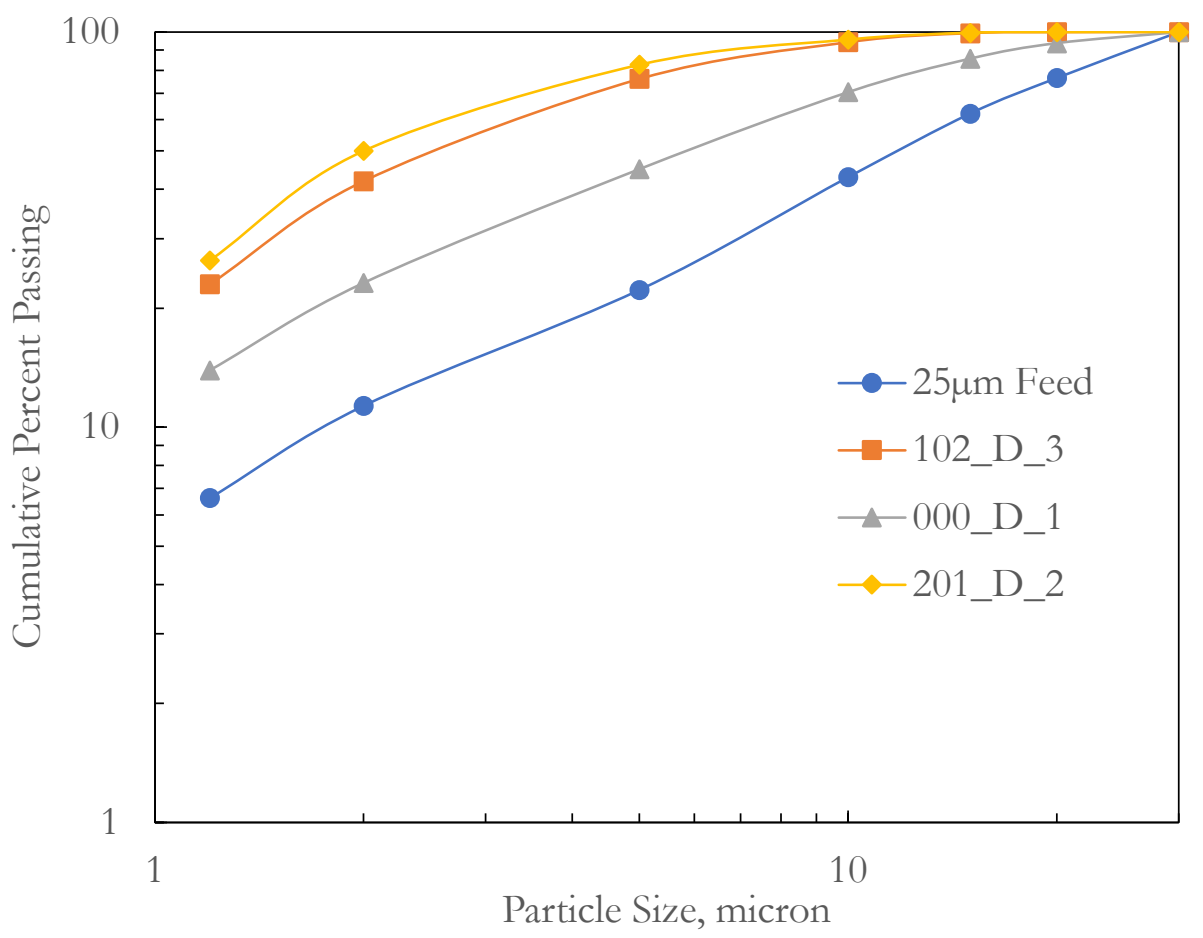

Figure 4.4: Particle size distribution of the 25-micron feed and the corresponding products.

Under varying grinding time, shaft speed and media size, the feedstock materials with a 25-, 150and 250-micron nominal size, respectively, were ground in batches. In Figure 4.4, the grinding pattern 201_D_2 which corresponds to a grinding time of 64 minutes, a media size of 420-595 microns and a shaft speed of $340 \mathrm{rpm}$ achieved a product $\mathrm{P}_{80}$ of 4.5 microns from the feed $\mathrm{F}_{80}$ of 21.6 microns. This pattern generated the finest product size amongst other patterns (000_D_1 and 102_D_3) with the same feed $F_{80}$. Patterns 000_D_1 and 102_D_3 produced product $\mathrm{P}_{80}$ of 12.8 microns and 5.7 microns, respectively.

Likewise, in Figure 4.5, the grinding pattern 011_D_3 which corresponds to a grinding time of 16 minutes, a media size of 595-841 microns and a shaft speed of $340 \mathrm{rpm}$ achieved a product $\mathrm{P}_{80}$ of 51.2 microns from the feed $\mathrm{F}_{80}$ of 86.4 microns. This pattern gave the finest product size amongst other patterns (110_D_2 and 212_D_1) with the same feed F80. Patterns 110_D_2 and 212_D_1 produced product $\mathrm{P}_{80}$ of 83.4 microns and 84.0 microns, respectively. 


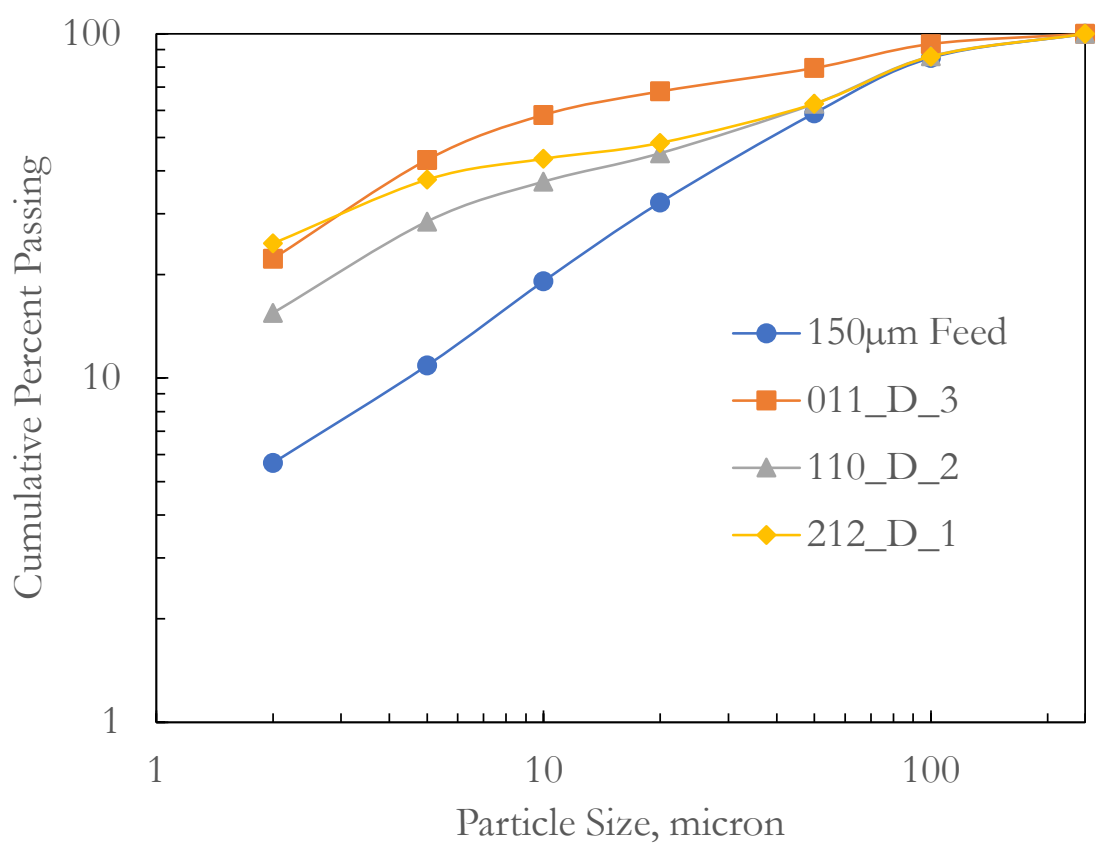

Figure 4.5: Particle size distribution of the 150-micron feed and the corresponding products.

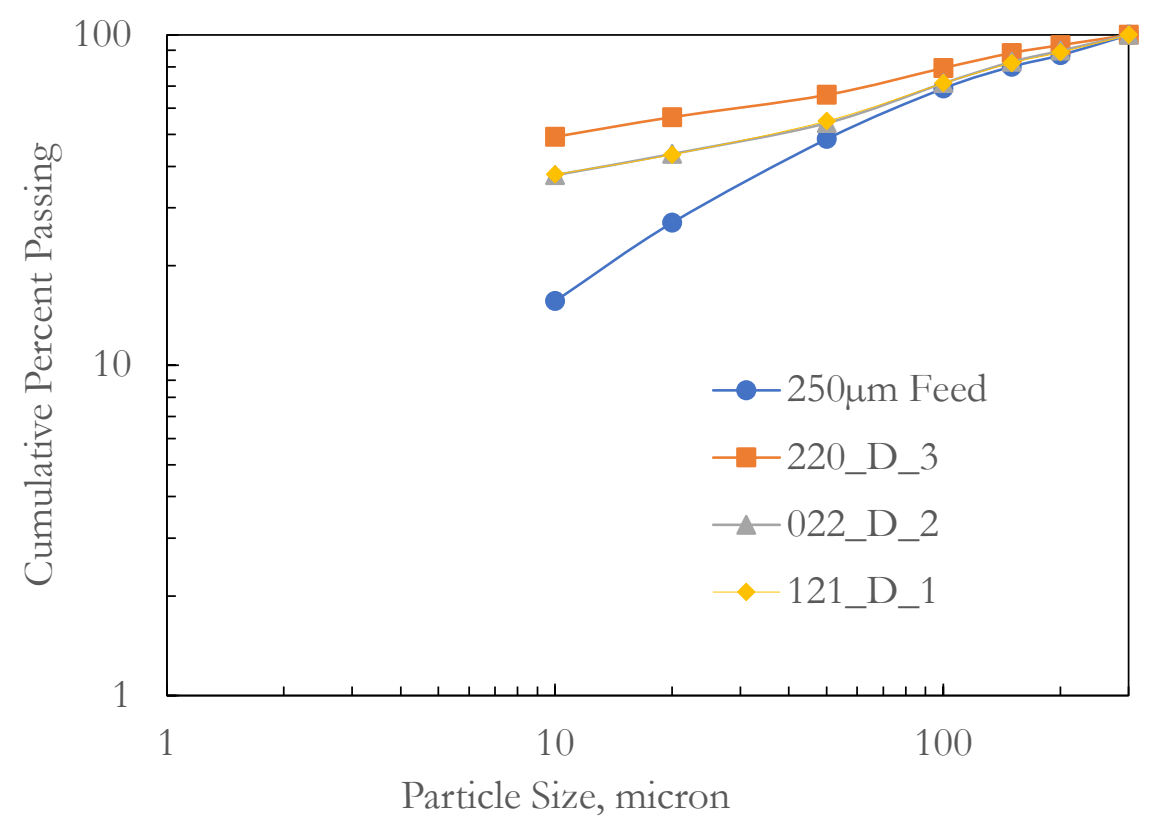

Figure 4.6: Particle size distribution of the 250-micron feed and the corresponding products.

Lastly, in Figure 4.6, the grinding pattern 220_D_3 which corresponds to a grinding time of 64 minutes, a media size of 595-840 microns and a shaft speed of $200 \mathrm{rpm}$ achieved a product $\mathrm{P}_{80}$ of 102.6 microns from the feed $\mathrm{F}_{80}$ of 149.2 microns. This pattern gave the finest product size amongst other patterns (022_D_2 and 121_D_1) with the same feed F80. Patterns 022_D_2 and 121_D_1 produced product $\mathrm{P}_{80}$ of 135.0 microns and 137.5 microns, respectively. 


\subsubsection{Specific Energy}

The power-time graphs for all grinding tests from which their corresponding specific energies were calculated are presented in Figures 4.7 to 4.15 . Table 4.4 shows the how power varied with time during grinding for all patterns. The unloaded motor power used in the calculation of specific energy is presented in Table 4.5. The specific energy expended during all batch grinding processes are presented in Figure 4.16. The most specific energy (416.3 kWhr/ton) was expended during grinding pattern 212_D_1 which corresponds to a grinding time of 64 minutes, a media size of 270-420 microns and a shaft speed of 400 revolutions per minute. The least specific energy (16.1 $\mathrm{kWhr} / \mathrm{ton}$ ) was expended during grinding pattern 000_D_1 which corresponds to a grinding time of 16 minutes, a media size of 270-420 microns and a shaft speed of 200 revolutions per minute.

\subsubsection{Reduction Ratio}

Reduction ratio is the ratio of the feed $\mathrm{F}_{80}$ to the product $\mathrm{P}_{80}$ as shown in Equation 4.4. It is a measure of grinding efficiency. The higher the reduction ratio, the better the grinding efficiency. The reduction ratios for all grinding tests are presented in Figure 4.16. The maximum reduction ratio (4.8) was achieved during grinding pattern 201_D_2 which corresponds to a grinding time of 64 minutes, a media size of 420-595 microns and a shaft speed of 340 revolutions per minute. The minimum reduction ratio (1.0) was achieved during grinding patterns 110_D_2 and 212_D_1. Grinding pattern 110_D_2 corresponds to a grinding time of 32 minutes, a media size of 420-595 microns and a shaft speed of 200 revolutions per minute while grinding pattern 212_D_1 corresponds to a grinding time of 64 minutes, a media size of 270-420 microns and a shaft speed of 400 revolutions per minute. Table 4.6 presents the feed $\mathrm{F}_{80}$, product $\mathrm{P}_{80}$, specific energy and the reduction ration for all batch grinding tests.

$$
\text { Reduction ratio }=\frac{F_{80}}{P_{80}}
$$

Table 4.4: Variation of power with time during batch grinding tests.

\begin{tabular}{|c|c|c|c|c|c|c|c|c|c|c|}
\hline Time & Time & & & & & Patter & & & & \\
\hline 忍 & $\begin{array}{l}\overparen{\Xi} \\
\stackrel{\Xi}{\Xi}\end{array}$ & $\begin{array}{l}\vec{\prime} \\
\bar{\theta}^{\prime} \\
\overline{8}\end{array}$ & $\begin{array}{l}n_{1} \\
a_{1}^{\prime} \\
= \\
0\end{array}$ & 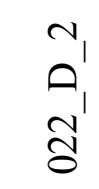 & $\begin{array}{l}n_{1} \\
D^{\prime} \\
\sigma^{\prime} \\
0\end{array}$ & $\begin{array}{l}N_{1} \\
\Omega_{1}^{\prime} \\
0^{\prime} \\
=\end{array}$ & $\begin{array}{l}\overrightarrow{a_{1}} \\
\vec{\beth} \\
\vec{\beth}\end{array}$ & $\begin{array}{l}N_{1} \\
D_{1} \\
\vec{d}^{\prime}\end{array}$ & $\begin{array}{l}\overrightarrow{a^{\prime}} \\
\vec{v}^{\prime}\end{array}$ & $\begin{array}{l}m^{\prime} \\
\overbrace{}^{\prime} \\
\stackrel{ }{N}\end{array}$ \\
\hline 2 & 0.033 & 0.12 & 0.28 & 0.28 & 0.32 & 0.15 & 0.31 & 0.26 & 0.31 & 0.15 \\
\hline 4 & 0.067 & 0.11 & 0.27 & 0.27 & 0.31 & 0.14 & 0.3 & 0.25 & 0.31 & 0.14 \\
\hline 8 & 0.133 & 0.1 & 0.26 & 0.26 & 0.31 & 0.14 & 0.3 & 0.24 & 0.31 & 0.14 \\
\hline 16 & 0.267 & 0.1 & 0.26 & 0.25 & 0.3 & 0.13 & 0.29 & 0.23 & 0.3 & 0.14 \\
\hline 32 & 0.533 & -- & -- & -- & 0.3 & 0.13 & 0.29 & 0.22 & 0.29 & 0.13 \\
\hline 64 & 1.067 & -- & -- & -- & -- & -- & -- & 0.21 & 0.29 & 0.13 \\
\hline
\end{tabular}


Table 4.5: Unloaded motor power for the calculation of specific energy.

\begin{tabular}{cc} 
Pattern & Unloaded Motor Power $(\mathbf{k W})$ \\
\hline 000_D_1 & 0.08 \\
\hline 011_D_3 & 0.11 \\
\hline 022_D_2 & 0.12 \\
\hline 102_D_3 & 0.12 \\
\hline 110_D_2 & 0.08 \\
\hline 121_D_1 & 0.11 \\
\hline 201_D_2 & 0.11 \\
\hline 212_D_1 & 0.12 \\
\hline 220_D_3 & 0.08 \\
\hline
\end{tabular}

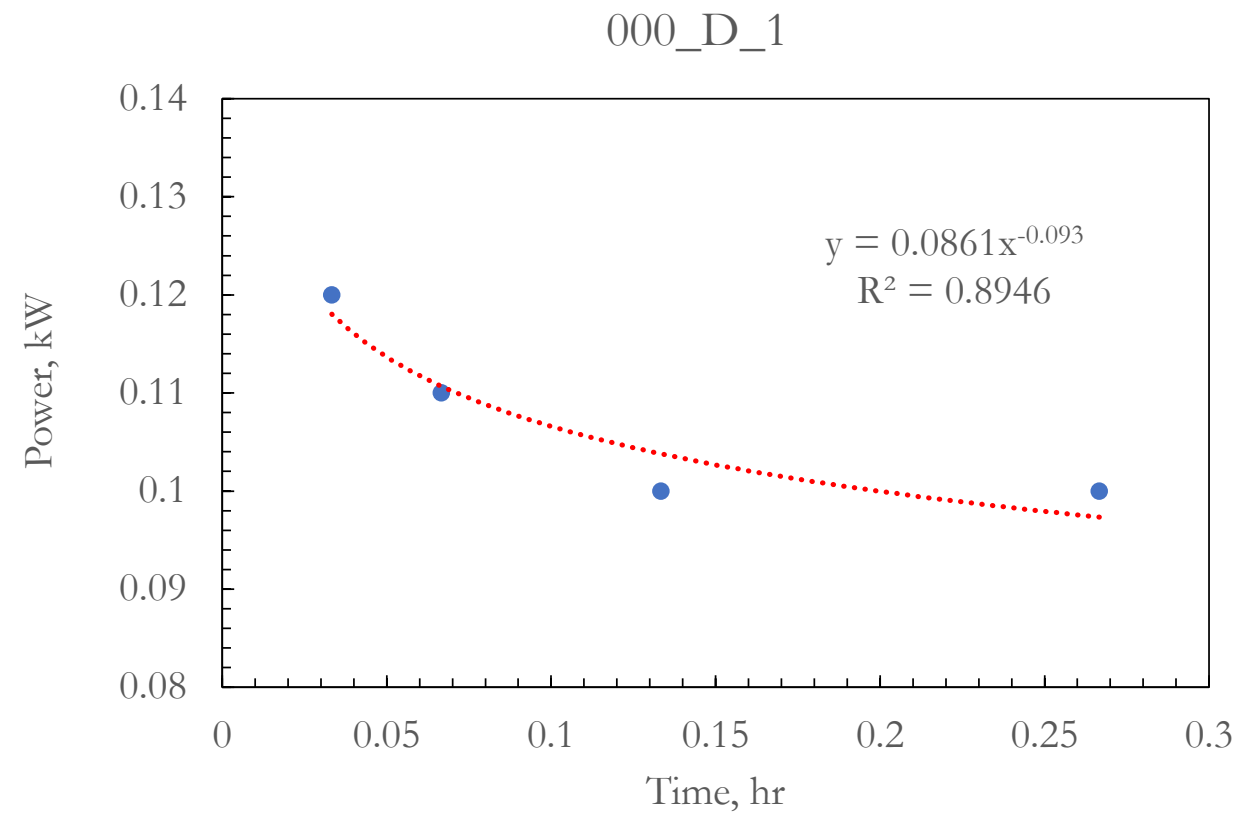

Figure 4.7: Power versus time graph for batch grinding pattern 000_D_1. 


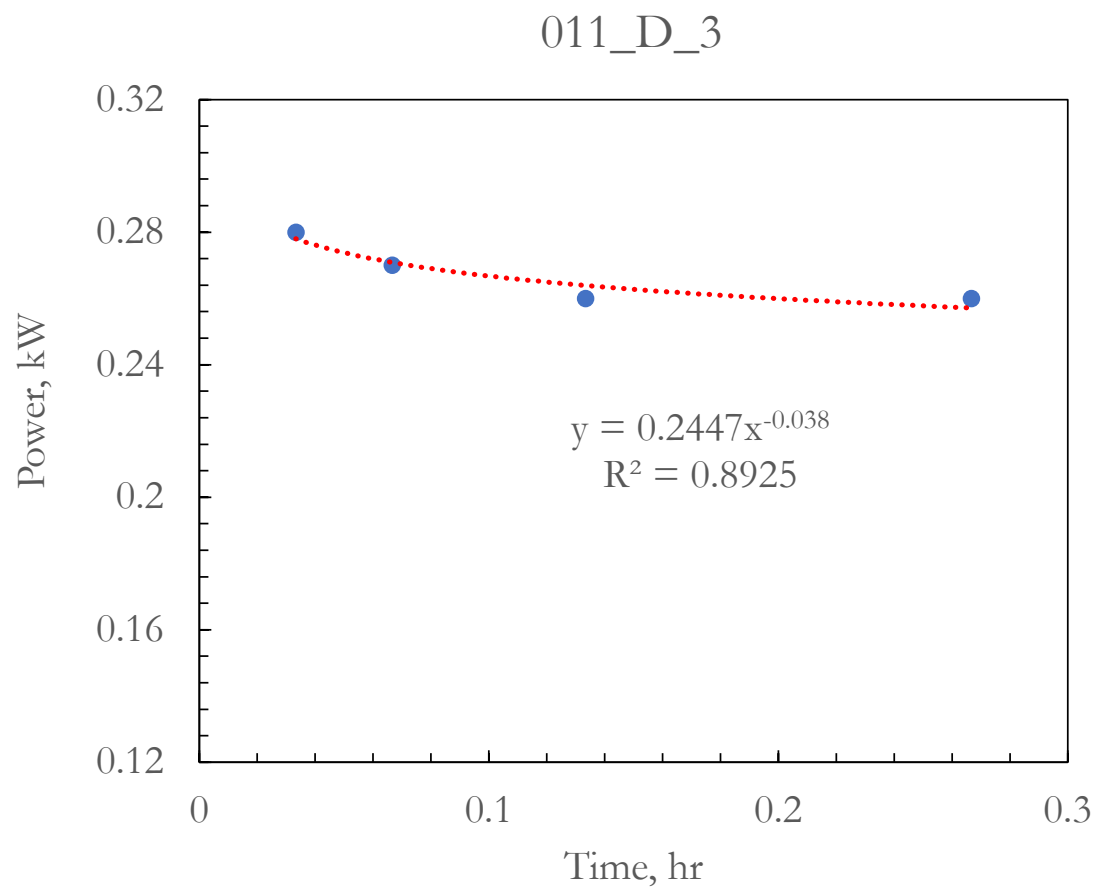

Figure 4.8: Power versus time graph for batch grinding pattern 011_D_3.

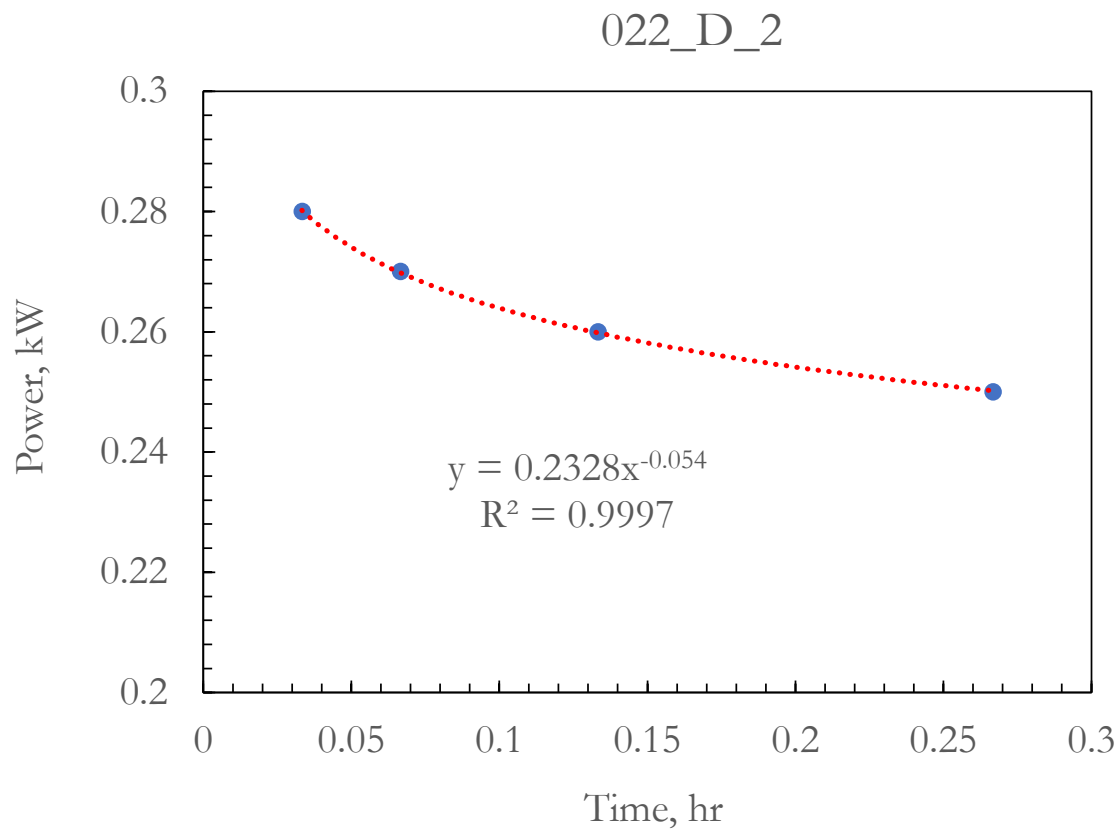

Figure 4.9: Power versus time graph for batch grinding pattern 022_D_2. 
102_D_3

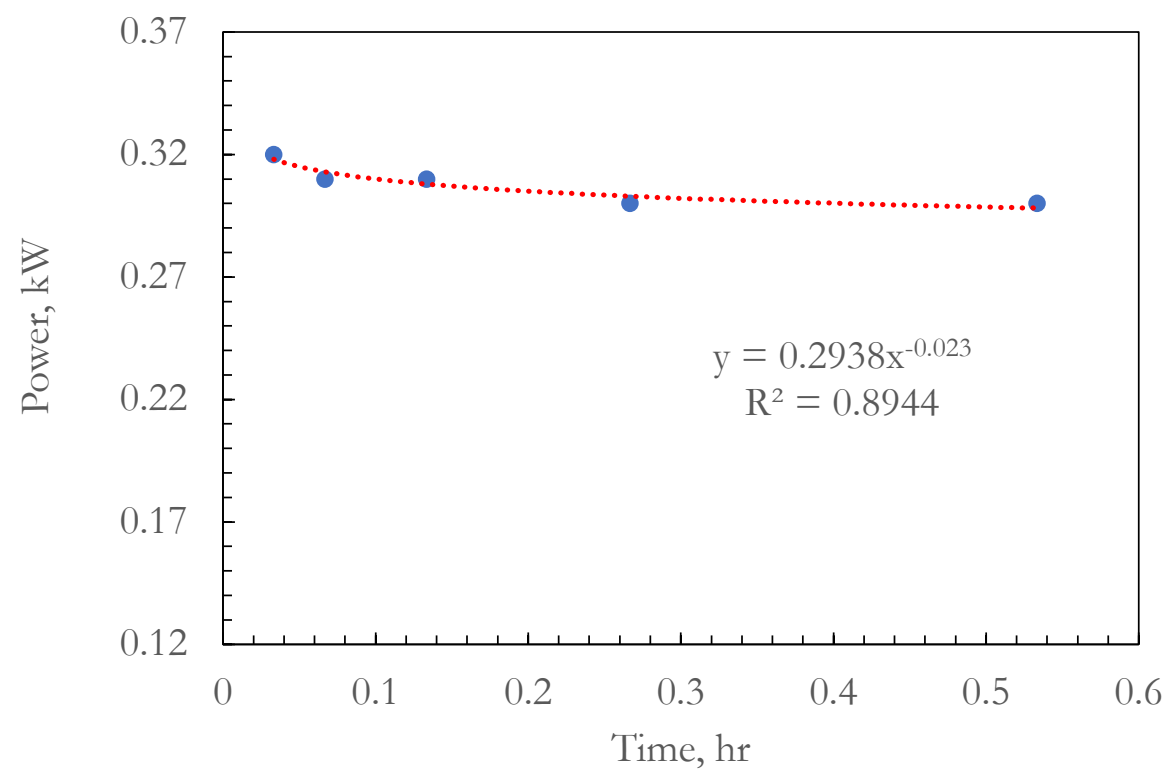

Figure 4.10: Power versus time graph for batch grinding pattern 102_D_3.

110_D_2

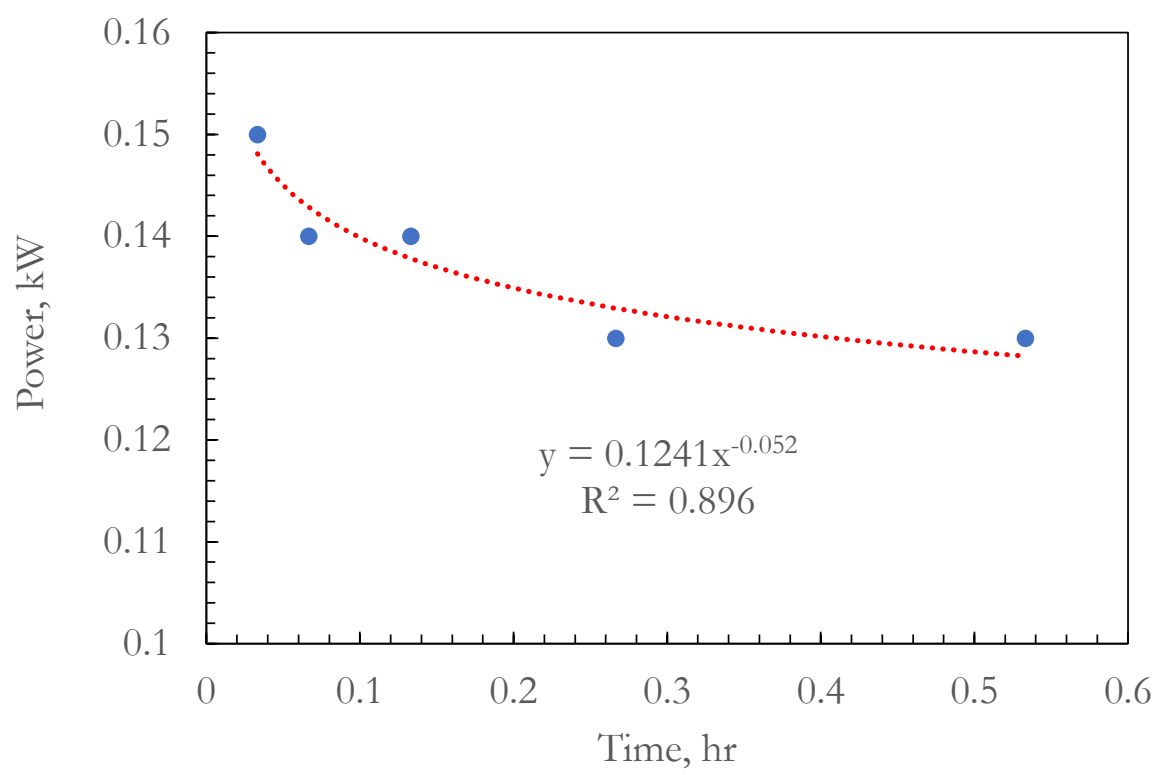

Figure 4.11: Power versus time graph for batch grinding pattern 110_D_2. 
121_D_1

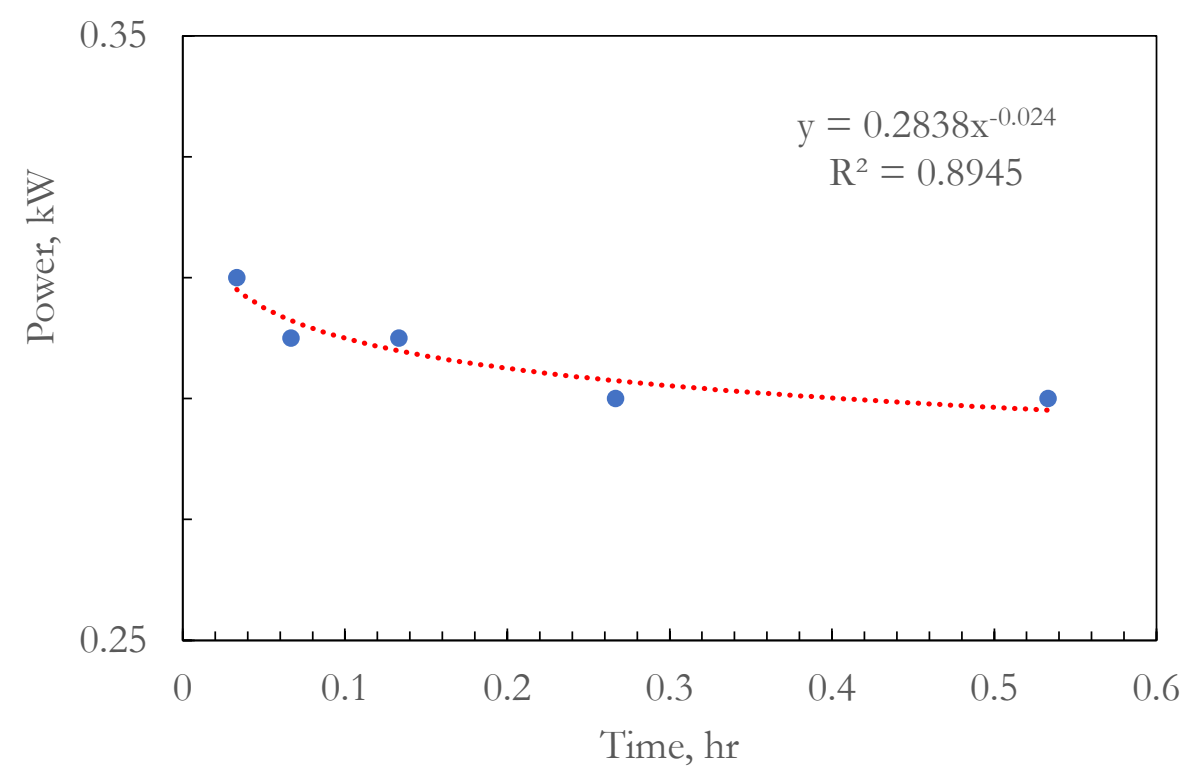

Figure 4.12: Power versus time graph for batch grinding pattern 121_D_1.

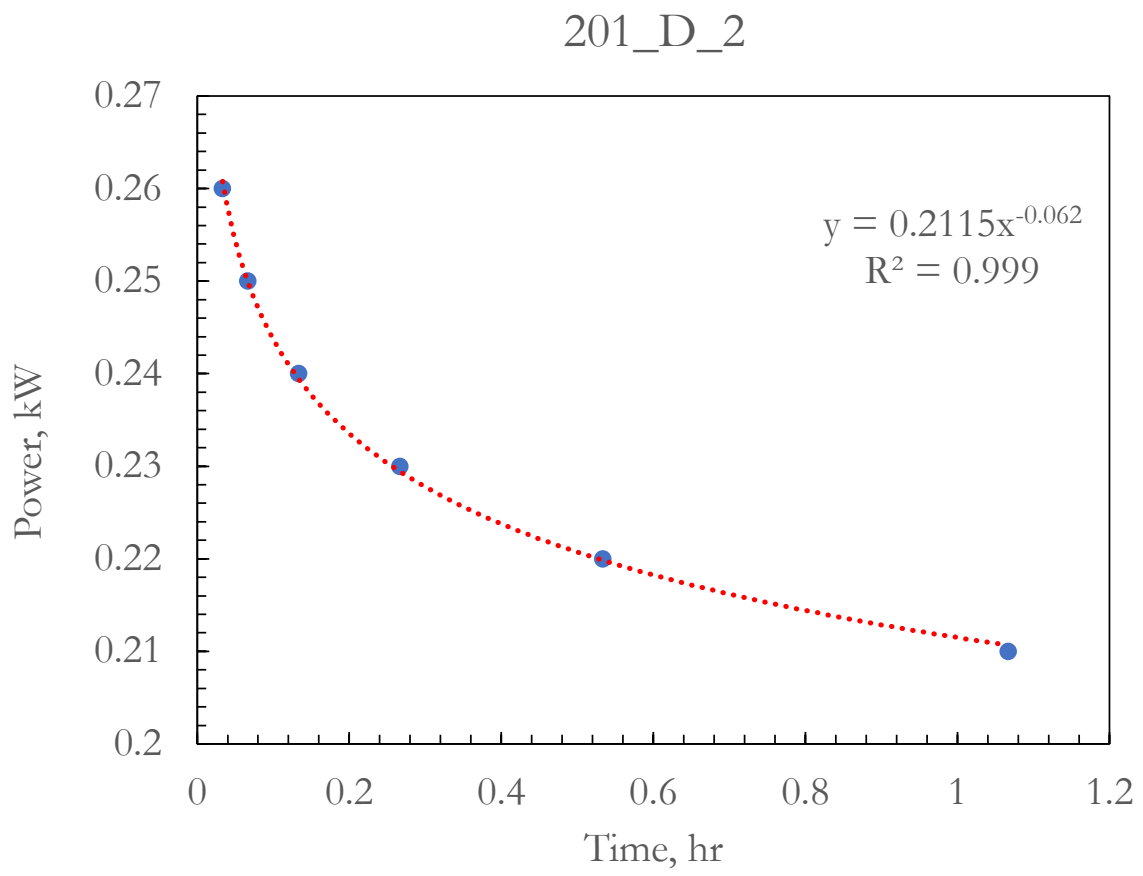

Figure 4.13: Power versus time graph for batch grinding pattern 201_D_2. 


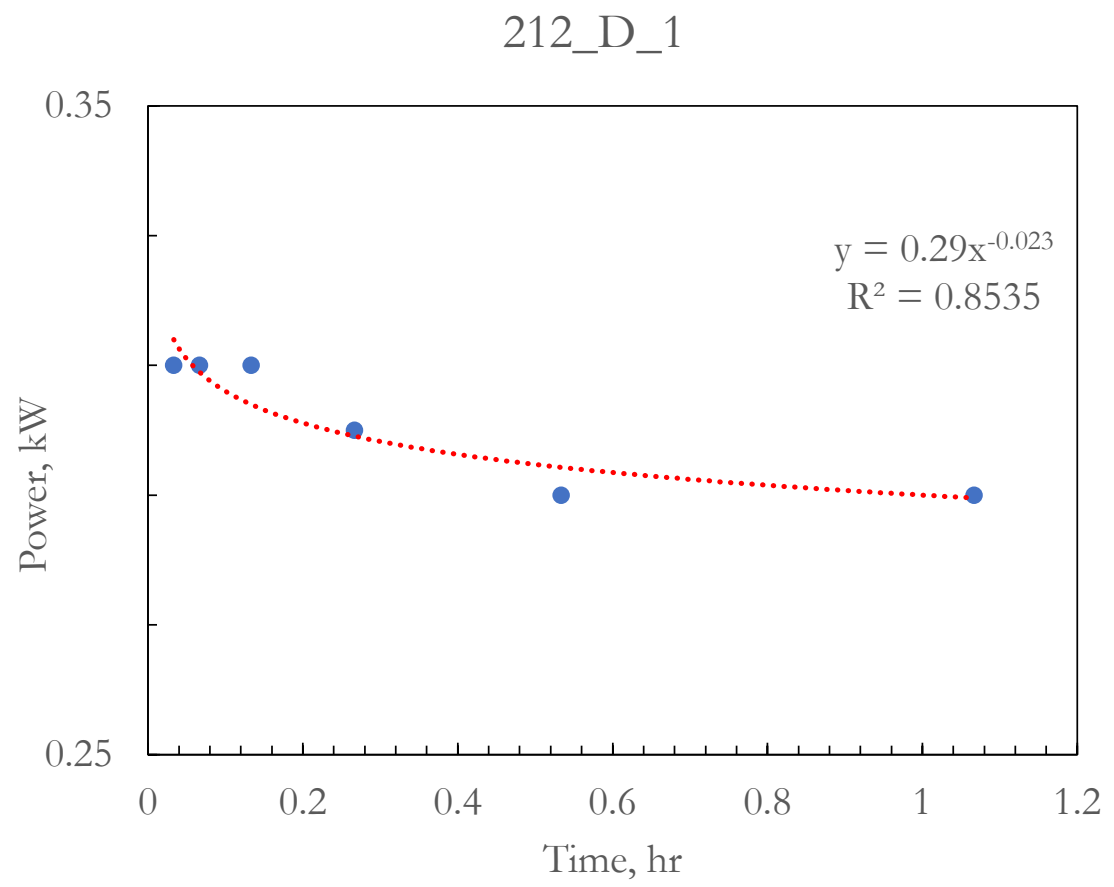

Figure 4.14: Power versus time graph for batch grinding pattern 212_D_1.

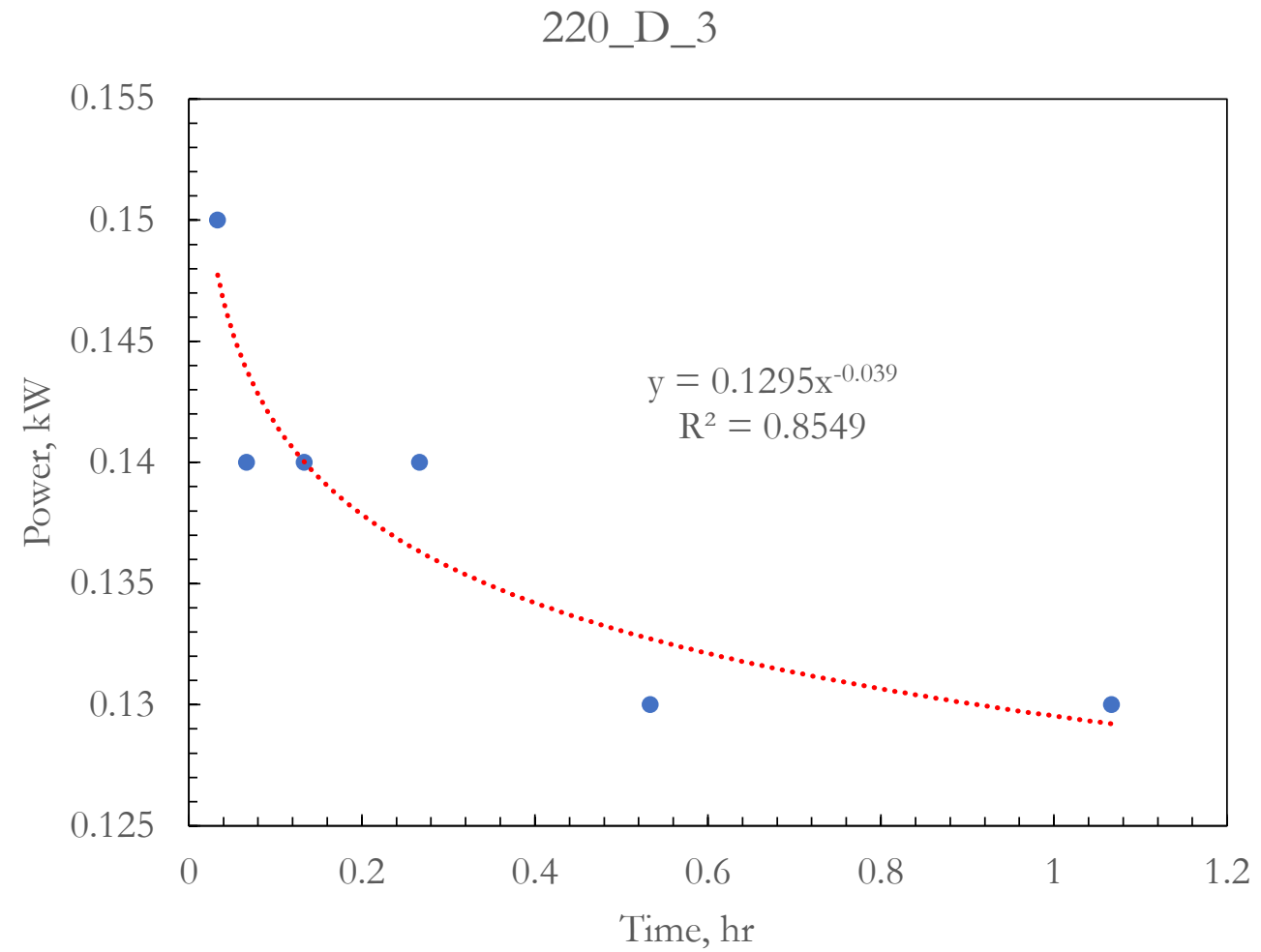

Figure 4.15: Power versus time graph for batch grinding pattern 220_D_3. 
Table 4.6: Raw data from batch grinding tests.

\begin{tabular}{lllll}
\hline Pattern & $\begin{array}{l}\text { Feed F80 } \\
\text { (micron) }\end{array}$ & $\begin{array}{l}\text { Product P80 } \\
\text { (micron) }\end{array}$ & $\begin{array}{l}\text { Specific Energy } \\
\text { (kWhr/ton) }\end{array}$ & Reduction Ratio \\
\hline 000_D_1 & 21.6 & 12.8 & 16.1 & 1.7 \\
\hline 011_D_3 & 86.4 & 51.2 & 92.9 & 1.7 \\
\hline 022_D_2 & 149.2 & 135.0 & 85.1 & 1.1 \\
\hline 102_D_3 & 21.6 & 5.7 & 218.4 & 3.8 \\
\hline 110_D_2 & 86.4 & 83.4 & 65.2 & 1.0 \\
\hline 121_D_1 & 149.2 & 137.5 & 218.6 & 1.1 \\
\hline 201_D_2 & 21.6 & 4.5 & 270.4 & 4.8 \\
\hline 212_D_1 & 86.4 & 84.0 & 416.3 & 1.0 \\
\hline 220_D_3 & 149.2 & 102.6 & 128.4 & 1.5 \\
\hline
\end{tabular}

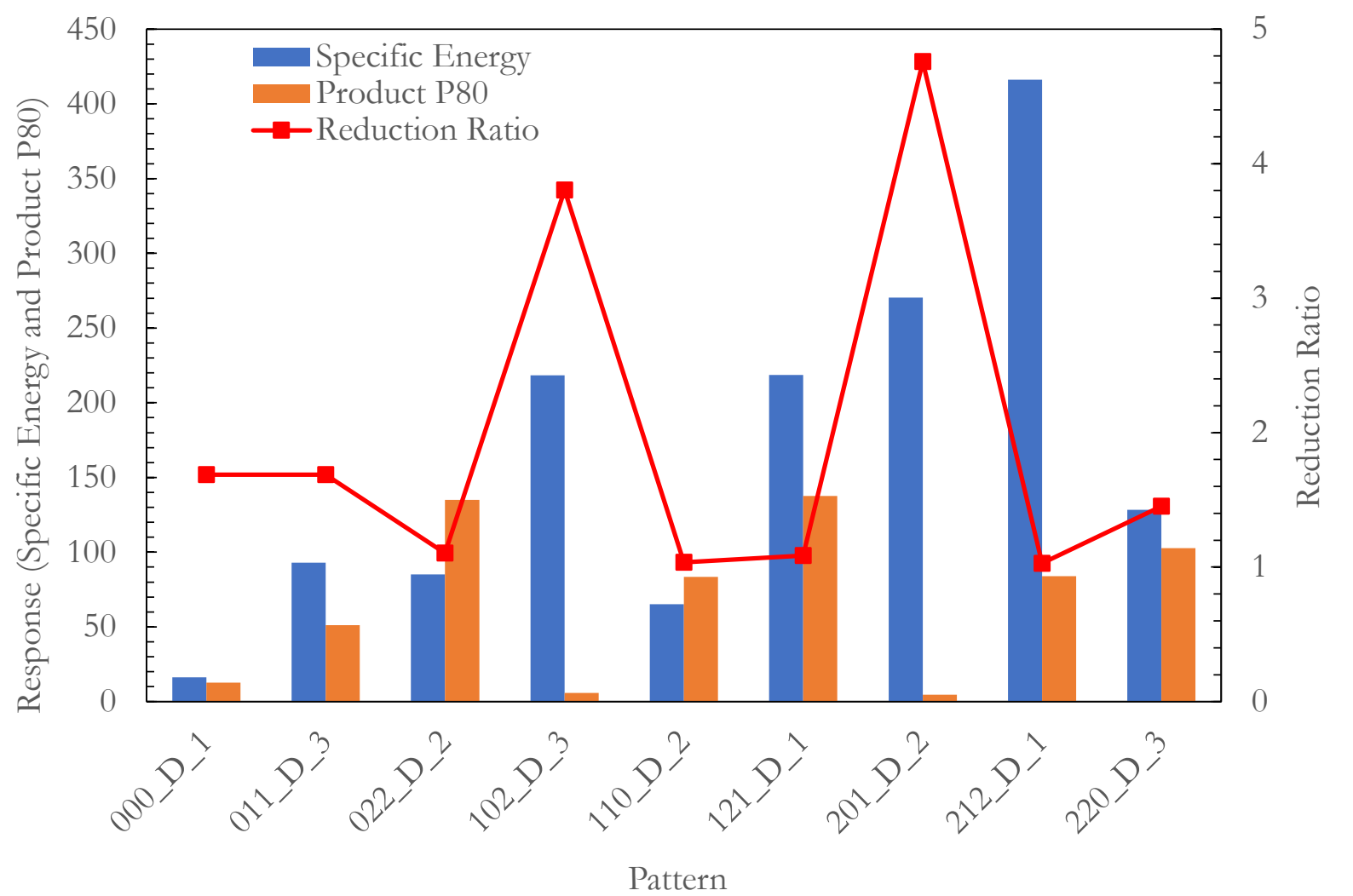

Figure 4.16: Specific energy, product $\mathrm{P}_{80}$ and reduction ratio for all grinding tests. 


\subsection{Ash Analysis}

The percent ash of feeds and their corresponding products is presented in Table 4.7. From Table 4.7, the insignificant difference between the percent ash (incombustible material) of Leatherwood coal before and after grinding for all grinding patterns indicates that there is no degradation of the media (silica) during the grinding process. If the silica had degraded during grinding, the percent ash of the product would have increased significantly due to the addition of silica (from the media) to the Leatherwood coal. In addition, shape analysis of silica beads before and after grinding by Huang et al. (2018) in Figure 4.17 shows that there was no degradation in the shape of silica due to the grinding process.

Table 4.7: Results from the ash analysis of all feeds and products.

\begin{tabular}{ccc}
\hline \multirow{2}{*}{ Pattern } & \multicolumn{2}{c}{ Percent Ash (wt \%) } \\
\cline { 2 - 3 } & Feed & Product \\
\hline 000_D_1 & 17.46 & 17.53 \\
\hline 011_D_3 & 17.46 & 17.51 \\
\hline 022_D_2 & 17.46 & 17.60 \\
\hline 102_D_3 & 17.46 & 17.60 \\
\hline 110_D_2 & 17.46 & 17.30 \\
\hline 121_D_1 & 17.46 & 17.55 \\
\hline 201_D_2 & 17.46 & 17.47 \\
\hline 212_D_1 & 17.46 & 17.51 \\
\hline 220_D_3 & 17.46 & 17.37 \\
\hline
\end{tabular}
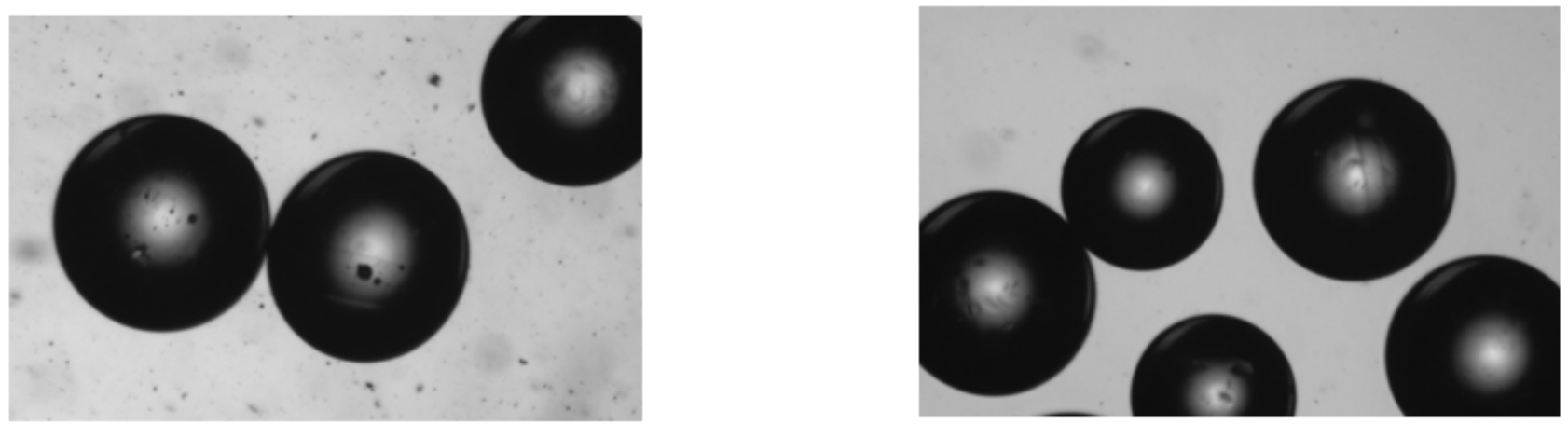

Figure 4.17: Shape analysis of silica beads $(250 \times 420 \mu \mathrm{m})$ before grinding (1eft) and after grinding (right) (Huang et al., 2018). 


\subsection{Statistical Analysis}

In this section, results of the statistical analysis of experimental data including regression analysis and normal probability plot of effects estimates are presented. The JMP statistical software was used for the statistical analysis in this study.

\subsubsection{Regression Analysis}

Regression analysis was done to determine the relationship between the significant design factors and the responses, product $\mathrm{P}_{80}$ and specific energy. The regression models can be used to predict the responses given the significant factors. However, the significant factors for each response must be first determined. Table 4.8 shows the effects, their estimates and the pseudo p-Value. The pValue of feed (0.001) at a five-percent significance level confirms that feed size has a significant influence on product $\mathrm{P}_{80}$. This is corroborated by the normal probability plot of effect estimates in Figure 4.18 which shows that only feed size does not lie on the straight line. This implies that only feed size has a significant effect on the product $\mathrm{P}_{80}$.

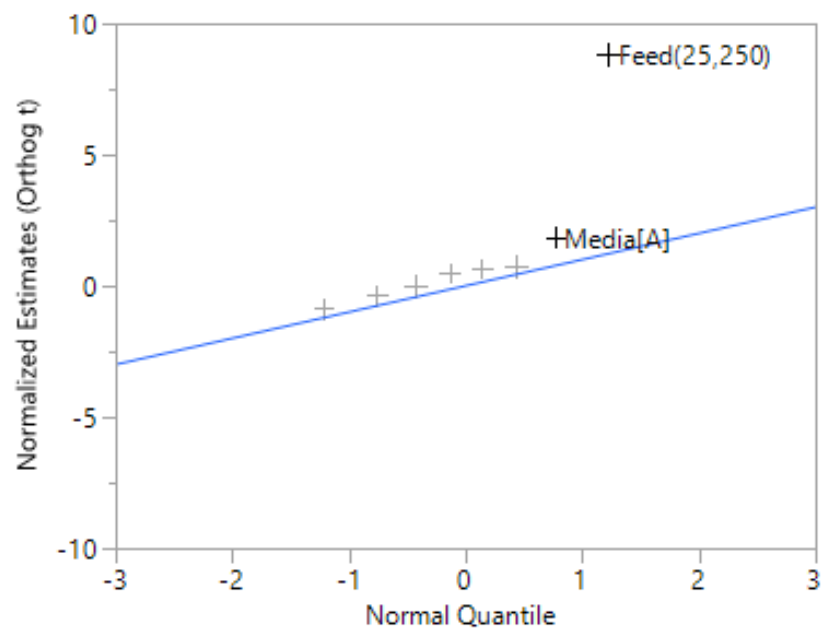

Figure 4.18: Normal probability plot of effect estimates for P80.

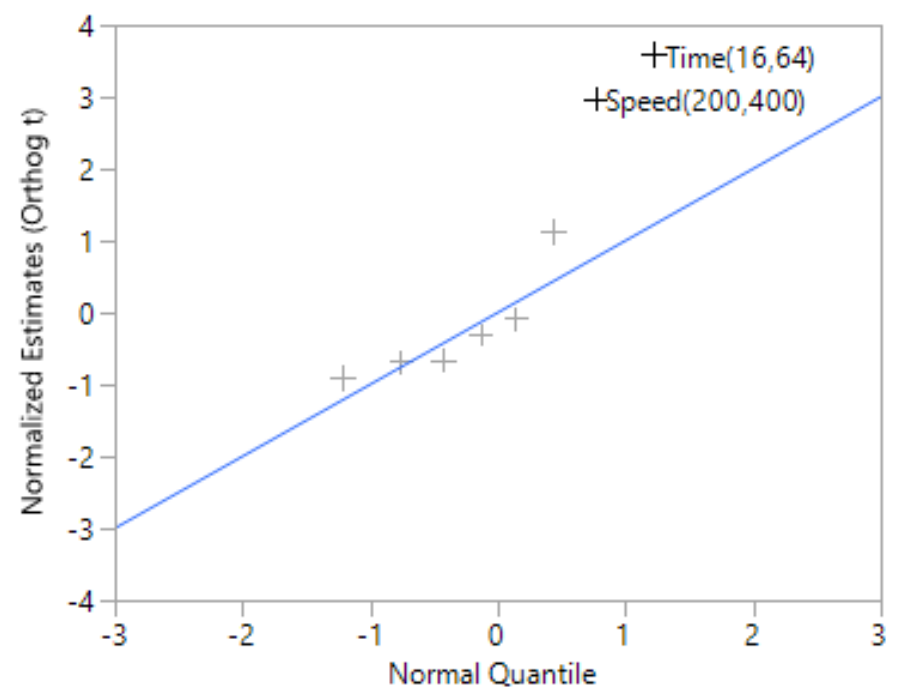

Figure 4.19: Normal probability plot of effect estimates for specific energy. 
Table 4.8: Sorted parameter estimates for P80.

\begin{tabular}{llllll}
\hline Term & Estimate & $\begin{array}{l}\text { Relative } \\
\text { Standard Error }\end{array}$ & $\begin{array}{l}\text { Pseudo } \\
\text { t-Ratio }\end{array}$ & $\begin{array}{l}\text { Pseudo } \\
\text { p-Value }\end{array}$ \\
\hline Feed & Biased & 58.687 & 0.4082 & 8.82 & 0.001 \\
\hline Media [D_1] & Biased & 9.588 & 0.4714 & 1.25 & 0.286 \\
\hline Time*Time & Biased & -11.335 & 0.8101 & -0.86 & 0.443 \\
\hline Media[D_2] & Biased & 5.771 & 0.4714 & 0.75 & 0.498 \\
\hline Speed*Speed & Biased & 9.388 & 0.8640 & 0.67 & 0.545 \\
\hline Speed & Biased & 4.307 & 0.408 & 0.65 & 0.556 \\
\hline Time & Biased & -1.293 & 0.408 & -0.19 & 0.856 \\
\hline Feed*Feed & Biased & 0.024 & 0.717 & 0.00 & 0.998 \\
\hline Time*Feed & Zeroed & 0 & 0 & -- & - \\
\hline Time*Speed & Zeroed & 0 & 0 & -- & -- \\
\hline Feed*Speed & Zeroed & 0 & 0 & - & \\
\hline
\end{tabular}

Using the effect estimates from Table 4.8, the regression model for predicting product $\mathrm{P}_{80}$ is given in Equation 4.5.

$$
\begin{aligned}
P_{80}=\quad & 66.835 \\
& -1.293 *\left(\frac{\text { Time }-40}{24}\right) \\
& +58.687 *\left(\frac{\text { Feed }-137.5}{112.5}\right) \\
& +4.307 *\left(\frac{\text { Speed }-300}{100}\right) \\
& + \text { Match }(\text { Media })\left\{\begin{array}{c}
D_{-} \_-1 \rightarrow 9.577 \\
D \_-15.359
\end{array}\right\} \\
& -11.335 *\left(\frac{\text { Time }-40}{24}\right) *\left(\frac{\text { Time }-40}{24}\right) \\
& +0.024 *\left(\frac{\text { Feed }-137.5}{112.5}\right) *\left(\frac{\text { Feed }-137.5}{112.5}\right) \\
& +9.388 *\left(\frac{\text { Speed }-300}{100}\right) *\left(\frac{\text { Speed }-300}{100}\right)
\end{aligned}
$$


Because feed size is the only significant factor for predicting product $\mathrm{P}_{80}$, adding other factors to the regression model would cause the sum of squares for regression to increase and the error sum of squares to decrease. Furthermore, adding an unimportant variable to the model can increase the mean square error, thereby decreasing the usefulness of the model. Removing negligible factors from Equation 4.5 gives Equation 4.6 which indicates that product P80 decreases with feed size and vice versa.

$$
P_{80}=0.522 * \text { Feed }-3.7379
$$

The same procedure was repeated for specific energy using parameter estimates and pseudo pValue from Table 4.9. From the p-Values of 0.026 and 0.05 at five percent significance level for grinding time and shaft speed, respectively, it can be concluded that only grinding time and shaft speed have significant effect on specific energy. This is corroborated by the normal probability plot of effect estimates on Figure 4.19 which shows that only grinding time and shaft speed do not lie on the straight line. This implies that only grinding time and shaft speed have most effect on product $\mathrm{P}_{80}$.

Table 4.9: Sorted parameter estimates for specific energy.

\begin{tabular}{llllll}
\hline Term & Estimate & $\begin{array}{l}\text { Relative } \\
\text { Standard Error }\end{array}$ & $\begin{array}{l}\text { Pseudo } \\
\text { t-Ratio }\end{array}$ & $\begin{array}{l}\text { Pseudo } \\
\text { p-Value }\end{array}$ \\
\hline Time & Biased & 105.745 & 0.4082 & 3.63 & 0.026 \\
\hline Speed & Biased & 83.324 & 0.4082 & 2.86 & 0.050 \\
\hline Media[D_1] & Biased & 47.810 & 0.4714 & 1.42 & 0.234 \\
\hline Media[D_2] & Biased & -29.880 & 0.4714 & -0.89 & 0.429 \\
\hline Time*Time & Biased & -38.520 & 0.8101 & -0.67 & 0.545 \\
\hline Feed*Feed & Biased & -33.526 & 0.7174 & -0.66 & 0.551 \\
\hline Feed & Biased & -9.977 & 0.408 & -0.34 & 0.751 \\
\hline Speed*Speed & Biased & -4.567 & 0.864 & -0.07 & 0.945 \\
\hline Time*Feed & Zeroed & 0 & 0 & -- & -- \\
\hline Time*Speed & Zeroed & 0 & 0 & -- & - \\
\hline Feed*Speed & Zeroed & 0 & 0 & -- \\
\hline
\end{tabular}

Using the effect estimates from Table 4.9, the regression model for predicting specific energy is given in Equation 4.7. 


$$
\begin{aligned}
& \bar{E}=\quad 224.030 \\
& +105.745 *\left(\frac{\text { Time }-40}{24}\right) \\
& -9.977 *\left(\frac{\text { Feed }-137.5}{112.5}\right) \\
& +83.324 *\left(\frac{\text { Speed }-300}{100}\right) \\
& +\operatorname{Match}\left(\text { Media) }\left\{\begin{array}{c}
D_{-} 1 \rightarrow 47.810 \\
D_{-} \rightarrow-29.880 \\
D_{-} 3 \rightarrow-17.929 \\
\text { else } \rightarrow 0
\end{array}\right\}\right. \\
& -38.519 *\left(\frac{\text { Time }-40}{24}\right) *\left(\frac{\text { Time }-40}{24}\right) \\
& -33.526 *\left(\frac{\text { Feed }-137.5}{112.5}\right) *\left(\frac{\text { Feed }-137.5}{112.5}\right) \\
& -4.567 *\left(\frac{\text { Speed }-300}{100}\right) *\left(\frac{\text { Speed }-300}{100}\right)
\end{aligned}
$$

By removing negligible factors from Equation 4.7 gives Equation 4.8:

$$
\bar{E}=-306.189+9.766 * \text { Time }-0.067 * \text { Time }^{2}+1.107 * \text { Speed }
$$

Equation 4.8 indicates that specific energy decreases with a reduction in grinding time and shaft speed and vice versa.

\subsection{Numerical Simulation}

As the (unknown) selection and breakage function parameters were iteratively perturbed during the numerical simulation of the batch grinding process using the particle swarm optimization algorithm in MATLAB, the MSE reduces slowly. After the stopping criterion (twenty iterations) was reached, the MSE had reduced to 0.01. As shown in Figure 4.20, following the trend, increasing the number of iterations would not result in a significant reduction of the MSE.

The optimum selection and breakage function parameters ((in Table 4.10) obtained from the model were used to predict the product particle size distribution and then compared with the product particle size distribution from the experiments. Figures 4.21 to 4.29 shows the comparisons between the product particle size distribution between the model and the experiment for all batch grinding patterns. The close match between the model and the experiments indicates that the

optimum selection and breakage function parameters are the actual grinding parameters of the Leatherwood coal. 


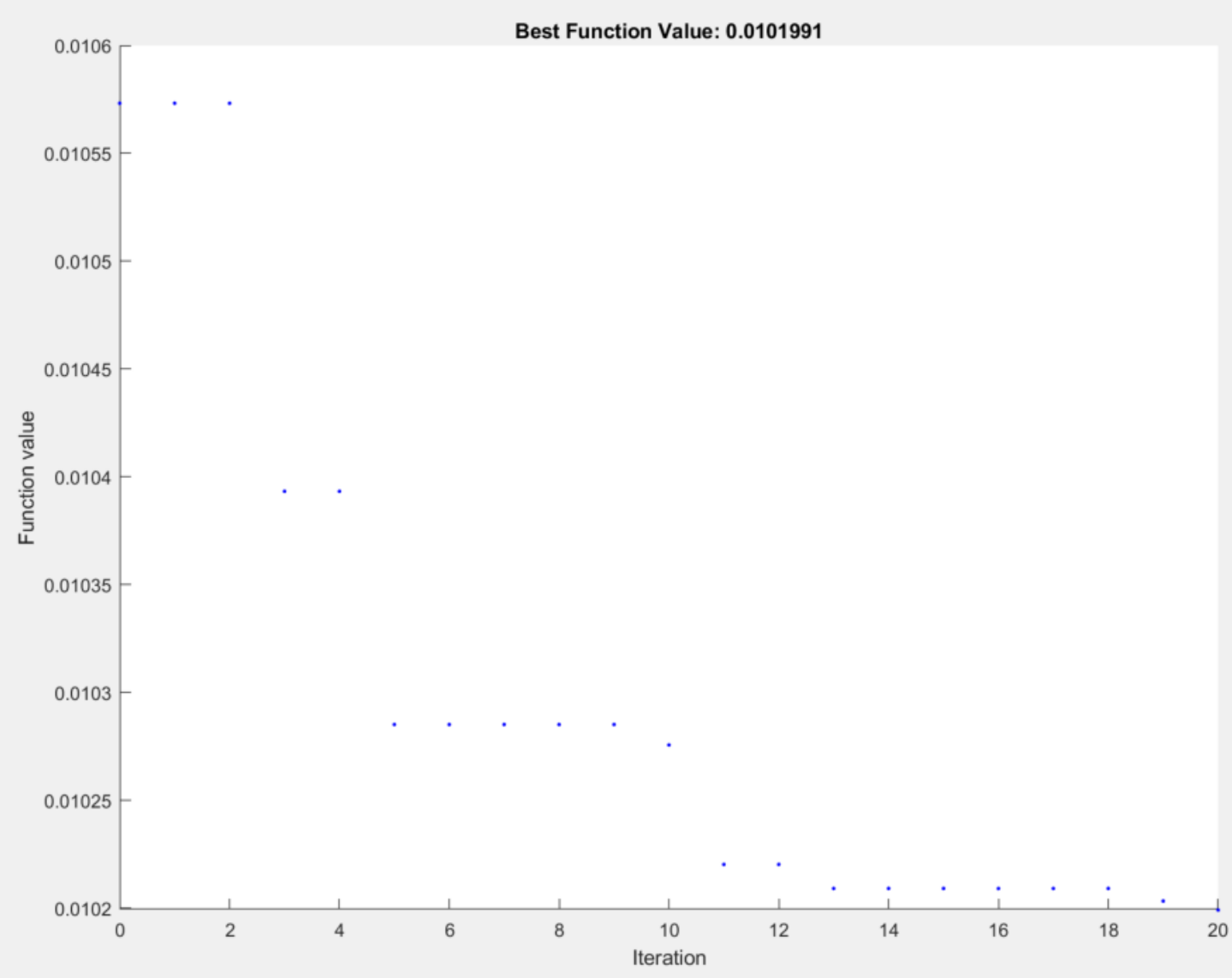

Figure 4.20: Decay of objective function using Particle swarm optimization.

Table 4.10: Bounds and optimum values of selection and breakage function parameters.

\begin{tabular}{clll}
\hline Unknown parameter & Lower bound & Upper bound & Optimum \\
\hline$S_{1}^{E}$ & 0.0 & 0.1 & 0.05 \\
\hline$\zeta_{1}$ & 0.0 & 5.0 & 4.98 \\
\hline$\zeta_{2}$ & -4.0 & 1.0 & -2.03 \\
\hline$\alpha_{1}$ & 0.0 & 2.0 & 1.34 \\
\hline$\alpha_{2}$ & 0.0 & 0.5 & 0.06 \\
\hline$\alpha_{3}$ & 10.0 & 25.0 & 10.15 \\
\hline
\end{tabular}




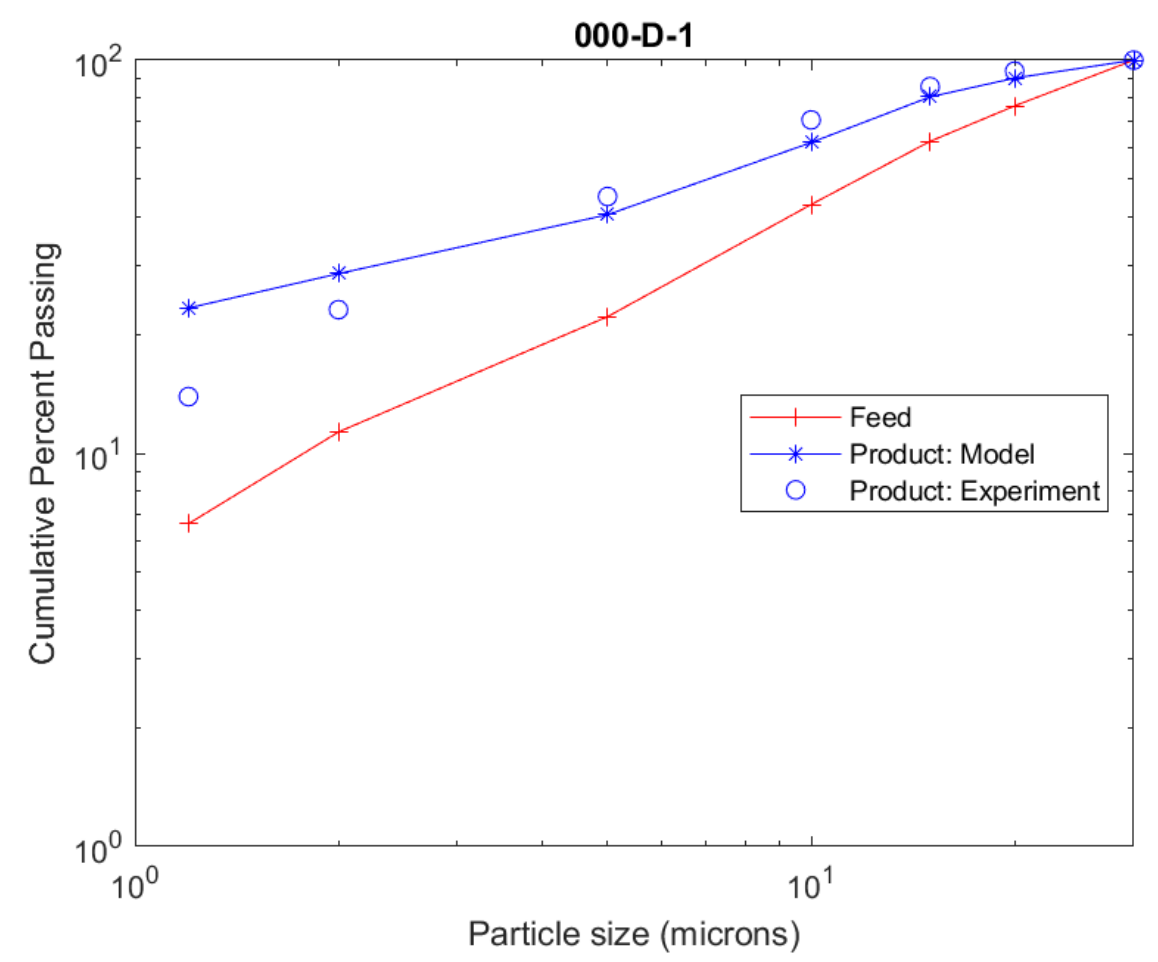

Figure 4.21: Particle size distribution of the feed and the grinding product from both the experiment and numerical simulation for pattern $000 \_$D_ 1 .

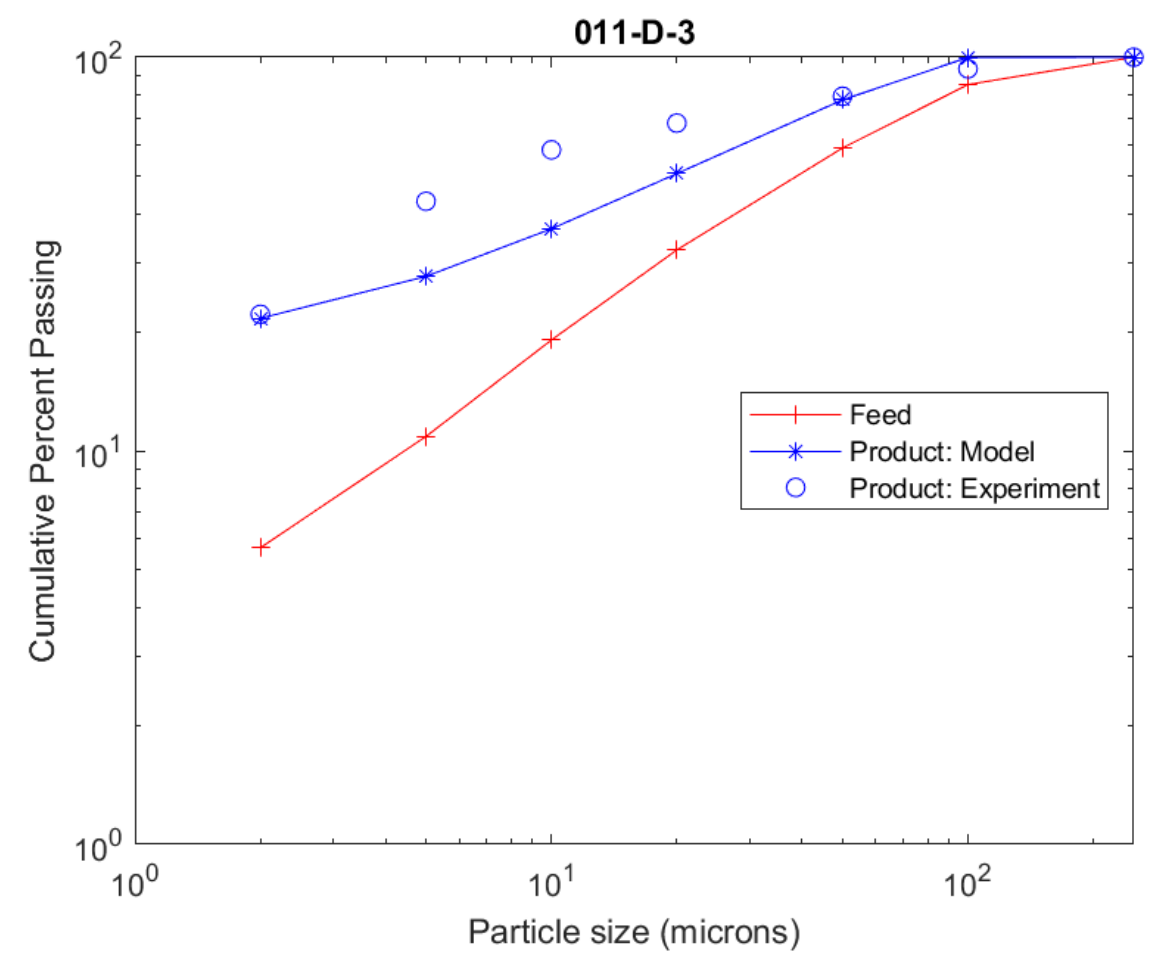

Figure 4.22: Particle size distribution of the feed and the grinding product from both the experiment and numerical simulation for pattern 011 _D_3. 


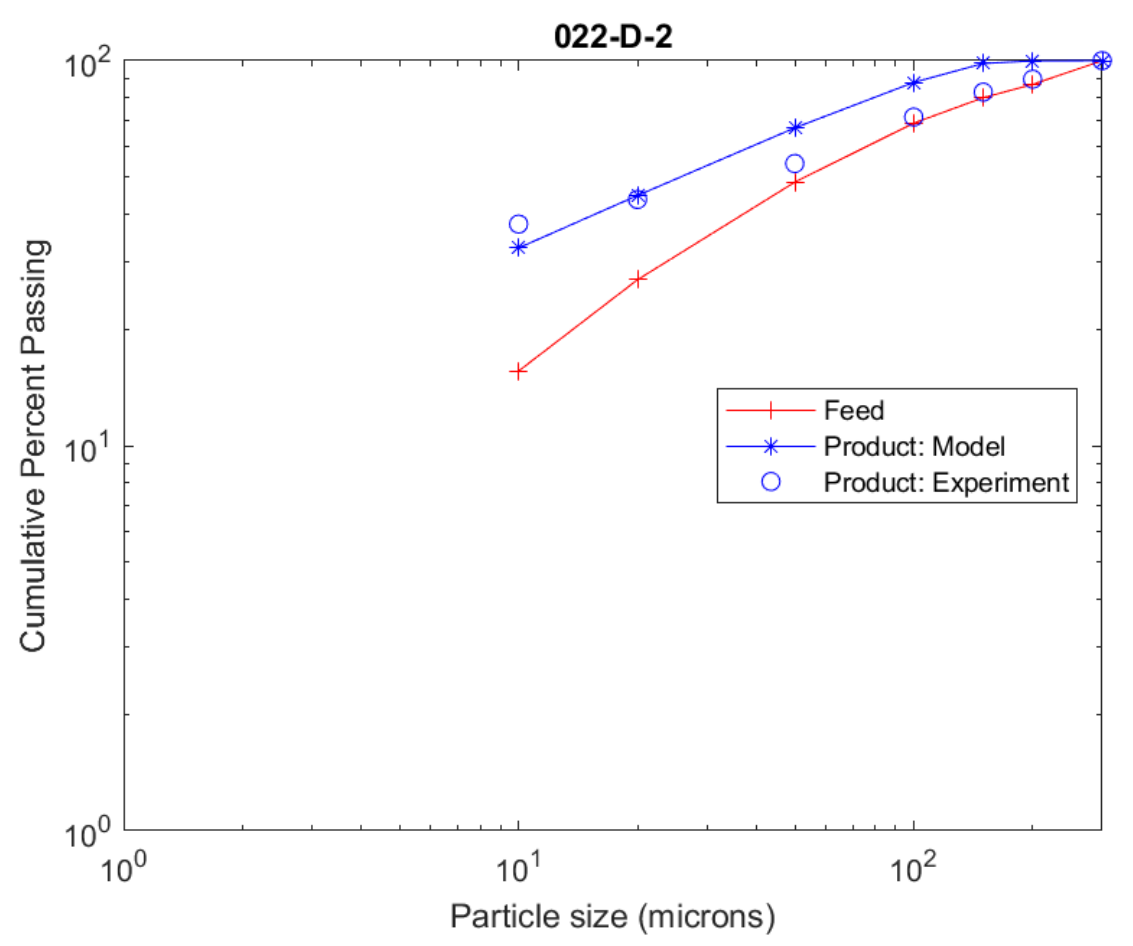

Figure 4.23: Particle size distribution of the feed and the grinding product from both the experiment and numerical simulation for pattern 022_D_2.

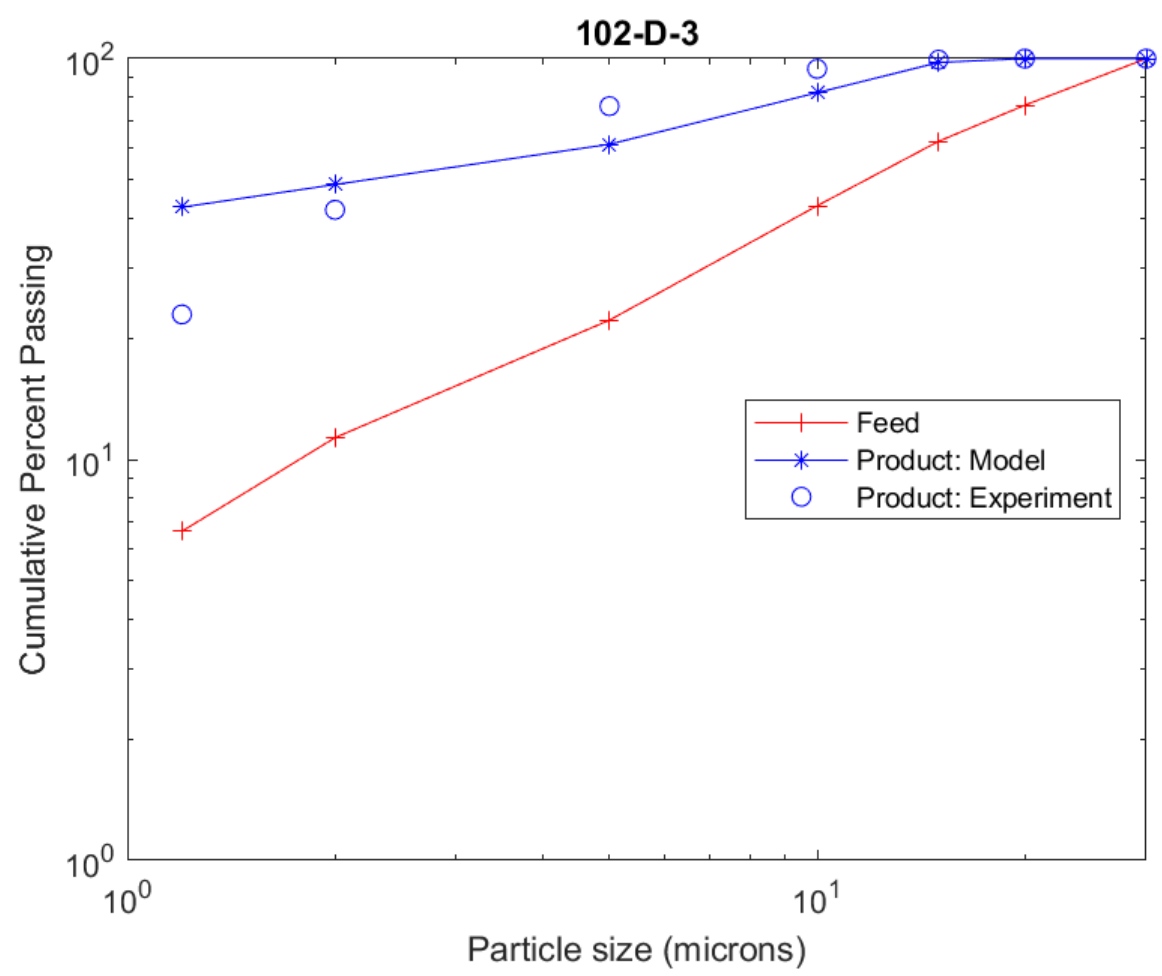

Figure 4.24: Particle size distribution of the feed and the grinding product from both the experiment and numerical simulation for pattern 102_D_3. 


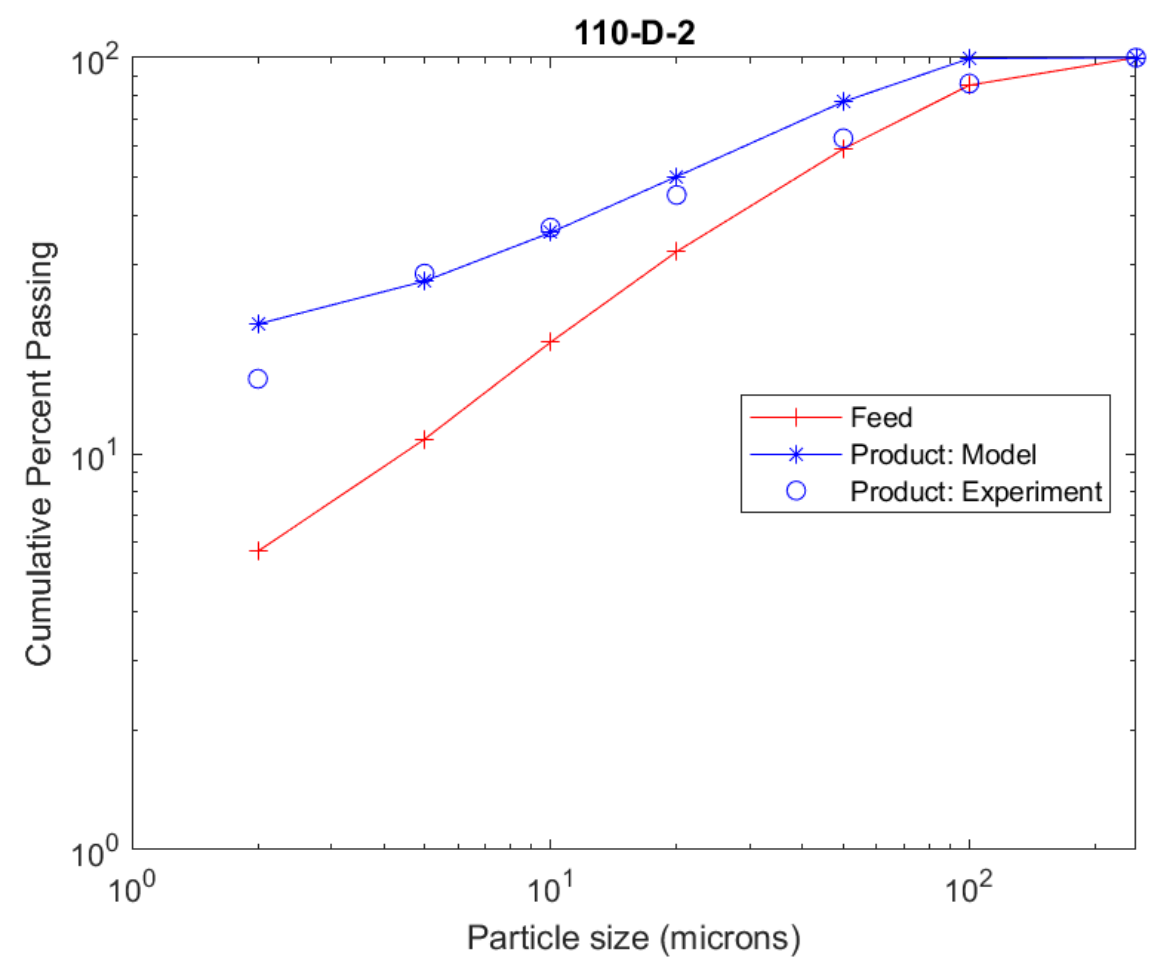

Figure 4.25: Particle size distribution of the feed and the grinding product from both the experiment and numerical simulation for pattern 110_D_2.

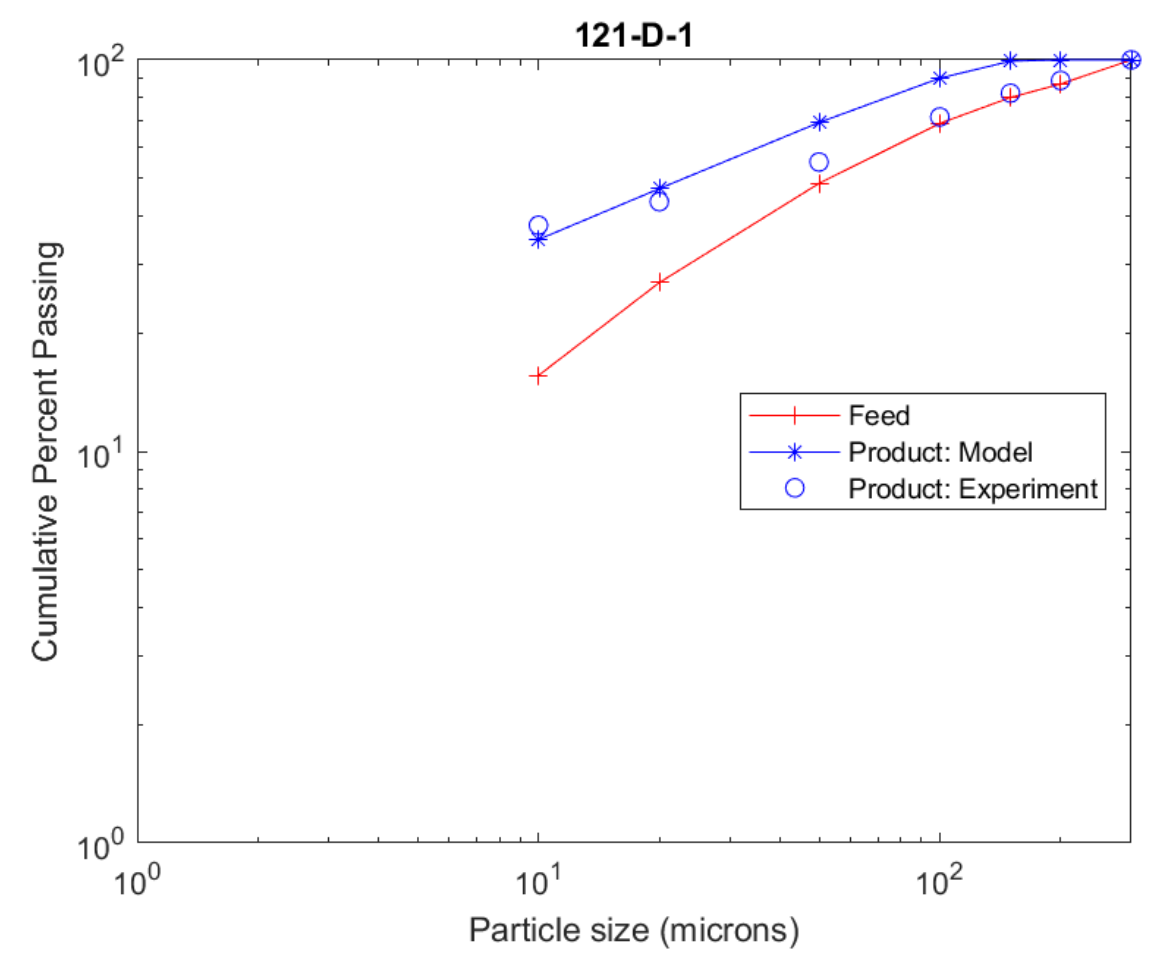

Figure 4.26: Particle size distribution of the feed and the grinding product from both the experiment and numerical simulation for pattern 121 _ D_1. 


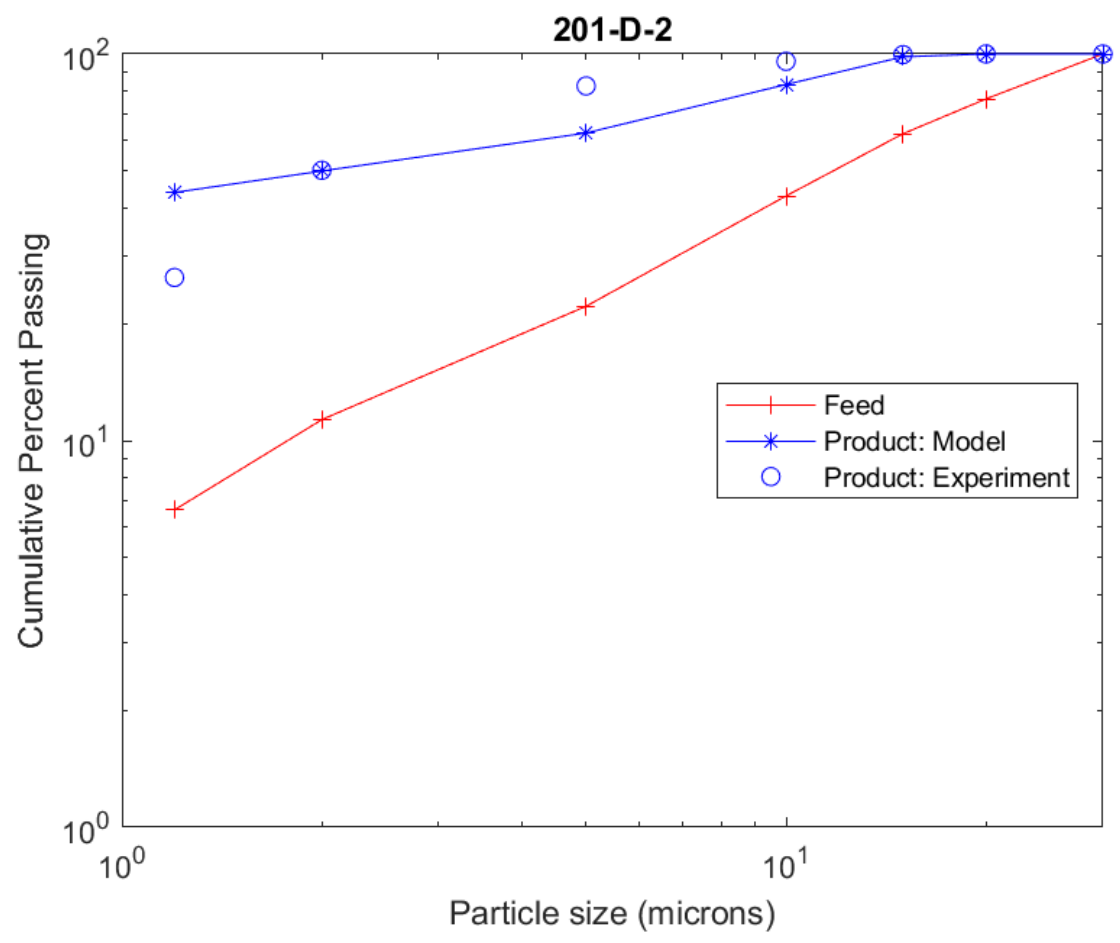

Figure 4.27: Particle size distribution of the feed and the grinding product from both the experiment and numerical simulation for pattern 201_D_1.

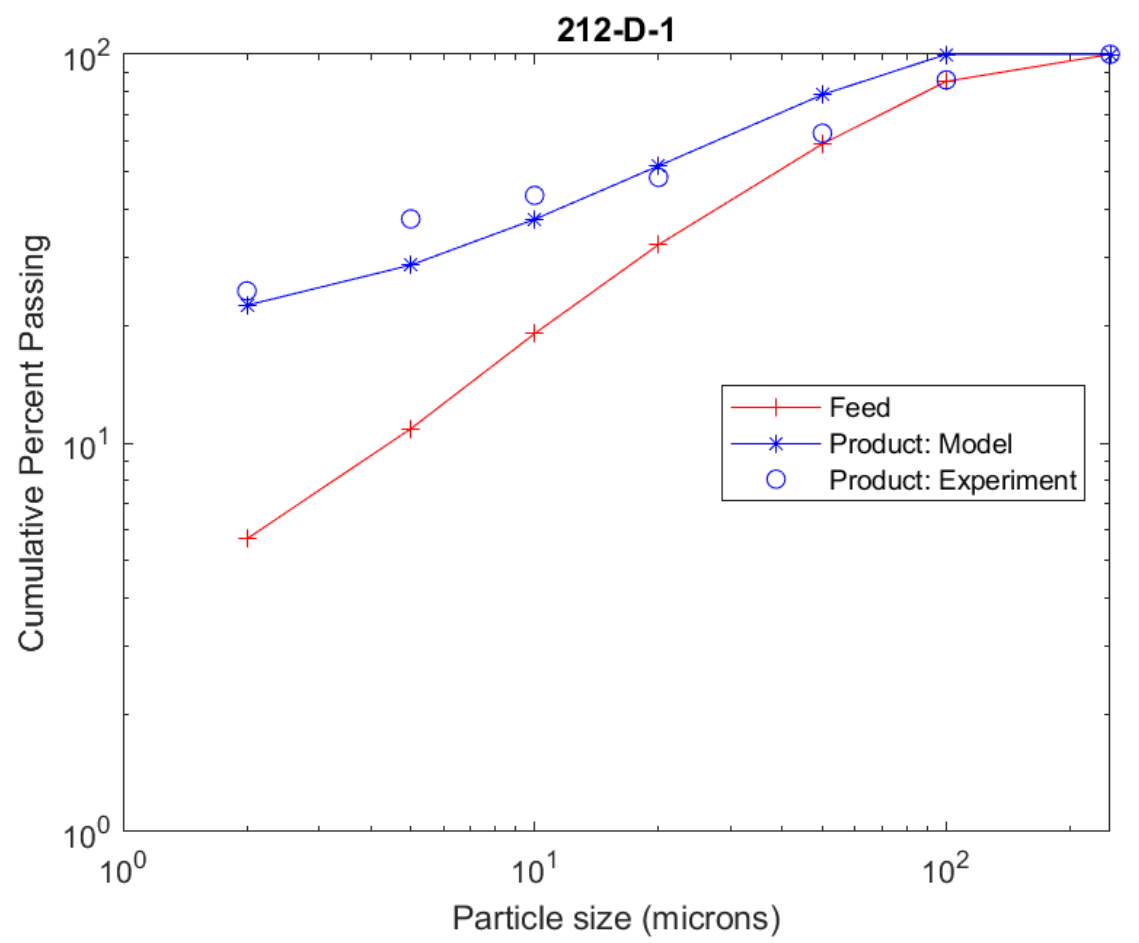

Figure 4.28: Particle size distribution of the feed and the grinding product from both the experiment and numerical simulation for pattern 212 _ _ 1 . 
220-D-3

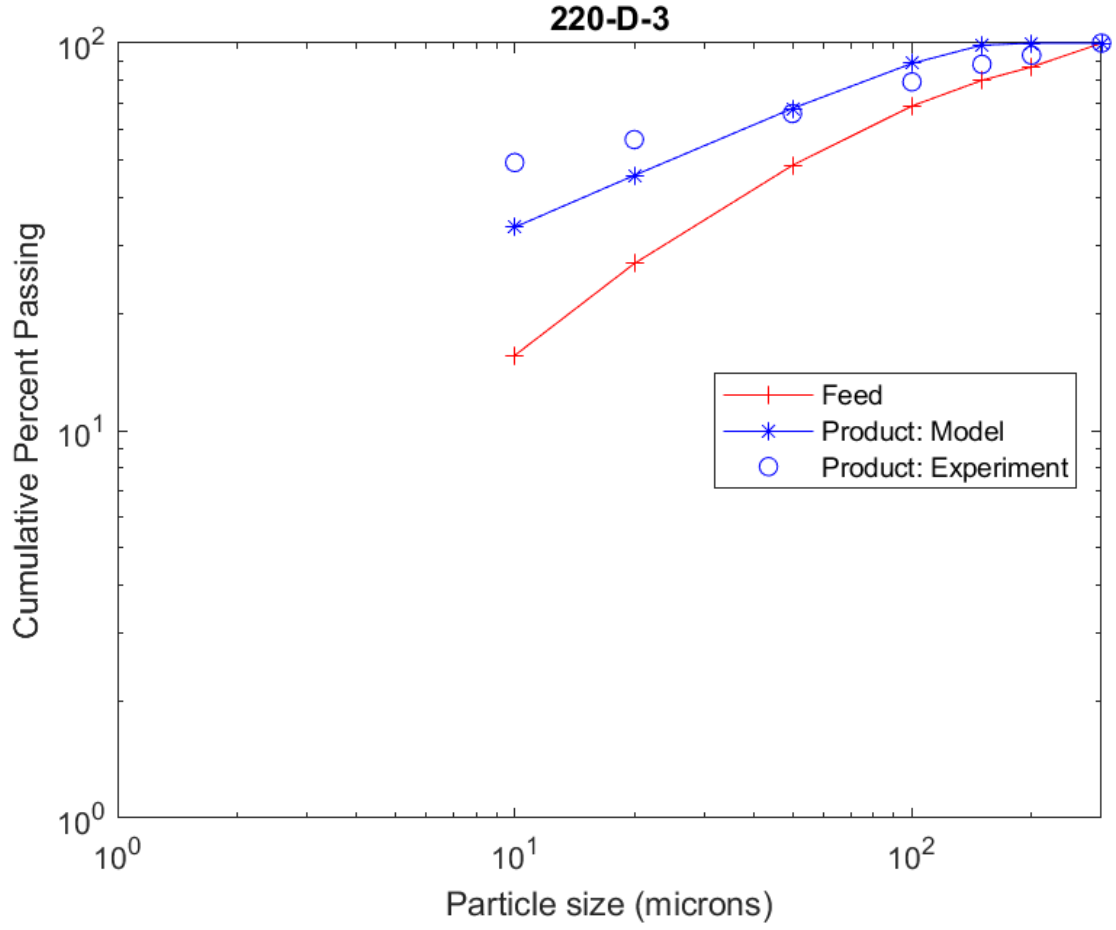

Figure 4.29: Particle size distribution of the feed and the grinding product from both the experiment and numerical simulation for pattern 220_D_1. 


\section{Chapter 5}

\section{Conclusions and Recommendations}

In this chapter, main conclusions based on the outcome of this study are presented and recommendations for future research studies are given.

\subsection{Conclusions}

The following are the conclusions derived from this study:

1. Using silica as the grinding media, the effects of nominal feed size, media size, shaft speed and grinding time, each of three levels on two responses (product $\mathrm{P}_{80}$ and specific energy) of a coal material were assessed.

2. The coal material was mixed-phase particles commonly referred to as middlings, sampled from the dense medium circuit at the Leatherwood preparation plant in Kentucky.

3. The Leatherwood coal material was characterized with both Bond and Hardgrove grindability tests. With a BWI of $31.75 \mathrm{kWh} /$ ton and a HGI of 41.1 , it can be concluded that the coal material is relatively difficult to grind with more energy being consumed during the grinding process.

4. The media sizes were in three standard size ranges as per manufacturer's design. Hence, media size was qualitative while other design factors were quantitative.

5. Leveraging on the sparsity of effects principle, a one-third fractional factorial design of experiment with resolution III was custom-designed in JMP statistical software.

6. A total of nine batch grinding tests were run in the Union Process attritor according to the one-third fractional factorial design. The product $\mathrm{P}_{80}$ and the specific energy were measured for each test.

7. Ash analysis was done for the Leatherwood coal before and after each grinding test to determine if there was any degradation of the silica media. Results from the ash analysis indicate no media degradation occurred during the grinding process, which was further corroborated by the media shape analysis.

8. The results obtained from the grinding tests were statistically analyzed to determine the significant operating parameters that influence the product $\mathrm{P}_{80}$ and the specific energy. According to the ANOVA and NPP of effect estimates, only feed size significantly influences product $\mathrm{P}_{80}$ while grinding time and shaft speed significantly affect the specific energy. It also implied that all interactions were negligible. This confirms the sparsity of effects principle and justifies running a fractional factorial design.

9. Regression analysis was performed to further develop mathematical models to predict product $\mathrm{P}_{80}$ and the specific energy based on the design factors that significantly influence them.

10. The lowest $P_{80}$ of 4.5 micron and the highest $P_{80}$ of 137.5 microns were obtained when the nominal feed size was at its low level (25 microns) and high level (250 microns), respectively. In the same vein, the lowest and highest specific energy $(16 \mathrm{kWh} /$ ton and 416 $\mathrm{kWh} /$ ton, respectively) were obtained when grinding time and shaft speed were at their low levels (16 minutes and $200 \mathrm{rpm}$ ) and high levels (64 minutes and $400 \mathrm{rpm})$, separately.

11. The batch grinding process was numerically simulated with PBM using results from the experiment. Particle swarm optimization, an in-built stochastic algorithm in MATLAB was used to iteratively fit the model to the experimental data with a mean squared error of 0.01 . 
12. The selection and breakage function parameters were estimated on the basis of the numerical simulation. The selection function parameters are: $0.053,4.982$ and -2.031 . The breakage function parameters are: $1.336,0.056$ and 10.156 .

\subsection{Recommendations}

Based on the findings from the presented work, the following recommendations are proposed for future studies in the similar field:

1. Other global algorithms such as the differential evolution and simulated annealing algorithms could be used to obtain a better match between the experiment and the simulation results.

2. Other grinding media including ceramics, sand, and stainless steel may be used and a comparative study can be made among various grinding media with respect to the grinding efficiency.

3. Different coal sources may be used to comprehensively study the effect of the factors considered and evaluate whether coal feedstock imposes a significant impact on the liberation behavior.

4. Full factorial experiment may be considered to corroborate the findings of this study, if allowed by time and resources. 


\section{Bibliography}

Andreatidis, J., (1995): Breakage Mechanisms and Resulting Mineral Liberation in a Bead Mill, M.Eng.Sc. thesis, University of Queensland, Brisbane, Australia.

Bai, Q. (2010). Analysis of Particle Swarm Optimization Algorithm. Journal of Computer and Information Science 3(1), p. 180

Bokányi, L., \& Csöke, B. (2003). Preparation of clean coal by flotation following ultra-fine liberation. Applied Energy, 74(3), 349-358.

Bond, F. C. (1952). The third theory of comminution. Trans. AIME, Vol. 193, pp. 484-494.

Bond, F. C. (1961). Crushing and grinding calculation. British Chemical Engineering, 6(6), 378391.

Choi, W. S, Chung, H. Y., Yoon, B. R \& Kim, S. S. (2001). Application of grinding kinetics analysis to fine grinding characteristics of some inorganic materials using a composite grinding media by planetary ball mill. Powder Technology 115 , pp. 209-214.

Choi, H., Lee, W. \& Kim, S. (2009). Effect of grinding aids on the kinetics of fine grinding energy consumed of calcite powders by a stirred mill. Advanced Powder Technology 20, pp. 350354

Dorigo, M., De Oca, A. M., \& Engelbrecht, A. (2008). Particle Swarm Optimization. Scholarpedia, 3(11), p. 486

Firth, B. \& O'Brien, M. (2002). Interaction of size classification and cleaning approaches to the yield ash moisture content relationship for fine coal. In XIV International Coal Preparation Congress and Exhibition, Johannesburg, South Africa 2002, 193-197. Marshalltown, South Africa: South African Institute of Mining and Metallurgy.

Fuerstenau, M. C. (2003). Principles of mineral processing. SME.

Gao, M., \& Forssberg, E. (1995). Prediction of product size distribution for a stirred ball mill. Powder Technology 84, pp. 101-106.

Gupty, C. K. (2003). Chemical metallurgy. Weinheim, Germany: Wiley-VCH Verlag.

Hasegawa, M., Kimata, M., Shimane, M., Shoji, T. \& Tsuruta, M. (2001). The effect of liquid additives on dry ultrafine grinding of quartz. Powder Technology 114, pp. 145-151.

Herbst, J. A., G.A. Grandy \& T.S. Mika (1971). On the development and use of lumped parameter models for continuous open- and closed-circuit grinding systems. Transactions of the Institution of Mining and Metallurgy, 80:C193.

Huang, Q., Noble, A., Herbst, J., Honaker, R. (2018). Liberation and release of rare earth minerals from Middle Kittanning, Fire Clay, and West Kentucky No. 13 coal sources. Powder Technology 332, pp. 242-252.

Jankovic, A.; Dundar, H. \& Mehta, R. (2010). Relationships between comminution energy and product size for a magnetite ore. Journal of the Southern African Institute of Mining and Metallurgy 110, pp.141-146. 
Jillavenkatesa, A., Dapkunas, S. J. \& Lum, L. (2001). Particle size characterization. Maryland, USA: NIST Special Publication.

Jimbo, G. (1992). Chemical engineering analysis of fine grinding phenomena and process. Journal of Chemical Engineering 25 (2), pp. 117-127.

Kalia, S., Trager, J., Sitton, O. C. \& Mormile, M. R. (2016). The use of a fractional factorial design to determine the factors that impact 1,3-Propanediol production from Glycerol by Halanaerobium hydrogeniformans. Life 6 (35), pp. 1-9

Kanda, Y., Simodaira, K., Kotake, N. \& Abe, Y. (1998). An experimental study on the grinding rate constant of a ball mill - the effect of feed size and ball diameter. Powder Technology. 35 12-17.

Kano, J., Yabune, H., Mio, H., \& Saito, F. (2001). Grinding of talc particulates by a highspeed rotor mixer. Advanced Powder Technology 12, pp. 207-214.

Kataria, R., Mol, A., Schulten, E., Happel, A. \& Mussatto, S. I. (2017). Bench scale steam explosion pretreatment of acid impregnated elephant grass biomass and its impacts on biomass composition, structure and hydrolysis. Industrial Crops Production 106, pp. 4858.

Kaya, E., Fletcher, P. C. \& Thompson, P. (2002, February 25 - 27). Reproducibility of Bond work index with different standard ball mills. Proceedings of the SME Annual Meeting, Phoenix, Arizona. p. 1.

Kelly, E. G., \& Spottiswood, D. J. (1982). Introduction to mineral processing.

Kennedy, J. \& Eberhart, R. (1995). Particle Swarm Optimization. IEEE International Conference on Neural Networks IV, pp. 1942-1948.

Klimpel, R. R., \& Austin, L. G. (1977). The back-calculation of specific rates of breakage and non-normalized breakage distribution parameters from batch grinding data. International Journal of Mineral Processing 4(1), 7-32.

Kotake, N., Kuboki, M., Kiya, S. \& Kanda, Y. (2010). Influence of dry ad wet grinding conditions on fineness and shape of particle size distribution of product in a ball mill. Advanced Powder Technology 22 pp. 86-92

Kumar, A. (2012). Crushers. Retrieved April 11, 2018, from http://technology.infomine.com/reviews/Crushers/welcome.asp?view=full

Kwade, A., (1999). Determination of the most important grinding mechanism in stirred media mills by calculating stress intensity and stress number, Powder Technology 105, pp. 382388.

Kwade, A., Schwedes, J. (2002). Breaking characteristics of different materials and their effect on stress intensity and stress number in stirred media mills, Powder Technology 122, pp. 109-121

Litcher, J. K. H. \& Davey, G. (2002). Selection and Sizing of Ultrafine and Stirred Grinding Mills. Mineral Processing Plant Design, Practice, and Control Proceedings, SME, USA, pp. 783800 . 
Lofthouse, C.H, Johns, F.E. (1999). The Svedala (ECC International) Detritor and the Metals Industry. Minerals Engineering 12(2), pp. 205-217.

Ma, Z., Hu, S. Zhang, S. \& Pan, X. (1998). Breakage behavior of quartz in a laboratory stirred ball mill. Powder Technology 100, pp. 69-73.

Momen, A. A., Zachariadis G. A., Anthemidis, A. N., \& Stratis, J. A. (2006). Use of fractional factorial design for optimization of digestion procedures followed by multi-element determination of essential and non-essential elements in nuts using ICP-OES technique. Talanta 71, pp. 443-451.

Montgomery, D. C (2013). Design and Analysis of Experiments. Eighth edition, John Wiley \& Sons, Inc. pp. 183-449

Nel, G., Swarts, A., Doriegan, S. \& Johnson, G. (2006). Comparing the Milling Efficiencies of Pilot Scale Horizontal and Vertical Ultrafine Grinding Mills for Tati Sulphide Concentrate. Proceedings of the Randol Innovative Metallurgy Forum 2005, Perth Australia.

Nesset, J., Radziszewski, P., Hardie C. \& Leroux, D. (2006). Assessing the Performance and Efficiency of Fine Grinding Technologies. Proceedings of the $38^{\text {th }}$ Annual Canadian Mineral Processors Conference, Ottawa, Canada, pp. 283-309.

O'Brien, G., Firth, B. \& Adair, B. (2011). The application of the coal grain analysis method to coal liberation studies. International Journal of Coal Preparation and Utilization 31(2), pp. 96-111.

Oki, T., Yotsumoto, H. \& Owada, S. (2004). Calculation of degree of mineral matter liberation in coal from sink-float separation data. Minerals Engineering 17(1), pp. 39-51.

Oksuzoglu, B. \& Ucurum, M. (2015). An Experimental Study on the Ultrafine Grinding of Gypsum Ore in a Dry Ball Mill. Powder Technology 291 pp. 186-192.

Ouattara, S., \& Frances, C. (2014). Grinding of calcite suspensions in a stirred media mill: Effect of operational parameters on the product quality and the specific energy, Powder Technology 255, pp. 89-97.

Ozcan, O. \& Benzer, H. (2013). Comparison of different breakage mechanisms in terms of product particle size distribution and mineral liberation. Minerals Engineering 49, pp. 103-108.

Parry, J. M. (2006). Ultrafine Grinding for Improved Mineral Liberation in Flotation Concentrates. M.Sc. thesis, The University of British Columbia, Canada.

Rabelo, S. C., Andrade R. R., Maciel, F. R. \& Costa, A. C. (2014). Alkaline hydrogen per- oxide pretreatment, enzymatic hydrolysis and fermentation of sugarcane bagasse to ethanol. Fuel 136, pp. 349-57.

Rezende, C. A., Atta, B. W., Breitkreitz, M. C., Simister, R., Gomez, L. D., \& McQueen-Mason, S. J. (2018). Optimization of biomass pretreatments using fractional factorial experimental design. Biotechnology for Biofuels 11, pp. $206-221$.

Rozenblat, Y., Grant, E., Kalman, H. \& Tomas, J. (2012). Selection and Breakage functions of particles under impact Loads. Journal of Chemical Engineering Science 71, pp. 56-66. 
Sahoo, B. K., De, S. \& Meikap, B. C. (2011). Improvement of grinding characteristics of Indian coal by microwave pre-treatment. Fuel Processing Technology. 92(10), pp. 1920-1928.

Saito, F. \& Kano, J. (1998). Correlation of powder characteristics of talc during planetary ball milling with the impact energy of the balls simulated by the particle element method. Powder Technology 98, pp. 166-170.

Sokamte, T. A., Mbougueng, P. D., Tatsadjieu, N.L. \& Mbofung, C. M. F. (2017). Application of fractional factorial design to improve hot smoked Nile Perch (Lates niloticus) quality. Food Research (4), pp. 118-132.

Todorovic D., Trumic, M., Andric, L., Milosevic, V. \& Trumic, M. (2016). A quick method for Bond work index approximate value determination. Journal of Physiochemical Problems of Mineral Processing 53(1), p. 323.

Williams, O., Eastwick, C., Kingman, S., Giddings, D., Lormor, S., \& Lester, E. (2015). Investigation into the applicability of Bond Work Index (BWI) and Hardgrove Grindability Index (HGI) tests for several biomasses compared to Colombian La Loma Coal. Fuel, 158(2015), 379-387.

Wills, B. A. (2006). Mineral Processing Technology. Elsevier Science \& Technology Books, 110117.

Yue, J. (2003). Rheological Effects on Ultrafine Grinding in a Stirred Mill. M.A.Sc. thesis, University of British Columbia, Vancouver, Canada.

Zheng, J., Harris, C.C. \& Somasundaran, P. (1996). A study on grinding and energy input in stirred media mills. Powder Technology 86, pp. 171-178.

Zheng, J., Harris, C. C. \& Somasundaran, P. (1997). The effect of additive on stirred media milling of limestone. Powder Technology 91, pp. 173-179.

Zheng, J. C. \& Cui, Z. H. (2004). A Guaranteed global convergence particle swarm optimizer. Journal of Computer Research and Development, Vol. 8, pp. 1333-1338. 


\section{Appendix}

$\% \%$ This MATLAB routine generates the possible treatment combinations in blocks

$\%$ for a fractional factorial design $3^{\wedge}(3-1)$.

$\%$ Written by Adewale Adeniji on April 10, 2018.

$\%$ Modified by Adewale Adeniji on October 17, 2018

numFactor $=3 ; \%$ Number of factors

numLevel $=3 ; \%$ Number of levels in each factor

numGenerator $=1 ; \%$ Number of generators or effects to be confounded

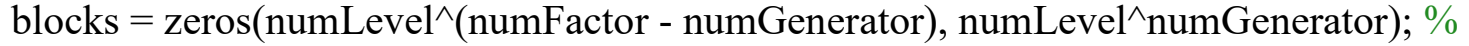

Preallocate possible treatment combinations in the blocks, each column corresponds to a block

coll row $=1 ; \quad \%$ Initialize row number to store treatment combinations for block 1

col2row $=$ col1row; $\%$ Initialize row number to store treatment combinations for block 2

col3row $=$ coll row; \% Initialize row number to store treatment combinations for block 3

$\mathrm{A}=[0,1,2] ; \quad \%$ Coding for the levels of factor $\mathrm{A}$.

$\mathrm{B}=\mathrm{A} ; \quad \%$ Coding for the levels of factor $\mathrm{B}$.

$\mathrm{C}=\mathrm{A} ; \quad \%$ Coding for the levels of factor $\mathrm{C}$.

count $=0$;

for $\mathrm{a}=1$ :numel(A)

for $b=1$ :numel(B)

for $\mathrm{c}=1$ :numel $(\mathrm{C})$

$\mathrm{u}=\bmod ((\mathrm{A}(\mathrm{a})+2 * \mathrm{~B}(\mathrm{~b})+\mathrm{C}(\mathrm{c}))$, numLevel $) ; \%$ remainder when $\mathrm{AB}^{\wedge} 2 \mathrm{C}^{\wedge} 2$ component

of $\mathrm{ABC}$ is confounded

$$
\text { count }=\text { count }+1 \text {; }
$$

if $\mathrm{u}==0$

$\operatorname{blocks}(\operatorname{col1}$ row, $\mathrm{u}+1)=$

str2double( $\operatorname{strcat}($ num $2 \operatorname{str}(\mathrm{A}(\mathrm{a}))$, num2str(B(b)),num2str(C(c)))); \% Treatment combination in block 1

$$
\begin{aligned}
& \text { collrow }=\text { collrow }+1 \\
& \text { elseif } \mathrm{u}==1 \\
& \text { blocks }(\text { col2row }, \mathrm{u}+1)=
\end{aligned}
$$

str2double( $\operatorname{strcat}($ num $2 \operatorname{str}(\mathrm{A}(\mathrm{a}))$, num2str(B(b)),num2str(C(c)))); \% Treatment combination in block 2

$$
\begin{aligned}
& \text { col2row }=\operatorname{col} 2 \text { row }+1 \text {; } \\
& \text { else } \% \text { This is when } u=2
\end{aligned}
$$

$\operatorname{blocks}(\operatorname{col} 3$ row, $\mathrm{u}+1)=$

str2double( $\operatorname{strcat}($ num $2 \operatorname{str}(\mathrm{A}(\mathrm{a}))$, num2str(B(b)),num2str(C(c)))); \% Treatment combination in block 3

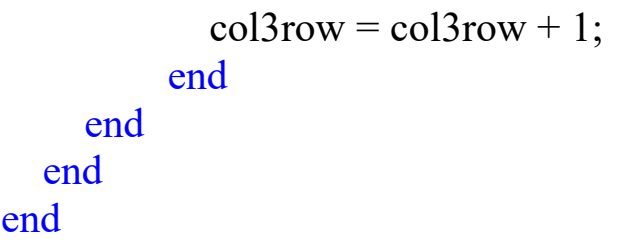


filename $=$ 'Fractional_Factorial_Design_Thesis_New_Approach.xlsx';

sheet $=1 ; \%$ first sheet in the workbook

xlRange $=$ 'F12';

xlswrite(filename,blocks, sheet,xlRange); 
$\% \%$ PSO.m

$\%$ This "Main" MATLAB routine invokes the in-built particle swarm optimization (PSO)

$\%$ algorithm for the purpose of simulating batch grinding of Leatherwood coal using population balance model.

\% Written by Adewale Adeniji on June 12, 2018.

\% Modified by Adewale Adeniji on October 17, 2018.

fun $=@($ bestParam $)$ GrindingMSE(bestParam);

nvars $=6$;

options=optimoptions(@particleswarm,'MaxIterations', 20,'SwarmSize',10*nvars,'HybridFcn',@fmincon, 'PlotFens','pswplotbestf');

rng default \% For reproducibility

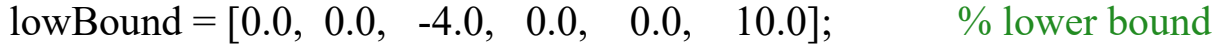

upBound $=\left[\begin{array}{llll}0.1,5.0, & 1.0,2.0, & 0.5,25.0\end{array}\right] ; \quad \%$ upper bound

[bestParam,fval,exitflag,output] = particleswarm(fun,nvars,lowBound,upBound,options);

save('bestParam.mat','bestParam')

save('fval.mat','fval') 
$\% \%$ GRINDINGMSE.m

$\%$ This MATLAB function reads in the unknown parameters and the experimental data and invokes the

$\%$ BatchGrinding function which solves the population balance model (PBM). The

$\%$ mean squared error is calculated each time the PBM is solved.

$\%$ Written by Adewale Adeniji on June 12, 2018.

\% Modified by Adewale Adeniji on October 17, 2018.

function $\mathrm{MSE}=$ GrindingMSE(param)

$\% \%$ IMPORT DATA

s1 = param(1);

syg $1=\operatorname{param}(2)$;

syg2 = param $(3)$;

alpha1 = param(4);

alpha2 $=$ param $(5)$

alpha3 = param(6);

spEnergy = xlsread('Adewale_Thesis_DoE.xlsm','SpEnergy','A1:B10'); \% Specific energy in $\mathrm{kW}-\mathrm{hr} / \mathrm{mt}$

sizeDist25 = xlsread('Adewale_Thesis_DoE.xlsm','25micron','H2:L9'); \% size distribution for 25 micron Feed

sizeDist150 =xlsread('Adewale_Thesis_DoE.xlsm','150micron','H2:L9'); \% size distribution for 150 micron Feed

sizeDist250 =xlsread('Adewale_Thesis_DoE.xlsm','250micron','H2:L9'); \% size distribution for 250 micron Feed

allSizeDist $=[$ sizeDist25, sizeDist150, sizeDist250];

numClass $=\operatorname{size}($ allSizeDist, 1$)$;

$\%$ numFeed $\quad=$ size(allSizeDist,2)/size(sizeDist 25,2$) ; \quad \%$ Number of feeds

$\% \%$ EXTRACT SIZE CLASSES

sizeClass25 = repmat(allSizeDist(:,1),1,3); $\quad \%$ each column is for each product

sizeClass $150=\operatorname{repmat}(\operatorname{allSizeDist}(:, 6), 1,3)$

sizeClass250 = repmat(allSizeDist(:,11),1,3);

allSizeClass = flipud([sizeClass25, sizeClass150,sizeClass250]);

$\% \%$ EXTRACT FEED SIZES (EXPERIMENT)

feedSize25 = repmat(allSizeDist(1:end,2),1,3);

feedSize150 = repmat(allSizeDist(1:end,7),1,3);

feedSize250 = repmat(allSizeDist(1:end,12),1,3);

allFeedSize = [feedSize25,feedSize150,feedSize250];

numProd $=$ size(allFeedSize, 2$) ; \quad \%$ Number of products

feed_EXP = flipud(allFeedSize./100); $\quad \%$ cum. fraction passing of feed

\% PREALLOCATE MEMORY

feedRET_EXP = zeros(numClass,numProd); $\quad \%$ mass retained of feed 


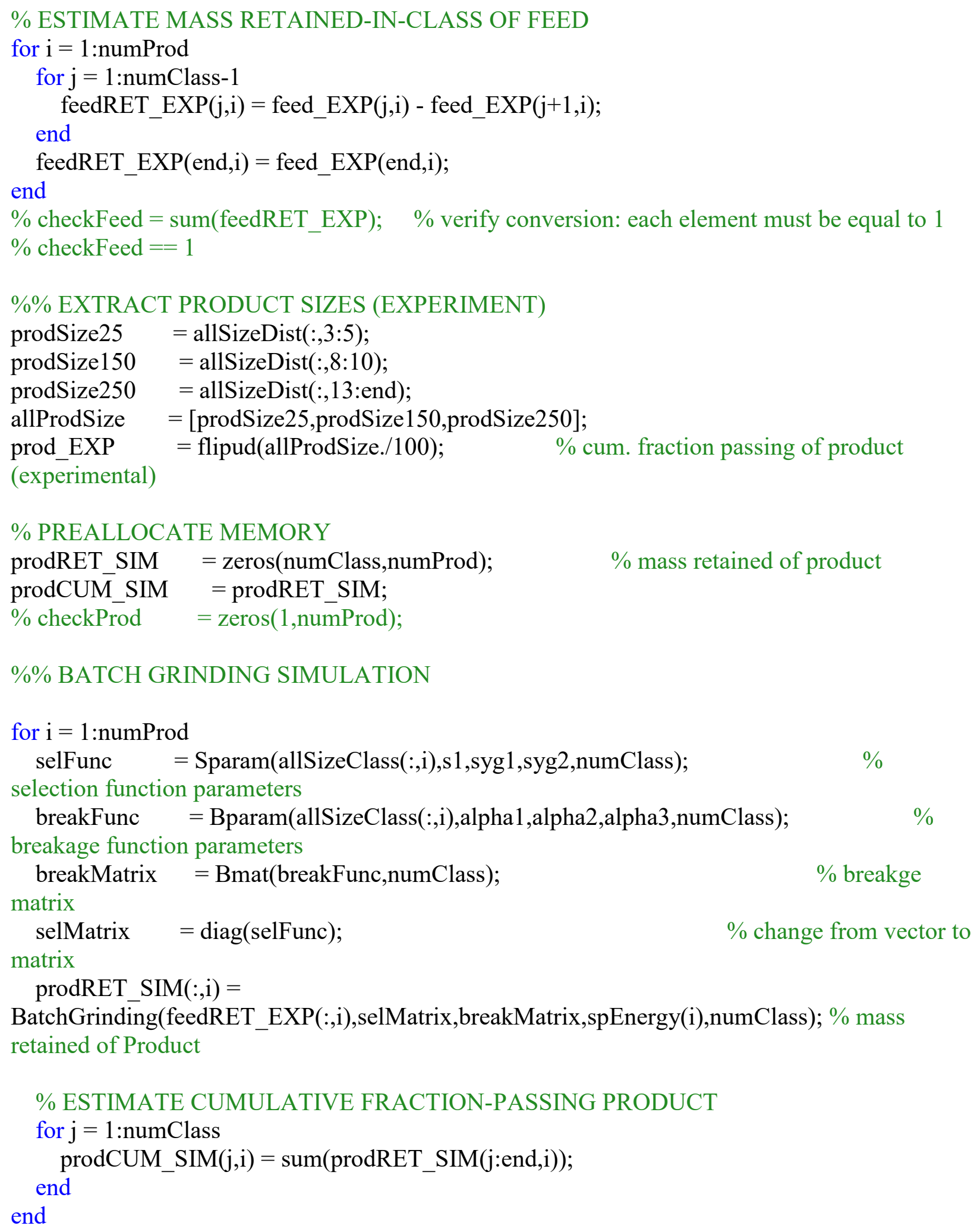


$\% \%$ ESTIMATE OBJECTIVE FUNCTION or Mean Squared Error (MSE)

Dif $=\left(\operatorname{prodCUM} \operatorname{SIM}(:)-\operatorname{prod} \_\right.$EXP(:)).^2; \% Subtract the two matrices and square it MSE $=\operatorname{sum}(\operatorname{Dif}(:)) /($ numClass*numProd $)$;

$\% \%$ SAVE VARIABLES OF INTEREST

save('prodCUM_SIM.mat','prodCUM_SIM') \% Simulated product size distribution save('prod_EXP.mat','prod_EXP') \% Experimental product size distribution

save('feed_EXP.mat','feed_EXP') \% Experimental feed size distribution

save('allSizeClass.mat','allSizeClass') \% size classes for all top feed sizes 
$\% \%$ BatchGrinding.m

$\%$ This MATLAB routine solves the population balance model using the inputs $\%$ arguments supplied.

\% Written by Adewale Adeniji on June 12, 2018.

\% Modified by Adewale Adeniji on October 17, 2018.

function $\mathrm{f} \_$product $=$BatchGrinding(f_feed,S_mat,brkg_matrix,E,Num_class $)$

$\mathrm{f} \_$product $=\operatorname{expm}\left(-(\right.$ eye $($ Num_class $)-$ brkg_matrix $\left.) * S \_m a t * E\right) * f \_f e e d ;$ 
$\% \%$ Bmat.m

$\%$ This MATLAB routine creates the breakage matrix from the individual breakage function.

\% Written by Adewale Adeniji on June 12, 2018.

\% Modified by Adewale Adeniji on October 17, 2018.

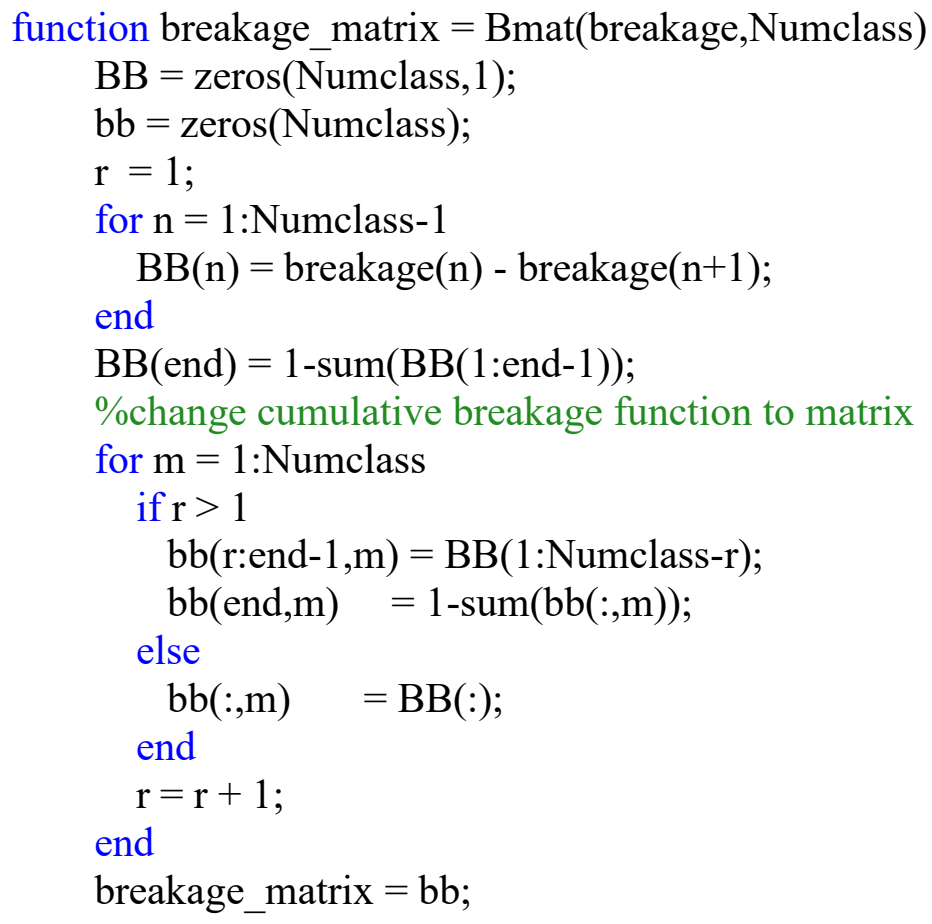


$\% \%$ Bparam.m

$\%$ This MATLAB routine creates the individual breakage function from the breakage function parameters.

\% Written by Adewale Adeniji on June 12, 2018.

\% Modified by Adewale Adeniji on October 17, 2018.

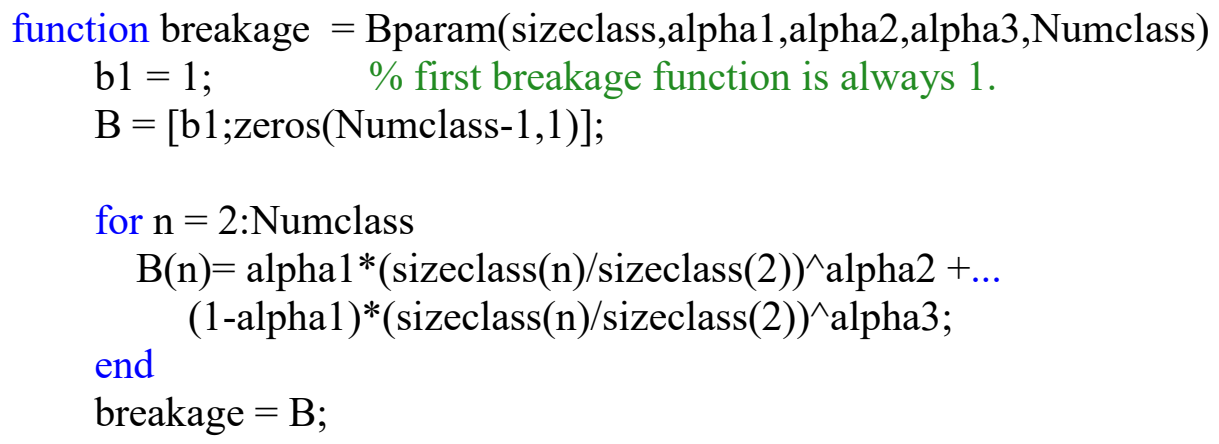


$\% \%$ Sparam.m

$\%$ This MATLAB routine creates the individual selection function from the selection function parameters.

\% Written by Adewale Adeniji on June 12, 2018.

\% Modified by Adewale Adeniji on October 17, 2018.

function selection $=$ Sparam $($ sizeclass, 1 , syg1,syg2,Numclass $)$

$\mathrm{s}=[\mathrm{s} 1 ; \operatorname{zeros}($ Numclass-1,1) $]$

for $\mathrm{n}=2$ :Numclass-1

$\mathrm{s}(\mathrm{n})=\mathrm{s} 1 * \exp (\operatorname{syg} 1 * \log (\operatorname{sizeclass}(\mathrm{n}) / \operatorname{sizeclass}(1))+\ldots$ $\left.\operatorname{syg} 2 *(\log (\operatorname{sizeclass}(\mathrm{n}) / \operatorname{sizeclass}(1)))^{\wedge} 2\right)$;

end

$\%$ selection function for the last class size is always zero selection $=\mathrm{s}$;

save('selection.mat','selection') 
$\% \%$ Optimum.m

$\%$ This MATLAB routine helps to visualize the particle size distribution (PSD) of

$\%$ Leatherwood coal using the optimum selection and breakage function

$\%$ parameters from the model and compare with PSD from the experiment.

$\%$ Written by Adewale Adeniji on June 12, 2018.

\% Modified by Adewale Adeniji on October 17, 2018.

load ('bestParam.mat');

MSEbest $=$ GrindingMSE(bestParam);

load ('prodCUM_SIM.mat');

load ('prod EXP.mat');

load ('allSizeClass.mat');

load ('feed_EXP.mat');

for $\mathrm{i}=1$ : size(prod_EXP,2)

figure(i)

$\log \log (\operatorname{allSizeClass}(:, \mathrm{i})$, feed_EXP(:,i).*100,'-+r', allSizeClass(:,i),prodCUM_SIM(:,i).*100,'$* b^{\prime}, \ldots$

allSizeClass(:,i),prod_EXP(:,i).*100,'ob')

xlabel('Particle size (microns)')

ylabel('Cumulative Percent Passing')

$$
\begin{aligned}
& \text { if } \mathrm{i}==1 \\
& \text { title("102-D-3") }
\end{aligned}
$$

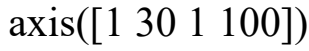

$$
\begin{aligned}
& \text { elseif } i==2 \\
& \text { title("000-D-1") }
\end{aligned}
$$

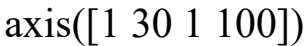

$$
\begin{aligned}
& \text { elseif } \mathrm{i}==3 \\
& \text { title("201-D-2") }
\end{aligned}
$$

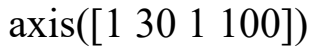

$$
\begin{aligned}
& \text { elseif } \mathrm{i}==4 \\
& \text { title("011-D-3") }
\end{aligned}
$$

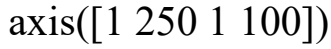

$$
\begin{aligned}
& \text { elseif } i==5 \\
& \text { title("110-D-2") }
\end{aligned}
$$

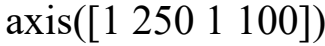

$$
\begin{aligned}
& \text { elseif } \mathrm{i}==6 \\
& \text { title("212-D-1") }
\end{aligned}
$$

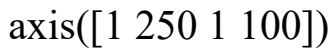

$$
\begin{aligned}
& \text { elseif } \mathrm{i}==7 \\
& \text { title("220-D-3") }
\end{aligned}
$$

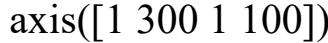

$$
\begin{aligned}
& \text { elseif } \mathrm{i}==8
\end{aligned}
$$




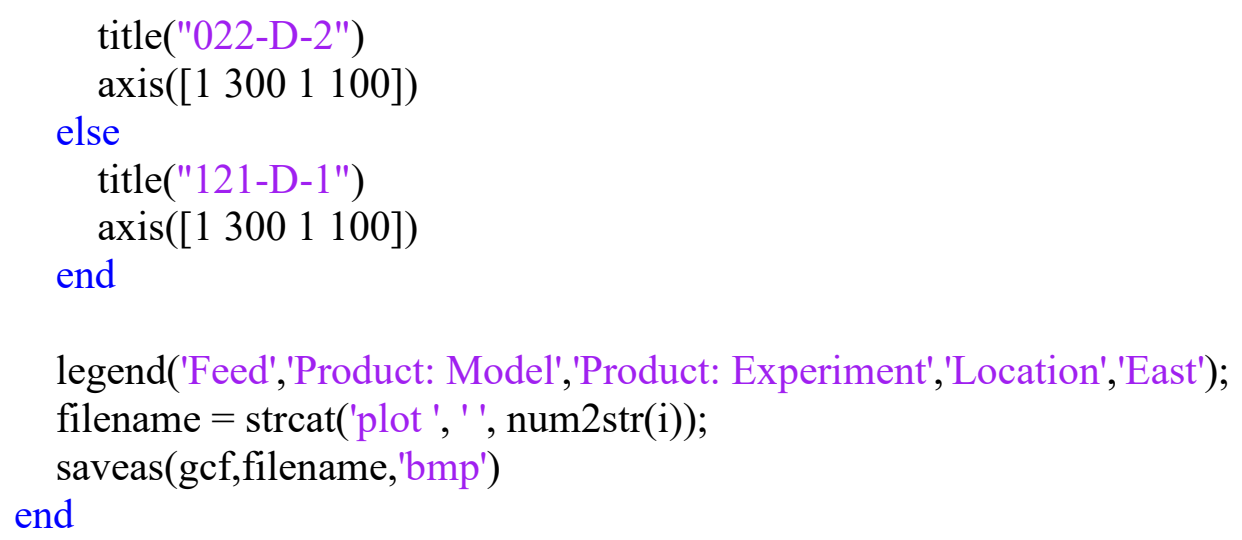

